\title{
In Defence of Invisiblized Noncitizens: Seeking Justice in the Canadian Immigration Detention System
}

\author{
by \\ Marie Coligado
}

A thesis submitted to the Faculty of Graduate and Postdoctoral Affairs in partial fulfillment of the requirements for the degree of

Master of Arts

in

Sociology

Carleton University

Ottawa, Ontario

(C) 2018

Marie Coligado 


\begin{abstract}
$\underline{\text { Abstract }}$
The Canadian immigration detention system is indefinitely holding noncitizens embodying precarious statuses without setting time limits to their deprivation of liberty. Presided over by Immigration Division board members, detention review hearings are supposed to be a means through which they can seek release. This thesis demonstrates, however, that immigration detainees have severely limited access to justice through these quasi-judicial proceedings where the evidentiary burden is shifted on to them. They face overlapping challenges in seeking legal representation while held in immigration holding centres and provincial prisons, including lack of information on their right to counsel, limited Legal Aid funding, and language barriers. Using interviews with lawyers and former detainees, and non-participant observation of detention reviews, this thesis argues immigration detainees are largely invisiblized by their limited access to justice, which is fostered by the Canadian sovereign state and its highly securitized political context that is particularly wary of racialized noncitizens.
\end{abstract}




\section{Acknowledgements}

I would like to thank my co-supervisors, Daiva Stasiulis and Aaron Doyle, for their immense support and patience throughout my research process. Your dedication and enthusiasm towards my academic growth are truly appreciated. I feel fortunate to have been able to work with both of you and receive your kind guidance along the way. Daiva, thank you for always reminding me of the story I sought to share through my thesis. I am grateful for your insightful feedback that encouraged me to produce a more thorough analysis than I thought I was capable of. Aaron, thank you for asking the challenging questions and motivating me to act for what I believe in. Your drive for social justice and stopping the 'revolving door' has been incredibly inspiring.

I wish to thank Patti Lenard for her thoughtful and instructive critique of my thesis. I am also grateful for the many professors and mentors, who have encouraged my academic pursuit and challenged me to become a more critical thinker, especially Kate Fletcher, Valerie Steeves, Janet Siltanen, and R. Karl Hanson. I hope you know that your devotion to your students' success does not go unnoticed.

Many thanks to our wonderful staff at the department, who never ceased to provide their utmost support. Thank you so much to Darlene Moss, Paula Whissell, and Xiaobei Chen for always having the answers and helping me not feel so lost in grad school. I am also grateful for the generous financial support provided by Carleton University's Department of Sociology and Anthropology, and the Social Sciences and Humanities Research Council of Canada.

This achievement would have been impossible without my family. To my parents, no words can describe how thankful I am for your unconditional love and patient understanding. I am incredibly blessed knowing that I have your full support in all that I do. Christine, thank you for always listening and reminding me that "soon the fog will clear up". We joke that you could have written this thesis for the many times you reviewed my drafts, but I hope you know just how much I truly appreciate your help and encouragement. Veronica, thank you for all the laughter and hugs that always make me feel better. Your excitement every time I submit a draft means so much more to me than I could ever express.

Big thanks to my dearest friends for their sincere support. Laleh and Joey, thank you for being by my side through grad school. It has been a challenging journey, but I feel very lucky to have been able to go through it with such intelligent and understanding friends like you. Javaria and Alanna, thank you for never failing to check in on me, and saying all the comforting words to lift me up. Daisy, I appreciate your listening to my worries 
and always encouraging me to persevere. Thank you for reminding me of my goals and my strength in times when I myself have forgotten them.

Finally, I am grateful to all the participants who shared their stories and experiences with me. Your perseverance towards seeking justice, despite the challenges embedded in the immigration detention system, is inspiring. I especially wish to thank Katherine for being incredibly generous with her time and knowledge. 


\section{Table of Contents}

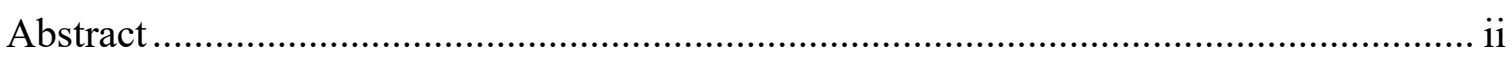

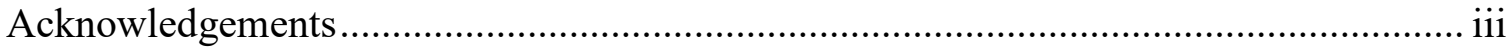

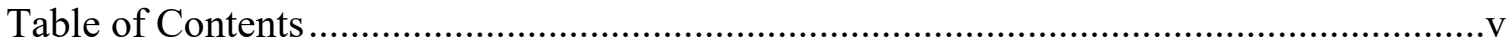

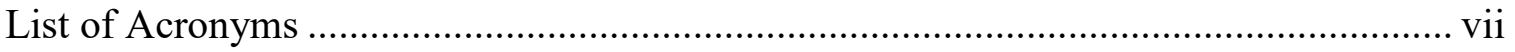

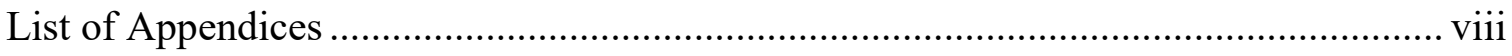

CHAPTER 1. INTRODUCTION .................................................................................1

1.1 Contextualizing the Research Question .........................................................

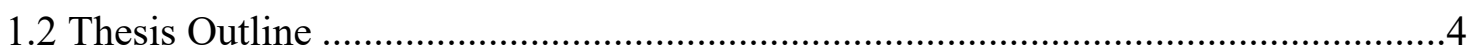

CHAPTER 2. OPENING THE "BLACK BOX" ........................................................7

2.1 Common Features of Immigration Detention .....................................................

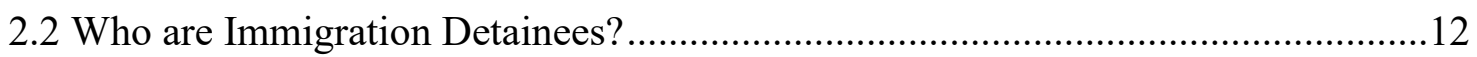

2.3 Legitimizing Deprivations of Liberty ...................................................................17

2.4 The Canadian Way of Administrative Confinement ............................................20

2.4.1 Immigration Detention at the Present Time ....................................................21

2.4.2 Reproducing Priorities of a White Settler Colony .........................................25

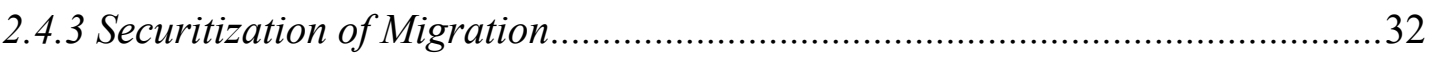

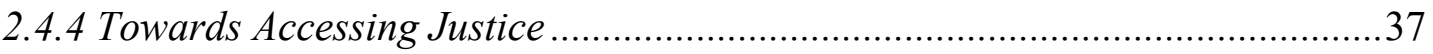

CHAPTER 3. METHODOLOGY ............................................................................39

3.1 Adopting Interpretive Methodology and Qualitative Approaches .........................39

3.2 Challenges in the Field: Negotiating Access to Invisiblized People.......................41

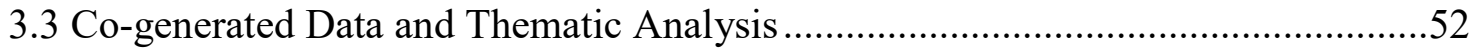

3.4 Remaining Cautious for Ethical Research ......................................................57

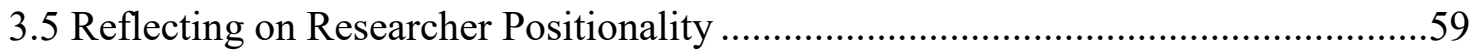

3.6 Lessons Learned as a Novice Researcher ......................................................63

CHAPTER 4. ACCESS TO JUSTICE AND LEGAL REPRESENTATION............65

4.1 Vanishing in the Immigration Detention System .............................................66

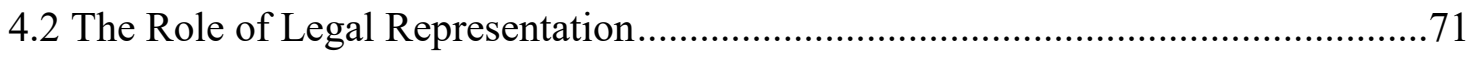

4.3 Detainees' Costly Right to Legal Counsel ............................................................75

4.4 Carceral Spaces: From IHCs to Provincial Prisons..................................................77

4.4.1 Locating Detainees in Securitized Provincial Prisons ..................................8 82

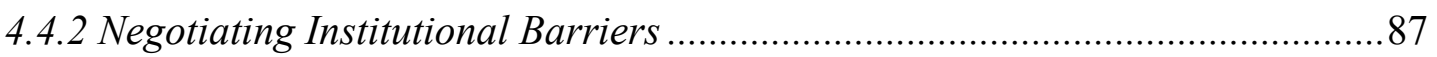

4.5 Tight Procedural Timelines: Immediacy of the 48-Hour Hearing .........................90

4.5.1 Preparation of the Release Plan....................................................................93

4.6 Roots in Detainees' Non-Citizenship................................................................97 
CHAPTER 5. DISCRETION IN DETENTION REVIEW HEARINGS

5.1 Rubber Stamp of Continued Detention

5.2 Non-Custodial Measures for Immigration Detainees

5.3 Making Sense of the IRB Decision-Making Process

5.4 To Bear the Evidentiary Burden.

5.5 Checks and Balances on Discretionary Powers

5.6 Discretion as a "Powerful Form of Government"

CHAPTER 6. CONCLUSION.

6.1 Summary of Sociological Contributions

6.2 Limitations and Future Research

6.3 Potential for Undoing Injustice

Footnotes

References

.150

Appendix 


\section{$\underline{\text { List of Acronyms }}$}

\begin{tabular}{|c|c|}
\hline ATD & Alternatives to Detention \\
\hline CBSA & Canada Border Services Agency \\
\hline $\mathbf{C C R}$ & Canadian Council for Refugees \\
\hline CUREB & Carleton University Research Ethics Board \\
\hline CECC & Central East Correctional Centre \\
\hline CCMS & Community Case Management and Supervision \\
\hline CDF & Contract Detention Facilities \\
\hline DFN & Designated Foreign National \\
\hline EIDN & End Immigration Detention Network \\
\hline ICE & Immigration and Customs Enforcement \\
\hline IRB & Immigration and Refugee Board \\
\hline IRPA & Immigration and Refugee Protection Act \\
\hline IRPR & Immigration and Refugee Protection Regulations \\
\hline IDC & Immigration Detention Centre \\
\hline ID & Immigration Division of the Immigration and Refugee Board \\
\hline IHC & Immigration Holding Centre \\
\hline IRC & Immigration Removal Centre \\
\hline LAO & Legal Aid Ontario \\
\hline NIDF & National Immigration Detention Framework \\
\hline NGO & Non-Governmental Organization \\
\hline OCDC & Ottawa-Carleton Detention Centre \\
\hline RLO & Refugee Law Office \\
\hline RPD & Refugee Protection Division \\
\hline $\mathbf{R P C}$ & Regional Processing Centre \\
\hline SPC & Service Processing Centre \\
\hline STHF & Short-Tem Holding Facility \\
\hline TBP & Toronto Bail Program \\
\hline TIHC & Toronto Immigration Holding Centre \\
\hline UNHCR & United Nations High Commissioner for Refugees \\
\hline
\end{tabular}




\section{List of Appendices}

Appendix A: Categories of Immigration Detainees

Appendix B: Statistics on Canadian Immigration Detention

Appendix C: Participant List

Appendix D: Consent Form (Former Immigration Detainee)

Appendix E: Consent Form (Legal Counsel) 


\section{CHAPTER 1. INTRODUCTION}

In these spaces where those without status or identity are caged, the struggle is against the disappearance of one's self. There are so many undocumented lives amongst us and in this world that can never be captured in numbers, barred by material and immaterial borders, or be confined to anonymous spaces. (Chak, 2014: 112)

Immigration detainees live among us, but we oftentimes fail to see them. They have been rendered invisible by the mighty sovereign power, indefinitely confined within institutional walls and at times ejected out of the nation state. This thesis, however, chooses to seek them out, understand their experiences, and question the very system leading to their erasure. In Discipline and Punish: The Birth of the Prison, Foucault (1977) addresses a significant shift in punishment, which was once imposed on the physical body under the watchful public eye, but later reconfigured to discipline the soul in concealed spaces. He suggests the sovereign previously exercised their power in brutally painful ways, holding "the body of the condemned man and displays it marked, beaten, broken" (Foucault, 1977: 49). The eighteenth century saw such bodily punishments lose their public nature as they moved inside prison walls where minds and souls became the objects of correction, pointing to the emergence of governmentality. Applied to the immigration context however, it is undeniable that sovereign power continues its reign in the detention and removal of noncitizens. As Pratt (2005) argues, such punishment may be different from Damiens' bloody torture in the town square, but it is still "the bodies, not the souls, habits, or risks, of noncitizens that are directly targeted" (p. 13). The difference, however, is that we can no longer observe these practices in public arenas. They have been kept out of sight, much like the very people they are inflicted upon. Immigration detainees are taken away from our communities with 
their everyday lives wrapped in much secrecy. They are confined in holding centres and carceral institutions, and without an end in sight, their deprivation of liberty persists as they disappear in the "black box" of immigration detention (Markowitz, 2009: 558).

\subsection{Contextualizing the Research Question}

More recently, immigration detainees have been fighting for attention, seeking justice against their indefinite detention and the inequalities embedded within the Canadian immigration detention system. In October 2015, detainees won an important case in Chaudhary v Canada (Public Safety and Emergency Preparedness) where the Ontario Superior Court of Appeal ruled that confined noncitizens have the right to seek habeas corpus ${ }^{1}$ relief in the provincial court to challenge their unlawful detention. This is a significant victory as it provides another legal avenue beyond detention review hearings conducted by the Immigration and Refugee Board (IRB) and judicial reviews at the Federal Court. Immigration detainees have also taken direct action against the Canadian government by initiating hunger strikes. On July 11, 2016, an estimated 50 individuals held in two Ontario prisons, Central East Correctional Centre (CECC) in Lindsay and Toronto East Detention Centre in Scarborough, protested against their indefinite detention in maximum-security institutions and demanded a meeting with Minister of Public Safety, Ralph Goodale. The following days saw tremendous support from around ten more detainees, who joined the hunger strike, and from activists and advocates across Canada, who showed solidarity by protesting outside the Minister's office, approaching other Members of Parliament, and using social media to call attention to the detainees' plight (EIDN, 2016, July 18). Although immigration detainees have previously resisted 
against the government with hunger strikes in September 2013 and April 2016, this direct action is perhaps the most successful as the following month saw the introduction of the National Immigration Detention Framework (NIDF). Minister Goodale announced that up to $\$ 138$ million over the next five years would be invested in creating "a better, fairer immigration detention system that supports the humane and dignified treatment of individuals while protecting public safety" (CBSA, 2018c). NIDF more specifically emphasized the development of infrastructure and alternatives to detention, prioritizing the needs of vulnerable populations and being more transparent with its practices.

Although these legal and political breakthroughs give more visibility to immigration detainees, it is imperative to remain critical of the very system that continues to erase them despite recent victories. For example, only immigration detainees in Ontario can access their right to habeas corpus relief as Chaudhary v Canada (Public Safety and Emergency Preparedness) was heard in Ontario courts. This means noncitizens held in other parts of the country are still denied the opportunity to challenge their indefinite detention, additionally bringing into question the Canadian government's inaction towards implementing a time limit. People are dying in immigration detention as well with 16 known deaths since 2000, including four since March 2016 (Molnar \& Silverman, 2017, November 14). This thesis argues that immigration detainees are already less visible by being held in carceral spaces, but they are rendered even more so by their extremely limited access to justice in the Canadian immigration detention system. It demonstrates the ways in which sovereign power continues to dominate in the governance of noncitizens. Hiding behind the discourse of national security and public safety, the Canadian state indefinitely confines racialized noncitizens, reifying borders of 
belonging and re-affirming its identity as a "white settler colony" (Brodie, 2002: 46).

This thesis also takes into account the highly securitized political context within which sovereign power plays out, theorizing how current and past government administrations impact access to justice in immigration detention.

\subsection{Thesis Outline}

In Chapter 2, I discuss the characteristics of administrative confinement, the different categories of immigration detainees, and the several ways in which nation states legitimize their deprivation of liberty with justifications ranging from reassertion of territorial sovereignty to general deterrence. This is followed by a critical analysis of the common claim of immigration detention as non-punitive, drawing upon literature on "crimmigration" or the increasing convergence of criminal and immigration law (Majcher \& de Senarcles, 2015; Chacón, 2014; Leerkes \& Broeders, 2010; Stumpf, 2006; Pratt, 2005; Miller, 2003). More specifically, I discuss the defining features of the Canadian immigration detention system, including its simultaneous use of immigration holding centres (IHC) and provincial prisons of the criminal justice system, its lack of time limits to detention, and the quasi-legal proceedings of detention review hearings. I conclude the chapter by providing a historical account of administrative confinement, connecting it to the nation state's historical foundation as a white settler colony and its persistent quest for national security.

Chapter 3 elaborates upon the methodological decisions made throughout my research process. It explains my incorporation of interpretive qualitative methodology, and my use of two different data collection methods, semi-structured interviews and non- 
participant observation. I describe how I recruited immigration and refugee lawyers, and former immigration detainees as study participants, as well as how I collected observational data from public detention review hearings. I also discuss my reliance on thematic analysis to further understand collected data. A significant contribution of this chapter is its detailed account of the challenges I faced as a novice researcher seeking to study the vulnerable population of immigration detainees, challenges which are another indicator of the invisibility of this population. I share my experiences in negotiating with gatekeepers and searching for participants rendered invisible by sovereign power, which may explain their desire to remain invisible out of fear. I demonstrate how difficulties of accessing respondents forced me to reconsider my research question and change the direction of my thesis. This chapter ends with a discussion on conducting ethical research and engaging in reflexive practice.

Chapters 4 and 5 draw upon my empirical work to present an analysis of the barriers faced by immigration detainees in accessing procedural justice with the end result being detention, often for long periods of time. Chapter $\mathbf{4}$ begins with a discussion on the difficulties of seeking high quality legal counsel, which often intersect with language barriers and financial issues due to detainees' limited access to legal aid. I then elaborate upon several compounding barriers to legal representation, including detainees' physical confinement in provincial institutions and the tight timelines of detention review hearings. In Chapter 5, I engage in a critical analysis of the decision-making process of Immigration Division (ID) board members and what participants perceive as a (mis)interpretation of jurisprudence that shifts the evidentiary burden on immigration detainees. Taken together, I argue that the unfair treatment of immigration detainees in 
their attempts to access justice is strongly related to their non-citizenship in the sovereign state of Canada, its expanding securitization of migration, and its tightening of territorial borders, particularly targeting racialized noncitizens.

In Chapter 6, I summarize the key sociological contributions of this thesis, namely its analysis of detainees' limited access to justice in relation to Canada's sovereign power as it plays out in a highly securitized political context. I also examine limitations of this research project and identify topics that can be explored in future research, particularly emphasizing the need to give visibility to immigration detainees and their lived experience in hopes to illuminate the human impact of administrative confinement. This chapter ends with a challenging thought on abolishing the Canadian immigration detention system. 


\section{CHAPTER 2. OPENING THE "BLACK BOX"}

Immigration detention gained academic attention at the turn of the twenty-first century despite its earlier use by several nation states. Previously, immigration scholars were preoccupied with removal practices upon observing a "deportation turn" across Western liberal democracies (Gibney, 2008: 148). This often resulted in narrow considerations of immigration detention as a mere "function of deportability" with limited analysis of its legal, institutional, and infrastructural characteristics (Martin, 2012: 313). However, detention's incorporation in border control policies and the expanding securitization of migration increasingly sparked interest among various disciplines, including, but not limited to, sociology, law, anthropology, geography, and criminology (Bosworth \& Turnbull, 2014). Although detention continues to be discussed concurrently with deportation due to their sequential nature, there is greater encouragement in interdisciplinary scholarship to examine immigration detention on its own. As Bhui (2013) warns, "The simple formulation of detention as a tool to achieve deportation hides a multitude of other, less overt functions and meanings of detention, which find expression in the way that immigration control operates." (p. 5). For its part, my thesis will argue that racialized noncitizens' limited access to justice in the immigration detention system is deeply connected to Canada's historical past and its incessant reproduction of white settler colonial mentality. It will also demonstrate how those detained have been constructed into threats in a highly securitized political context within which the Canadian state exercises sovereign power to implement and enforce more restrictive border controls. 
Conceptually, immigration detention constitutes deprivations of liberty enforced upon noncitizens, who are administratively held in designated holding centres and other carceral institutions for the achievement of immigration-related goals (Cleveland, 2015; Silverman \& Massa, 2012). It typically serves the external function of managing incoming migration, particularly the prevention of unauthorized entry into the nation state. It further has the internal function of detecting individuals residing within territorial boundaries without an official migration status and holding them pending deportation. Silverman and Nethery (2015) also describe immigration detention as "simultaneously a practice and a policy; an enforcement priority and a legislative by-product; a site of tension between extreme sovereign power and people claiming universal rights in the face of that display..." (p. 1). In combination, these definitions highlight the complexity of immigration detention, which involves relations of power, and different categories of people, who threaten sovereign authority and others, who seek to apprehend them using an assemblage of enforcement practices and processes, surveillant technologies, and spatial and temporal orderings (Martin, 2012; Mountz, Coddington, Catania, \& Loyd, 2012; Pratt, 2005). More importantly, they demonstrate how detention does not simply start and end at the holding of noncitizens, but is part of a larger assemblage of border control. This chapter will explore the phenomenon of immigration detention in general, its historical and current use in the Canadian context, and this thesis' contribution to the sociological literature on access to justice in immigration detention. 


\section{$\underline{\text { 2.1 Common Features of Immigration Detention }}$}

Although the use of immigration detention varies across nation states, it is generally an administrative process that is distinct from criminal incarceration (Turnbull, 2017, March 29). It is regarded by state authorities as "a non-punitive, bureaucratic measure" that holds noncitizens for administrative purposes, such as the verification of identity, the control of flight risk, and the execution of removal orders (Leerkes \& Broeders, 2010: 831). In contrast to the supposed rationales of criminal imprisonment, it is not designed to punish individuals for their wrongdoings against society nor rehabilitate them for social reintegration. As Pratt (2005) suggests, "The forcible confinement of these individuals does not aim to 'correct,' 'reform,' or 'transform' souls, habits, or risks. It has no official purpose other than to confine and ultimately expel the actual bodies of undesired noncitizens." (p. 23). Beyond their contrasting functions, immigration detention also does not incorporate formal elements and procedures of the criminal justice system, such as police warrants, laid charges, extensive court proceedings, and oversight bodies (Silverman \& Nethery, 2015). It can cast a wider net by applying to groups of people at a time without an examination of their individual cases; there are generally no trials to determine their culpability, which means they may not have been convicted of any crimes and therefore, are not held to serve a criminal sentence. Despite the claim of non-punitiveness, which characterizes immigration detention as an administrative process without the deliberate function of punishment, scholars contend it nonetheless inflicts harm on noncitizens. As Gerard and Pickering (2014) state, "Punishment in relation to border control is not explicit but is enacted through administrative policies and practices that result in punishment." (p. 598). This 
point will be discussed later in the context of overlapping criminal and immigration law, resulting in the "criminalization of migration" (Miller, 2003: 616) or "crimmigration law" (Stumpf, 2006: 10).

Detention of noncitizens is most often at the discretion of border officials, but some nation states also practice mandatory detention. Canadian legislation, for instance, gives authority to immigration officers to arrest and detain foreign nationals upon arrival at the border or anywhere in the nation state, without a warrant from the judiciary. They may order release with or without conditions within 48 hours if reasons for detention are no longer valid. More recently, legislative changes gave broad discretionary powers to the Minister of Public Safety to effectuate the mandatory detention of any group of foreign nationals suspected of human smuggling. Individuals designated as "irregular arrivals" are only given access to a review hearing after 14 days and every six months thereafter. These provisions were in fact inspired by the Australian model, which has mandatorily detained migrants and asylum seekers since 1992, particularly those arriving by boat (Fleay \& Briskman, 2013). They are held indefinitely until granted a visa or deported to their country of origin. The Minister of Immigration has sole discretion to release asylum seekers while their refugee claims are being processed. Unlike the Canadian example however, Australian immigration detention is non-reviewable unless an error has been made in the legal process (Sampson, 2015).

Although nation states have created some specific spaces of confinement for noncitizens, they also often use the prisons and jails of the criminal justice system. In the United Kingdom, the first permanent holding centre, Campsfield House, was constructed in 1993 (Griffiths, 2015). An immense expansion in detention practices has since led to 
the current operation of fifteen facilities, which includes eleven immigration removal centres (IRC), three short-term holding facilities (STHF), and one pre-departure centre for families near Gatwick Airport (Griffiths, 2015). The government has also reserved 1000 prison beds across the country for noncitizens, who are inadmissible due to criminality (Bosworth, 2014). Similarly, the US Immigration and Customs Enforcement (ICE) uses six service processing centres (SPC) to hold noncitizens. The American case also exemplifies the increasing privatization of immigration detention, as it contracts seven private prisons called contract detention facilities (CDF), and employs both public and private jails across the country. Inda and Dowling (2013) emphasize the harms of this partnership, suggesting "the delegation of immigrant confinement to organizations whose main purpose is to generate profits inevitably produces pressure to increase detentions" (p. 16). Meanwhile, instead of hiring private corporations, Australia entered into agreements with its former colonies to facilitate offshore detention practices. It implemented the Pacific Solution in August 2001, which allows the transfer of asylum seekers, usually apprehended at sea, to Nauru and Papua New Guinea ${ }^{2}$ where they are detained in regional processing centres (RPC) funded by the Australian government. These facilities are in addition to another offshore centre on the Australian territory of Christmas Island, and immigration detention centres (IDC) and related facilities on the mainland. These spatial arrangements will be further discussed in another section, as their extreme exclusion and isolation of migrants and asylum seekers from the general population challenges the claim of non-punitiveness in administrative detention.

Another defining characteristic of immigration detention is its temporal ordering. Individuals generally do not know how long they will be held, as some nation states have 
not implemented a "presumptive period" or specified a time limit (Gros \& van Groll, 2015: 91). For example, Canadian legislation does not stipulate when detention should cease, resulting in lengthy deprivations of liberty. Although border officials report that the average number of days spent in detention in 2016-2017 is 19.5 days (CBSA, 2018a), there have been noteworthy cases in which detainees spent several years in holding centres and provincial prisons (see Chaudhary v Canada (Public Safety and Emergency Preparedness) 2015 ONCA 700.). Importantly, this practice of indefinite detention has garnered critical attention from activists, advocates, and scholars, who are calling for the enactment of a 90-day presumptive period (Hussan, 2014). Similarly, immigration detention in the UK is also indefinite. The UK is an outlier in the European context for refusing to ratify the European Union Returns Directive, which limits the holding of noncitizens to a maximum of 18 months (Turnbull, 2017, March 29). Studying the lived experience of this temporal ordering, Turnbull (2016) found indefinite detention practices have resulted in experiences of uncertainty and unpredictability marked by constant waiting, particularly "waiting to know both when and how detention will end" (p. 2). Immigration detainees in IRCs also expressed feelings of being stuck in time (Turnbull, 2016) and sentiments of hopelessness without an end point towards which to strive (Griffiths, 2014).

\subsection{Who are Immigration Detainees?}

Immigration detainees are commonly identified as unauthorized noncitizens. They have also been called "irregular," "undocumented," and "illegal" (Wilsher, 2011, p. xi). Responding to these labels, Wilsher (2011) argues such umbrella terms obscure the 
"underlying diversity" among individuals held in administrative detention (p. xi). He contends the category of immigration detainees is in fact much more heterogeneous, comprising of multiple and varied identities. This is confirmed in Cleveland's (2015) work in the Canadian context, where she distinguishes between several groups of people based on how they are apprehended by the internal and external functions of detention. With the objective of controlling incoming migration at the border, asylum seekers are most often held pending an examination from border officials, who have discretionary power over release or continued detention. When detention is used to facilitate deportation, there are three categories of people most affected. The first is comprised of noncitizens, who do not have an official migration status. This group can be further broken down to include asylum seekers whose refugee claims have been refused and individuals, who have violated the terms of their visa (e.g., migrant workers, international students, travellers on a visitor visa). The second includes foreign nationals and permanent residents, who have lost their status after committing a criminal offence. After serving their criminal sentence, they are transferred to immigration hold pending deportation. More specific to the Canadian case, Cleveland dedicates the last category to individuals under the security certificate regime, who are held for removal due to national security concerns. Although this classification is helpful, Silverman (2011) warns it is also possible these categories may overlap within the same individual in that a stateless person without a migration status may also be a refugee claimant. Although these arguments importantly show the heterogeneity of the immigration detainee population, the umbrella terms of "immigration detainees" and "noncitizens" will be used for the purposes of this thesis (see Appendix A). 
Among the groups mentioned, there is particular attention given to asylum seekers because of international legal frameworks on asylum and moral issues involved in assisting those in extremely vulnerable situations (e.g., Silverman \& Nethery, 2015; Cleveland, 2015; Cleveland \& Rousseau, 2013; Nakache, 2011). The legally-binding provisions of the 1951 Refugee Convention guide the regulation of asylum and specify that a refugee is someone, who has the legal right to seek protection due to "a wellfounded fear of being persecuted." They also ensure respect for the principle of nonrefoulement, which forbids the return of refugees to their home countries where threats to life exist. For their part, asylum seekers occupy a precarious position outside of this legal definition because they have yet to receive approval from refuge-granting states (Silverman \& Nethery, 2015). Although they may present legitimate claims, there is always risk of rejection with harmful outcomes such as detention and deportation. The Australian case is also a reminder that they can be detained prior to a negative decision. In her ethnographic study in the United States, Haas (2017) found that the waiting period in the refugee determination system caused heightened anxiety among asylum seekers. They are forced to embody the dual positionality of "citizens-in-waiting and deporteesin-waiting" in which a single decision could swiftly award them legal refugee status or render them vulnerable to removal (Haas, 2017: 76). She further describes how they are living in "existential limbo," persistently immobilized by the asylum process that has continued past experiences of pain and suffering (Haas, 2017: 77). The detention of asylum seekers will be further discussed in the Canadian context as scholars note national discursive shifts are to blame for its proliferation (Pratt, 2005). 
Perhaps the most vulnerable group in immigration detention is the unknown population of minors, who are at times held by themselves or with family members. Although international law and national legislation place limits on child detention, it continues to be routinely practiced by several Western states including Canada, Australia, the UK, and the US (Bosworth \& Turnbull, 2014). Article 37 of the United Nations Convention on the Rights of the Child clearly stipulates that depriving children of their liberty is always "only a measure of last resort and for the shortest appropriate period of time". This is echoed, for example, in Canadian immigration legislation, which also emphasizes the need to consider "the best interests of the child" (IRPA, s. 60). Gathering data on children in detention has been challenging because of the general lack of transparency in government practices. It was only within the last year that the Canadian government publicly published statistics on immigration detention, which includes the number of detained minors from the past three years. In fiscal year 2016-2017, it reported that a total of 162 minors were held by the Canada Border Services Agency (CBSA), breaking down to 151 children detained with family members and 11 unaccompanied children (CBSA, 2018a). This is a considerable development as previous statistics erased children by considering them as mere "guests" of detained parents (Pratt, 2005: 29). These numbers importantly shed light on the persisting practice of child detention despite its detrimental consequences for minors, such as mental and emotional distress (Gros \& Song, 2016; Kronick, Rousseau \& Cleveland, 2015).

This discussion about who are immigration detainees would be incomplete without considering the racialization of detention practices. It calls attention to the ways in which migration control exceptionally disadvantages non-white populations. 
Hernández (2013) observed this phenomenon in the American context where Latinos are overwhelmingly represented in immigration detention (p. 206). Although he recognizes that other racialized migrants (e.g., Arabs, Muslims, South Asians) have also become targets in the post $9 / 11$ period, he argues Latino communities have been consistently apprehended and deported long before the "war on terror" gained traction. More specifically, they were detained as "contagious" migrants from 1917 until the beginning of World War II, as asylum seekers in the Cold War era and as "criminal aliens" with the expansion of crimes punishable by deportation. Their experience thus represents the most striking episode in US history where "the convergence of national security, race, and noncitizenship" resulted in extreme deprivations of liberty (Hernández, 2013: 211). From the UK, Turnbull and Hasselberg (2017) similarly argue that the treatment of racialized and gendered foreign national offenders is largely determined by their "non-citizen status" (p. 137). Despite already serving their custodial sentence in prison, foreign nationals are generally transferred to an IRC where they are held pending deportation. In their interviews, they perceived this process as double punishment that also denies them the supposed benefits of imprisonment, such as rehabilitation and reintegration. Together, these examples underline the ways in which immigration detention is used to incapacitate and exclude racialized bodies, particularly by "naturalizing the illegality of non-white, non-citizen others" (Bosworth \& Turnbull, 2014: 93). The racialization of immigration detainees in the Canadian context will be discussed later in relation to the state's colonial past and expanding securitization. 


\section{$\underline{\text { 2.3 Legitimizing Deprivations of Liberty }}$}

To some extent, the threat of immigration detention is used informally by nation states to deter migrants and asylum seekers from accessing their territorial boundaries (Leerkes \& Broeders, 2010). It accompanies other laws and policies implemented to reduce the number of available means of entry, such as visa systems that require authorization prior to state admission and apprehension of boats on territorial waters. Scholars have largely observed this latent function in the discourse of policymakers. Silverman and Nethery (2015) note that when the Canadian government introduced the mandatory detention of designated foreign nationals, then Immigration Minister Jason Kenney endorsed the new provisions for their preventative function. He stated, "Every year, thousands of people die in smuggling operations around the world. We need to send a message to the potential customers of smuggling syndicates: 'Don't pay a smuggler to come to Canada - you're putting your life in jeopardy. Try to come a different way, a legal way'." (as cited in Ball, 2012, June 27). Similarly in the Dutch context, Leerkes and Broeders (2010) found that administrative detention has been justified as a method of general deterrence. Policymakers assumed that when individuals learn about restrictive migration controls, they would be dissuaded from illegal movement and residence. Contrary to these beliefs however, asylum seekers do not receive and interpret policy information in the same way public officials expect. Richardson (2010) suggests this is dependent on their nationality, level of education, area of residence, and source of information (e.g., mass media, family members). She also observed that despite clear knowledge of Australia's mandatory detention, asylum seekers were still undeterred, believing their deprivation of liberty is legitimate and would be carried out in a humane 
way. When faced with severe persecution and constant threat to life, the issue of administrative confinement is perhaps less important than immediately escaping from one's country of origin.

More formally, nation states defend immigration detention as an exercise of territorial sovereignty that allows them to reassert control over land borders through exclusion and the granting of membership (Stumpf, 2006). As observed by Mountz and her colleagues (2012), detention operates upon exclusionary processes, controlling the movement of migrant identities and bodies, particularly those of racialized individuals as discussed above. Migrants are sometimes detained because they lack identification documents. In the effort to confirm their identity however, they suffer the (un)intended consequence of gaining another, namely that of the detainable, criminal migrant. Here, the logic is circular: "migrants might be criminals, necessitating detention; migrants must be criminals, because they are detained." (Mountz, et al., 2012: 527). The exclusion of migrants is much more evident in the ways in which they are physically detained in holding centres and often transferred between carceral institutions. Elsewhere, these spaces have been described as resembling prisons of the criminal justice system (Bosworth \& Turnbull, 2014; Silverman \& Nethery, 2015).

Importantly, Rygiel (2008) gives nuance to the top-down theorization of sovereign power by demonstrating the ways in which citizenship is transforming into "a globalizing regime of government" (p. 211). She contends technologies of governing, namely in the form of border controls and detention practices, are not only administered by the state, but also by other bodies like private corporations (privatization), international organizations (internationalization), and by people themselves 
(individualization). This can be seen in the Australian model, which uses offshore processing centres and detention camps in declared countries, which are paid by the Australian government to "house" irregular migrants. Internationalization exists in parallel to privatization as demonstrated by private companies' managing of detention spaces. Adding another layer to this discussion, Wong (2015) argues the political context should similarly be taken into account as it is involved in the way in which immigration control plays out. He suggests the degree of restrictiveness in this control is determined by "policy outputs" and not merely the exercise of sovereign power (Wong, 2015: 6).

Immigration detention and its exclusions exemplify the ways in which protecting territorial sovereignty results in arbitrary and inhumane deprivations of liberty (Wilsher, 2011). A growing number of interdisciplinary scholars are particularly challenging the claim of non-punitiveness in the confinement of noncitizens. They argue detention is much more than exclusion for administrative purposes; it is about imposing deliberate punishment on whole categories of racialized people (Majcher \& de Senarcles, 2015; Chacón, 2014; Silverman, 2014; Leerkes \& Broeders, 2010; Pratt, 2005). These arguments emerged after observations of an increasing overlap between immigration and criminal law across different national contexts. This convergence is described as the "criminalization of migration" (Miller, 2003: 616) or "crimmigration law" (Stumpf, 2006: 10). Scholars importantly suggest this is reflected in the intensifying resemblance between immigration detention and criminal incarceration as demonstrated in theoretical and empirical research on the criminalization of noncitizens (Aliverti, 2012; Chacón, 2012), and the increasing use of carceral logics, mechanisms, and spaces in the immigration setting (Kaufman, 2015; Majcher \& de Senarcles, 2015; Leerkes \& 
Broeders, 2010; Martin \& Mitchelson, 2009). Qualitative studies on the lived experience of detainees also provide strong evidence of its implicit punitive nature (Silverman \& Nethery, 2015; Bosworth, 2014; Pratt, 2005). Elsewhere, other scholars are calling attention to the misplaced justification of immigration detention for administrative purposes, arguing it allows nation states to remove legal safeguards normally guaranteed in the criminal context, such as rights to due process and judicial oversight (Majcher \& de Senarcles, 2015; Hernández, 2014; Chacón, 2014; Wilsher, 2011). In sum, this literature suggests the holding of noncitizens is implicitly punitive as it increasingly integrates features of criminal law and incarceration, but fails to protect noncitizens against arbitrary detention by denying procedural safeguards.

\subsection{The Canadian Way of Administrative Confinement}

As is the situation in other nation states, Canadian immigration detention is characterized by its deprivations of liberty imposed upon noncitizens, who are indefinitely held for the administrative purposes of controlling migratory flows and facilitating deportation (Cleveland, 2015). The statutory grounds for detention are incorporated in the Immigration and Refugee Protection Act (IRPA) and the accompanying Immigration and Refugee Protection Regulations (IPRR), which give immigration officers of the CBSA specific discretionary powers to arrest and detain noncitizens. More specifically, section 55 and its subsections state officers may arrest and detain permanent residents and foreign nationals on entry or at any point thereafter, in some cases with or without a warrant, if there are reasonable grounds to believe they: (1) are inadmissible to the nation state and pose a danger to the public, (2) are unlikely to appear for an examination, an admissibility hearing, removal from Canada, or any 
proceeding that can lead to removal (flight risk), or (3) do not satisfy identification requirements. As per section 55(3.1), officers may also execute the mandatory arrest and detention of designated foreign nationals. The Canadian government justifies these provisions using a language of protection, particularly emphasizing how the IRPA seeks to "protect the health and safety of Canadians and to maintain the security of Canadian society" (Immigration, Refugees, and Citizenship Canada Enforcement Manual on Detention (ENF 20), 2015: 5). In fiscal year 2016-2017, it detained a total of 6,251 noncitizens, including 162 minors, in immigration detention centres (IHC) and provincial prisons across the country (CBSA, 2018a). The following sections will discuss the current Canadian immigration detention system in terms of the intersection of two ongoing processes - namely the historical processes of nation-building as a white settler colony, and the securitization of migration.

\subsubsection{Immigration Detention at the Present Time}

Immigration detainees are confined in designated immigration holding centres (IHC) located in Toronto (195 beds), Laval (109 beds), and Vancouver (24 beds) ${ }^{3}$. IHCs are medium-security quasi-penal institutions dedicated to hold, rather than to deliberately punish. As previously discussed, they are not required like prisons to "transform 'deficient' outsiders into desirable, governable citizen-subjects” (Pratt, 2005: 13). Rather, they are used to facilitate the removal of undesirable foreigners and control migration altogether. The Toronto Immigration Holding Centre (TIHC), for example, was previously a budget hotel that simultaneously operated to accommodate paying guests and to hold noncitizens (Pratt, 2005). This was often capitalized upon by the 
Conservative government with former Immigration Minister Jason Kenney claiming, "They [IHCs] are not jails, and in the case of the Toronto one...it's a former three star hotel with a fence around it." (Mallick, 2012, December 14). In contrast to this government rhetoric, Pratt (2005) argues these spaces ensure a "distinctly carceral experience," mirroring the retributive and exclusionary nature of prisons (p. 28). This is demonstrated by the strict regulation of detainees whose everyday lives are structured by institutional rules, ranging from early wake-up calls to mandatory searches. Refusal or failure to comply is also met with punishment, namely solitary confinement (Cleveland, Rousseau, \& Kronick, 2012). Most importantly, the punitive nature of IHCs is much more prominent in cases leading to death. Although there is a veil of secrecy around deaths in CBSA custody, it is reported that since 2000, at least 16 people have died while being held for immigration purposes (Molnar \& Silverman, 2017, November 14). Of these cases, three involved confirmed suicides, whereas the cause of eight other deaths is still unknown. The border agency also refuses to release the names of some deceased noncitizens for privacy reasons; it is unknown whether they will ever be identified, highlighting their dehumanization and erasure by the Canadian state.

Beyond these holding centres, the CBSA has contracted provincial prisons in the detention of noncitizens. In 2016-2017, 2,647 noncitizens or 38.5\% of the total detainee population were held in these institutions and other non-CBSA facilities (CBSA, 2018a). This is most commonly practiced in areas where the border agency does not operate or to alleviate overcrowding in holding centres. Detainees may also be transferred if they display "non-cooperative" behaviour or have mental health issues (Gros \& van Groll, 2015). Many critics charge that the use of prisons is an inappropriate response as these 
institutions operate on the overarching objectives of discipline and punishment, which shapes the ways in which prisoners are treated. These institutions in themselves also provide inhumane living conditions with the criminal population's everyday lives burdened by lockdowns, overcrowding, poor or absent programming, and reliance on segregation (Rushowy, 2017, October 3; Pilieci, 2017, February 24; Robin, 2017, February 15; White, 2016, March 8; Robinson, 2016, January 9). In Ontario alone, these institutional issues have prompted class-action lawsuits launched by detainees themselves against the provincial government ${ }^{4}$ (Syed, 2017, November 18; Fedio, 2016, May 26). Focusing on Lindsay's Central East Correctional Centre (CECC), which has a separate area for immigration detainees, Gros and van Groll (2015) shockingly found that detainees were confined to their cells for approximately 17 hours a day and subjected to strip searches as regularly practiced in maximum-security facilities.

The claim of non-punitiveness in administrative detention is further dismantled by the indefinite nature of this hold. Without a legislated presumptive period, government officials can order detention provided there are reasonable grounds to believe noncitizens in question continue to pose a danger to the public or present a flight risk. This could also result from unsatisfactory identification and delayed travel documents. The Canadian government denies the accusation of institutionalizing indefinite detention in carceral spaces by pointing to statutory detention reviews, which may order the release of immigration detainees into the community pending removal (Silverman \& Molnar, 2016). These hearings are held within 48 hours of detention, repeated within seven days and every 30 days thereafter. They are presided over by Immigration Division (ID) board members of the Immigration and Refugee Board (IRB), Canada's independent 
administrative tribunal. They are also adversarial; the federal government is represented by a CBSA hearings officer, whereas often impoverished detainees have the right to legal counsel at their own expense. Silverman and Molnar (2016) suggest that injustice is embedded in the very structures and processes of the immigration detention system, including within these hollow legal proceedings and its transfer of the burden of proof on detainees. Theoretically, the onus is on the government to prove on a balance of probabilities that continued detention is justified. As these authors observe however, this gets reversed in subsequent hearings where previous decisions have been negative. This institutional bias against release of detainees comes from the case of Thanabalasingham where the Federal Court of Appeal ruled that Immigration Division board members must show deference to previous decisions, and provide "clear and compelling reasons" if departing from them (Canada (Minister of Citizenship and Immigration) $v$ Thanabalasingham, [2004] 3 FCR 572, 2004 FCA 4, para. 10). This effectively shifts the evidentiary burden on to immigration detainees, who must then provide new evidence against their continued detention. Gros and van Groll (2015) refer to these reasons for describing detention reviews as "one of the most disempowering aspects of immigration detention" (p. 27).

The issue of procedural fairness in detention review hearings is highlighted in the Chaudhary case in which the Ontario Superior Court of Appeal ruled that immigration detainees may exercise their rights to habeas corpus in the provincial courts (Chaudhary v Canada (Public Safety and Emergency Preparedness), 2015 ONCA 700). This case involved four appellants, who sought to challenge their long-term detention resulting from consecutive negative decisions of Immigration Division board members. 
Procedurally, detainees can apply for judicial review and seek leave from the Federal Court; however, this court can only check the reasonableness of a decision and cannot substitute its own opinion. Although it can order a new detention review at the IRB, it does not have jurisdiction over the actual release of an immigration detainee. The Chaudhary decision is an incredible development as it renews detainees' habeas corpus rights, and gives them access to review and relief from the provincial courts; however, it is also only available to detainees in Ontario, which will be further discussed in a following chapter. More recently, similar issues emerged in Brown where lawyers of former detainee, Alvin Brown, challenged the constitutionality of Canadian immigration detention practices (Brown v Canada (Attorney General), 2017 ONSC 251). They argued indefinite detention violates multiple sections of the Canadian Charter of Rights and Freedoms, including the right against arbitrary detention, and freedom from cruel and unusual punishment. They also highlighted the problematic limited access to justice in detention reviews and suggested the implementation of a 90-day presumptive period (see also Hussan, 2014). In its decision however, the Federal Court ruled that the source of injustice is not the system itself, but the misapplication of law. The IRB responded to this by announcing it will conduct an internal review of its detention review practices (IRB 2018c; Loriggio, 2017, August 17).

\subsubsection{Reproducing Priorities of a White Settler Colony}

The Canadian state has historically rejected and detained undesirable, foreign others in the name of nation-building while endeavouring to maintain its character as a white settler colony (Coulthard, 2014; Abu-Laban, 2014; Bosworth \& Turnbull, 2014; Brodie, 2002). As a privileged subject of the British Empire, it capitalized on its relative 
political freedom to imitate the revered British standard in its political, cultural, and economic formation (Stasiulis \& Jhappan, 1995). This is particularly salient in Canada's immigration practices, which favoured white immigrants from Britain, then Europe and America more generally. Dating back to the early 1890s, Speeches from the Throne read in the opening of every new Parliamentary session signalled the need to control migrant movement from Asian countries (Brodie, 2002). These sentiments were reflected in state policies such that the already discriminatory collection of Chinese Head Tax was raised to $\$ 500$ in 1903 , whereas Japanese migration was limited to 400 people as termed in the 1908 “Gentleman's Agreement” (Stasiulis \& Jhappan, 1995: 112). They were also formally implemented in immigration laws as exemplified by section 38(c) of the 1910 Immigration Act, which instituted the denial of "immigrants belonging to any race deemed unsuited to the climate or requirements of Canada, or of immigrants of any specified class, occupation or character". These explicitly discriminatory legislative provisions were carried forward in the 1952 Immigration Act, again empowering officials to deny migrant entry based on nationality, citizenship, and ethnic membership. Pratt (2005) argues this demonstrates how "racism had intermingled with morality, gender, and class in the constitution of the (un)desirable citizen, and (un)desirability was linked discursively with the need to protect national purity" (p. 75). The reproduction of "white Canada" continued despite the reform of immigration policy in the 1960s, as will be discussed in a following section.

Heightened anxiety around national identity was not strictly isolated to incoming migration, but similarly emerged against particular groups already residing within territorial boundaries. For example, although fears induced by World War I led to the 
construction of European immigrants as "enemy aliens," non-white minorities and Indigenous populations still faced "the most virulent and institutionalized forms of racism" (Stasiulis \& Jhappan, 1995: 111). Dhamoon and Abu-Laban (2009) also trace three instances in Canadian history during which the intersection of racialized foreignness, security, and nation-building resulted in the categorical construction of "internal dangerous foreigners," encompassing "an insider who legally belongs to the state and simultaneously deemed an outsider/Other who does not substantively belong within the nation" (p. 169). They discuss the internment and forced labour of over 20000 Japanese-Canadians following the Pearl Harbour attack in World War II, the othering of minority Francophones labelled as "non-English extremists" during the 1970 October Crisis, and the arrest of 34 Mohawks over Indigenous land claims marking the 1990 Kanehsatake/Oka Crisis (Dhamoon \& Abu-Laban, 2009: 173). Canada's emphasis on racialized foreignness allowed it to use exceptional means to contain the imagined danger posed by these groups that did not fit its ideal white British citizenry. It used physical violence and exclusionary detention with Bashford and Strange (2002) suggesting the latter "has intermittently been part of the process in the definition and assessment of who belongs and who doesn't, and in enforcing and creating degrees of belonging and alienness in the project of nation-building." (p. 510).

Applied to the current context, it is perhaps better to explain the administrative confinement of noncitizens by referencing the Canadian state's past and its incessant reproduction of white settler colonial mentality. In forwarding this argument, I do not seek to glorify contributions made by the British and neglect the involvement of other groups in the nation's growth; however, I do contend that the construct of white settler 
colony provides an important analytical frame through which contemporary immigration detention could be understood. Stasiulis and Jhappan (1995) warn that the idea of white settler colony erases the history of Indigenous peoples, who inhabited and thrived on their rightful lands prior to British and French colonization (see also Coulthard, 2014). Although the Aboriginal population guided European explorers and engaged in the mutually-beneficial fur trade system, they were violently exploited by white settlers with the British seizing their lands on the false promise of treaties, and the French believing they discovered and thereby owned native lands. Despite France's colonist participation however, their English counterparts largely dominated with the identity of Canada as a dual-settler colony built on two founding races merely used to appease French settlers and "forestall their own claims to national sovereignty" (Stasiulis \& Jhappan, 1995: 110). The construct's focus on the British also fails to account for feminist movements fighting for women's rights and their place in the socio-political sphere, as well as ethnic minorities' involvement in shaping the nation's multicultural identity. Although I recognize the limitations of the concept of white settler colony, I argue today's practice of immigration detention is still very much rooted in Canada's imitation of the British example as particularly demonstrated by the racialized categories of people confined in immigration holding centres and provincial prisons across the country.

Demographic statistics on immigration detainees in Canada are limited, rendering it a challenge to understand exactly who are confined for administrative purposes. One could only speculate how this might be another strategy to ensure the population's invisibility. It was not until November 2016 after the announcement of the National Immigration Detention Framework (NIDF) that more statistical information on CBSA's 
immigration detention practices and the IRB's detention review hearings were published. In seeking to know noncitizens' identities however, these statistics fail to break down the heterogeneous category of immigration detainees, and only differentiate between adults and minors (CBSA, 2018a) and by grounds for detention as they relate to the IRPA's legislative provisions (IRB, 2018a). They do not account for gender, countries of origin, nor the various migration statuses embodied by detainees such that some of them are asylum seekers awaiting examination, refused refugee claimants, individuals on expired or violated visas, former permanent residents, and stateless persons. One exception is Nakache's (2011) Canadian study for the United Nations High Commissioner for Refugees (UNHCR), which provides partial statistics on the proportion of refugees in immigration detention (see Appendix B). In 2004 to 2005, she found that $42 \%$ of detainees belonged to the 'refugee' category, which conflated incoming asylum seekers and those whose applications have been denied. Although this increased to $47 \%$ in 2010 to 2011 , it remained relatively stable at approximately $43 \%$ within the study period of 2004 to 2011. Nakache also reported that this group was largely comprised of male detainees at an average of $76 \%$ in comparison to female detainees at $24 \%$.

Absent more recent and detailed statistics, I endeavour to develop a profile of immigration detainees by examining available data on the Canadian refugee system, particularly considering Nakache's (2011) previous findings that a significant proportion of those administratively held are 'refugees'. For this, I turn to protection claims referred to the Refugee Protection Division (RPD), which is a quasi-legal tribunal that determines whether an applicant is a Convention refugee or in need of protection. I draw on these statistics as they encompass asylum seekers, who may have been held pending 
examination, as well as claimants potentially detained following their rejection. In 2017 , the top five countries represented were Haiti $(8,286)$, Nigeria $(5,575)$, Turkey $(2,197)$, Pakistan $(1,664)$, and India $(1,460)$; their claims alone made up about $40 \%$ of the 47,425 total number of claims received by the RPD (IRB, 2018b). This demonstrates that a great proportion of asylum seekers hail from the poorest and traditionally non-white nations of the Global South. As they can be targets of immigration detention, it is also highly likely that many of those currently held in IHCs and provincial prisons are vulnerable racialized noncitizens fleeing persecution from their home countries. This is further supported by secondary sources like Gros and van Groll's (2015) study in which they interviewed ten immigration detainees, including failed asylum seekers from West Africa and the Middle East, former permanent residents from the Caribbean, and stateless persons whose identities could not be confirmed. Although dated, Pratt's (2005) ethnographic research in the TIHC emphasizes the detention of racialized noncitizens has been a persistent trend even in early 2000 as she found "the general characteristics [of detainees] remain relatively stable over time: the vast majority are always nonwhite, mostly male. Most are without resources, financial or otherwise" (p. 46).

News reports on Canadian immigration detention also reveal that longest-serving detainees tend to be racialized men. For example, Victor Vinnetou spent more than eleven years in detention as his home country could not be identified; he arrived in Canada using a false Zambian passport and refused to cooperate with the CBSA to establish his identity (York, 2016, June 14). Michael Mvogo, known as the "man with no name" was also held for almost a decade because his identity could not be confirmed (Logan, 2015, August 25). He entered Canada with a falsified American passport and 
caught the attention of CBSA after a criminal conviction. When his country of origin was finally discovered, the Cameroon government refused to provide travel documents because of his identity issues. Mvogo became one of the appellants in the Chaudhary case that fought for noncitizens' habeas corpus rights in Ontario courts (Chaudhary $v$ Canada (Public Safety and Emergency Preparedness), 2015 ONCA 700). Further, Kashif Ali was detained for over seven years in a maximum-security jail as the Canadian government failed to deport him. Although born in the West African nation of Ghana, he did not have any identity documents to prove his citizenship, which impeded his removal. He was finally released last year with Justice Ian Nordheimer of the Ontario Superior Court stating, "One thing is clear, and that is that Canada cannot purport to hold someone in detention forever." (Ali v Canada (Attorney General), 2017 ONSC 2660, para. 33). Currently, Ebrahim Toure, a failed asylum seeker, is the longest-serving detainee. He cannot be removed as his birthplace of Gambia refuses to acknowledge his citizenship in the absence of identity documents (Kennedy, 2017, March 17). He has been confined for over five years in a provincial prison and was only recently transferred to the TIHC as the Canadian government continues to pursue his deportation (Kennedy, 2017, October 5). The stories of these four men highlight the difficulty of being held for identity reasons, resulting in indefinite detention without a presumptive period in Canadian legislation. Although only providing a snapshot, they again demonstrate that it is often racialized people hailing from the Global South who are being held for administrative purposes. Here, I reiterate such practice profoundly exemplifies Canada's reproduction of white settler colonialism, rendering invisible racialized others, who do not fit its white ideal. 


\section{$\underline{\text { 2.4.3 Securitization of Migration }}$}

The emergence of human rights discourses in the 1960s and concerns over the labour needs of Canadian businesses seemingly trumped most desire for national purity, resulting in the dismantlement of explicitly racial discriminatory laws and the adoption of a points system for migrant selection (Kelley \& Trebilcock, 2010; Pratt, 2005). Regulations introduced in 1962 and 1967 prioritized applicants' labour power over ethnic membership with the new system evaluating their suitability based on factors, such as education, training, and skills. These changes were acclaimed for liberalizing Canadian immigration law as they employed objective methods in selecting prospective newcomers. Reflecting on these regulations however, scholars argue they were partially implemented in response to the declining emigration from Canada's preferred source countries such that the proportion of British immigrants fell from $28 \%$ in 1962 to $16 \%$ in 1976; this is also exemplified by the more general decrease in European immigrants from $78 \%$ to $38 \%$ in the same time period (Kelley \& Trebilcock, 2010: 354). The Canadian government was forced to open its immigration system to seek "the talented, acquisitive, and (economically) independent prospective citizen" (Pratt, 2005: 86). Its desire for white European immigrants, however, still subtly prevailed despite implementing an ostensibly neutral points system and eradicating overtly discriminatory provisions. For example, immigration offices were much more concentrated in traditionally white nations. The UK and the US had a combined total of fifteen locations, whereas merely three offices could be found across South America and one in India; five offices were also located in Africa, two of which were in South Africa (Jakubowski, 1999). Although reconfigured with migrant labour, this demonstrates the primacy of white settler colonialism once more, 
which continues today with Canada's burgeoning reliance on the temporary migrant labour of racialized peoples, who are only acceptable as long as they contribute to the economy without remaining permanently and draining the nation's resources (see Choudry \& Smith, 2016; Lenard \& Straehle, 2012; Goldring \& Landolt, 2013; Goldring, Berinstein, \& Bernhard, 2009; Sharma, 2006).

At the same time that the Canadian state committed to non-discriminatory immigration laws, it also expanded legislation related to security and criminality in fear of enemy foreigners in the post-Cold War period. This was formally reflected in the 1976 Immigration Act in which new inadmissibility grounds prohibited the entry of persons, who may pose a threat to national security by participating in subversion, espionage, or terrorism, and to public safety by engaging in violent acts and organized crime. Pratt (2005) argues these changes highlight the ways in which national security began encompassing categories of crime, further suggesting this crime-security nexus became one of the justifications for "immigration penality" under which exists the technologies of detention and deportation (p. 1). This intersection of security, crime, and migration is nothing new as I have previously discussed the construction of dangerous aliens; however, in the late 1990s, the Canadian state largely shifted its attention towards refugees after the unexpected boat arrival of asylum seekers, which became the catalyst for more restrictive immigration laws and policies. New border controls resulted in what Macklin (2005) calls the "discursive disappearance of the refugee" (p. 365). As the nation state offered fewer options for legal entry, refugee claimants were forced to pursue dangerous and non-traditional pathways, sometimes by human smuggling, to escape persecution in their home countries. These actions, however, produced a dichotomized 
image of the refugee; those pre-selected were perceived as having genuine claims and thus deserving of help, whereas others arriving spontaneously by boat were equated with illegality and thereby underserving of the state's generous hospitality (Dawson, 2017; Diop, 2014; Macklin, 2005; Pratt, 2005). This shift led to the erasure of refugees and migrants more generally as they "themselves are now 'illegal'; states are concerned about ‘illegals."” (Dauvergne, 2008: 16).

The enforcement of immigration laws and policies is an exercise of sovereign power that presumably allows the nation state to differentiate between members and nonmembers; the boat arrivals of asylum seekers on Canadian shores violate this order as they "represent a direct affront to the integrity of national borders" (Mountz, 2011: 8). Macklin (2000) explains it is not surprising that these events were constructed into threats against the nation state as "self-selected" refugee claimants effectively force Canada to accept them (p. 389). As a signatory to the 1951 United Nations Refugee Convention, Canada is bound by international law to the principle of non-refoulement, which means it is prohibited from turning back any individual, who fits the definition of a refugee. In seeking to regain control over its disrupted borders however, the nation state strategically responds with securitization, which refers to "the process of constructing an object as an existential threat," enabling it to adopt exceptional methods of control (Rygiel, 2012: 216). This is clearly exemplified by the way in which the federal government dealt with the arrival of 599 asylum seekers from Fujian, China in 1999, as well as the arrival of MV Ocean Lady and MV Sun Sea in 2009 and 2010, respectively. These events were framed as refugee crises and used in changing the contours of Canadian immigration law. 
Within a six-week period in 1999, Canadian authorities intercepted four boats arriving off the coast of British Columbia, leading to the apprehension of 599 asylum seekers from Fujian, China. These individuals were transferred to a military base where they filed asylum claims citing fear of persecution in their home country. Those on the first boat were released soon after; however, when they failed to appear for subsequent hearings, the remaining claimants were administratively detained en masse on the grounds of flight risk. Most were detained in long-term facilities, but around 90 were also secretly deported out of the country (Mountz, 2011; Mickleburgh, 2000, May 11). The Canadian state capitalized on this event to pass Bill C-11, the Immigration and Refugee Protection Act, which would eventually become the foundation of our current immigration law and the immigration detention system more specifically. Government representatives were particularly involved in discursively re-imagining asylum seekers as bogus claimants, who were abusing the country's generous refugee system (Dawson, 2017; Diop, 2014; Macklin, 2005; Pratt, 2005). In justifying Bill C-11, former Immigration Minister Elinor Caplan of the Liberal government explicitly stated, "[I]t provides us with all that we need to fulfill our dual mandate, which is to close the back door to those who would abuse our generosity and not obey our rules, so that we can open the front door wider to the immigrants and refugees like those who came before them, who came here to build this wonderful country." (House of Commons, 2001, February 26). This rationale is productive in shaping the contrasting tropes of the "deserving" refugee claimant, who patiently waits her turn in refugee camps outside of the nation state, and the bogus asylum seeker, who jumps the queue by arriving on shore. 
The securitization of migration intensified after the terror attacks of September 11, making way for even more restrictive border controls in the quest for national security and public safety (Dauvergne, 2007). Although the IRPA and its accompanying Regulations were introduced well before these events, they were perceived as "an almost clairvoyant, cutting-edge response to the new terrorist threat" (Pratt, 2005: 3). The image of refugees and migrants was once again reconfigured in terms of terrorism with the menacing figure of the racialized Muslim male requiring the greatest attention. It is in this context that the Canadian government reintroduced its practice of security certificates, which denied all procedural and substantive rights to those deemed as threats to national security (see Larsen \& Piché, 2009; Larsen, Harkat, \& Harkat, 2008). This discursive shift also made it easier for the Conservatives to respond to the more recent boat arrivals of MV Ocean Lady in 2009 and MV Sun Sea in 2010. Although both were carrying Tamil and Sri Lankan asylum seekers, authorities detained all those aboard citing threats to criminality and terrorism. The Canadian government then responded by ratifying of Bill C-31, Protecting Canada's Immigration System Act, which formally implemented the mandatory detention of "irregular arrivals" (Silverman, 2014: 28). This new legislation broadens discretionary powers of the Public Safety Minister in naming any group of noncitizens aged 16 or older as "designated foreign nationals" (DFN) in cases where identity examinations cannot be conducted promptly or if there are reasonable grounds to believe human smuggling is an issue. DFNs are only given two weeks to prove their identity and if unsuccessful, they are detained for another six months until the next review. They also do not have access to an appeal if their refugee applications are denied. Although these provisions have only been used once in the 2012 
case of Romanian Roma refugee claimants, their harsh character is particularly revealing given Canada's image as a humanitarian leader (Cleveland, 2015; Mountz, 2011).

\subsubsection{Towards Accessing Justice}

With a particular focus on the quasi-judicial proceeding of detention review hearings, this thesis demonstrates the ways in which noncitizens have severely limited access to justice that would allow them "to participate competently and confidently in the legal system of Canada" (Silverman \& Molnar, 2016: 111). This process renders them invisible in ways beyond their physical separation from the public (Dawson, 2016; Hernández, 2014). I will expand on Silverman and Molnar's (2016) research that demonstrates how "failure is hardwired" in the current detention regime, complementing their study with an ethnographic account of detention reviews, and qualitative interviews with legal counsel and former immigration detainees. I seek to contribute to the wider sociological literature by analyzing racialized detainees' limited access to justice within the Canadian state's colonial past and its persistent tendencies to replicate white settler colonial preferences. This proceeds through the exercise of sovereign power, which also plays out in a highly securitized political context influenced by the government officials in Parliament. Interestingly, it is often assumed that the Conservative government of Stephen Harper pushed for some of the most restrictive anti-immigrant legislation and policies; however, as this historical account demonstrates, the securitization of migration was also prioritized by the Liberals as they ratified the IRPA upon which the current immigration detention system is founded. Following this review of the literature, the next 
chapter will discuss my research process and the methodological considerations undertaken to conduct this study. 


\section{CHAPTER 3. METHODOLOGY}

Most literature on social science research methodology emphasizes the divisive camps of qualitative and quantitative approaches. In my undergraduate studies, the strengths and weaknesses of both were heavily discussed in classes and their accompanying textbooks. It was not until I participated in research methods courses at the graduate level that I was able to fully comprehend how these methods are informed by specific values. Importantly, in incorporating them in research designs, scholars are consciously performing "their ontological and epistemological presuppositions" (Schwartz-Shea \& Yanow, 2012: 5). To this end, I will discuss interpretive methodology and its assumptions to explain my incorporation of semi-structured interviews and nonparticipant observation in seeking to answer my research question. This chapter will review the many challenges I faced in conducting fieldwork with a focus on accessing participants and negotiating with gatekeepers; it will then discuss how these challenges changed the direction of my research and its new focus on access to justice. It will also examine ethical issues associated with studying vulnerable populations and my essential engagement with reflexive practice. While I write this chapter intending to explain my methodological decisions, I also humbly share lessons learned as a novice researcher in hopes that my experience, barriers encountered, and decisions made are instructive to future researchers.

\section{$\underline{\text { 3.1 Adopting Interpretive Methodology and Qualitative Approaches }}$}

My thesis draws from interpretive methodology while employing the phenomenological approach of semi-structured interviews and the ethnographic approach 
of non-participant observation. It was essential to adopt an interpretive design due to my initial interest in the lived experience of detention review hearings. This methodological framework importantly disputes the existence of a single truth and operates on the assumption that all individuals have situated knowledge. As Schwartz-Shea and Yanow (2012) suggest, it "rests on a belief in the existence of (potentially) multiple, intersubjectively constructed 'truths' about social, political, cultural, and other human events" (p. 4). Interpretive methodology recognizes that participants are positioned in specific environments, which inspire their narratives and meanings. It prioritizes understanding their realities insofar as they comprehend them. It does not seek to detect lies or denials to ensure the accuracy of data because these "are themselves potentially data that are relevant to the unfolding of analysis" (Schwartz-Shea \& Yanow, 2012: 81). Undocumented noncitizens, for example, may hold back or give short answers out of fear of being detected by state actors. Their silence is equally important and can be telling of their experiences and attitudes towards the immigration system. With these methodological assumptions, I used semi-structured interviews along with nonparticipant observation to examine how immigration detainees, as situated participants, experience detention review hearings.

Importantly, interpretive methodology acknowledges that research is not a straight process; it is dynamic and requires flexibility from researchers (Schwartz-Shea \& Yanow, 2012). It follows an abductive logic of inquiry in which researchers are continuously engaged in sense-making. They encounter puzzles in the field, which appear when their knowledge and expectations do not align with their observations. They may seek an explanation by starting with the familiar then gradually expand their understanding while 
confronting other emerging puzzles. This suggests the research process is an endless pursuit with "only momentary stopping points, to collect one's thoughts, perhaps to publish or otherwise disseminate what one understands at that point in time..." (Schwartz-Shea \& Yanow, 2012: 30-31). It is this very element that allows me to account for the many changes in my thesis. For example, I initially believed I would be able to research the lived experience of immigration detainees; however, my access to participants was very limited and forced me to seek other types of evidence, such as interview data with legal counsel. I then thought lawyers would be able to share their clients' experience of detention review hearings, but they were mostly focused on their processes and the challenges they faced. Here, I engage in interpretive methodology's abductive logic of inquiry and come up with a new research question on access to justice after encountering puzzles in the field whereby what I expected to find did not match what I observed. As I elaborate in the following section, the research process can be very difficult, requiring renewal of motivations, persistent negotiation, and flexibility to change. I begin with my research journey to demonstrate the challenges I needed to overcome prior to being able to conduct interviews with participants and gathering observations on detention review hearings.

\subsection{Challenges in the Field: Negotiating Access to Invisiblized People}

My original intention was to research the lived experience of immigration detention. I was inspired by my personal connection to the Filipino migrant community where struggles of navigating the immigration system and adapting to the Canadian ways of life are casually discussed in daily conversations. I was also motivated by my 
educational background in critical criminology, which taught me about the abuses perpetuated by the criminal justice system and the importance of humanizing prisoners trapped in its revolving door. In increasingly anxious times, I wondered about the intersection of these two systems, particularly how noncitizens with precarious legal statuses would experience the quasi-penal practice of immigration detention. Perhaps too ambitiously, I prioritized listening to their voices and sought to use my thesis as a medium through which we could learn from their narratives to deconstruct the 'illegal immigrant' identity and critically question the current detention system. Although I discuss these potential benefits to immigration detainees and their communities, I also recognize this project is advantageous for me as a graduate student, allowing me to fulfill requirements of my Master's thesis and provide opportunities for presentations and publications. I, therefore, intended to design and conduct my research project in a mutually beneficial way, to expand knowledge on Canadian immigration detention practices and share findings that could have practical implications.

Early on, I recognized that securing access to participants would likely be the greatest challenge in my research process. My thesis supervisors and colleagues warned me of the high level of difficulty associated with seeking vulnerable and marginalized populations. I also learned from the experience of other scholars, who went through lengthy bureaucratic procedures to gain institutional access to participants in spaces of detention (see Kronick, Rousseau \& Cleveland, 2015; Bosworth, 2014). It seemed that previous contact with the target population would have been ideal, as exemplified by Griffiths (2012), who was initially employed as an asylum caseworker and volunteered with a non-governmental organization (NGO) providing services to those in the UK's 
Campsfield Removal Centre. I unfortunately lacked connection to and had no experience working with refugee or migrant organizations that support noncitizens in immigration detention. This prompted my early attempts to contact a prominent activist organization based in Toronto beginning in February 2016. This volunteer-based group is the most active in denouncing the federal government's detention of noncitizens. Its members organize community events, appear in media releases, and have published a report on the injustices of administrative confinement. Importantly, they also provide some services to immigration detainees, supporting them through phone calls and visitation, and seeking legal counsel for their representation at the IRB and in other court proceedings. They could, therefore, serve as the gatekeepers in my research. I spent several months contacting a few members to whom I presented myself as a researcher and ally with an offer to conduct a collaborative thesis on research questions they hoped to answer. At the end of June 2016, I also travelled to Toronto to support a community event and introduce myself to other organizers. All of these efforts, however, were met with much resistance for several reasons. As a volunteer-based group, it had very limited capacity to connect me with former detainees with whom it may take time to develop trusting relationships. Members also expressed the need to protect this vulnerable population, who may not want research attention altogether. They additionally shared previous negative experiences with researchers, who failed to give back and share their findings, which points to the problematic "grab it and run" mentality that impacts researched communities and future researchers alike (Gobo, 2008: 306). Despite negotiating with these gatekeepers, these overlapping issues blocked meaningful access to potential participants. 
Although I was still motivated to interview former detainees, I had to strategically seek other sources of data assuming I would not be able to access participants. New sources might not necessarily answer my initial research question on the lived experience, but could perhaps reveal other issues or aspects of immigration detention for me to investigate. This exploration led me to the IRB's quasi-judicial proceedings, particularly detention review hearings presided over by ID board members, which are open to the public with a few exceptions. They are strictly held in private when dealing with noncitizens, who have claimed refugee protection. Observers are excluded unless the ID member is convinced they are not "members of the public," meaning those approved to be present were normally family members and friends (IRB, 2005: 4-7). Presiding adjudicators may also exercise discretionary powers and call for a private hearing if there are confidentiality concerns. Because the rest of the hearings are still held in public, I thought they would be accessible sources of data for my study purposes; however, several challenges later emerged once I entered the field. First, detention review hearings were previously conducted in person, but budgetary issues led to the 2014 closure of the IRB in Ottawa and forced the transfer of Ottawa cases to the Montreal office. Although these proceedings have since been held over videoconference in the Ottawa-Carleton Detention Centre (OCDC), it would be difficult to observe them, as I would very likely need institutional permission to enter the securitized jail. It is important to point out that this change in location and format takes away the 'public' character of detention review hearings, exhibiting another way in which immigration detainees are rendered invisible by the system. Moreover, to observe these proceedings in person, I needed to travel to either Montreal or Toronto, which are both several hours away from 
the capital city. As a graduate student, this data collection was quite taxing because of time constraints and limited resources. I had few personal connections in both cities and had to be strategic with my visits. Because of these logistical issues, I was only able to travel to Toronto twice, and observe two detention review hearings and three admissibility hearings.

Additionally, collecting observational data of detention reviews was even more challenging as these hearings are held in the securitized space of the TIHC. IRB offices and courtrooms are located in the same building where noncitizens are physically held. Because of their joint location, I had to navigate through a heavily-surveilled site simply to observe these quasi-judicial proceedings. When I walked into the IRB office, two private security officers greeted and ushered me through a security screening that was somewhat akin to airport checks. They asked me to take off my jacket and place my backpack on a separate table. After going through a metal detector, I then had to show them the contents of my bag, opening every pocket to prove my harmlessness. Being treated to this high level of security was incredibly surprising considering the population of noncitizens served by this independent tribunal. More specifically, the TIHC only houses "low risk" detainees, who are defined by the CBSA as those who do not pose a security or danger concern and do not have a criminal record (Nakache, 2011: 47). It does not hold "high risk" detainees, who may have a violent criminal history as these individuals are transferred to provincial prisons where detention reviews are typically held over videoconference (CBSA, 2018b). In comparison, it was also only in the past few years that the provincial court house in Ottawa, which deals with criminal cases, began implementing metal detectors (CBC, 2015, August 31). Before then, I had been 
able to freely observe public hearings without going through security checks. This is not to encourage the heavier monitoring of criminal populations whatsoever; however, I seriously question the need for this high level of security in tribunal spaces for "low risk" detainees. I would reiterate this critique even if the IRB dealt with "high risk" detainees whose level of risk is based on criminal wrongdoings for which they have already served a sentence. It is even more concerning when the category of "high risk" detainees also includes individuals, who may have displayed disruptive behaviour, which can very well stem from mental health issues (Gros \& van Groll, 2015). The securitization of tribunal spaces and the application of arbitrary risk levels are extremely "productive," however, in that they can further construct noncitizens into criminals, who require continued detention (see Pratt, 2005).

Along with these security issues, I also faced several administrative barriers, specifically due to the absence of an accessible court schedule. I had to physically present myself to the IRB office early in the morning to determine if there were any public detention reviews scheduled for the day. Despite communicating with IRB staff prior to my first visit to Toronto, I was not informed of these bureaucratic procedures and forbidden from observing the hearings for being "too late". It was especially difficult when court schedules were belatedly changed. For example, I was once told there were public hearings, but later found out that they were deemed for private audiences only, which ultimately suspended my data collection. It also exhausted my time and resources, as I had to travel to the TIHC's fairly inaccessible location in Etobicoke near the Toronto Pearson Airport. The building is situated on a busy, industrial road and takes around 30 minutes by bus from the last subway station. I then spent half the day waiting for these 
public hearings. For my second visit, I prioritized contacting the staff member involved in organizing the daily court schedule after learning that early notification was preferred by the IRB. I informed her of my intention to observe hearings for research purposes to which she responded positively. Because of the public nature of detention reviews, I did not anticipate the need to negotiate institutional access with IRB employees as gatekeepers. I was not seeking entry into detention centres unlike other scholars, who very likely expected to go through bureaucratic procedures to gain access to these centres (see Kronick, Rousseau \& Cleveland, 2015; Bosworth, 2014). However, albeit in a much more informal manner, some negotiation was still necessary to facilitate access to public detention review hearings.

Interpretive research using qualitative approaches is necessarily flexible. As Schwartz-Shea \& Yanow (2012) suggest, researchers are constantly learning from and adapting to the dynamic research process, which often results in the emergence of new questions and answers. Employing this particular methodology and its abductive logic of inquiry has importantly allowed me to account for the various changes in my project as exemplified again in the incorporation of observational data from detention review hearings. After navigating through the challenges in accessing the securitized spaces of the TIHC and IRB offices, I was finally able to observe hearings presided over by ID board members; however, this data inspired new research questions regarding the ways in which noncitizens are governed through these quasi-judicial proceedings. I became interested in how this heterogeneous group is constructed into immigration detainees. It also allowed me to act on my initial desire to examine lived experience by asking how noncitizens experience detention review hearings and the potential transformation 
occurring within them. These new questions and available data sources encouraged changes in my research design. It meant that I did not only need to heavily rely on interviews with former immigration detainees, who have been extremely hard to access. I could also speak with other actors involved in governing relations with noncitizens, such as legal counsel. Overall, my interpretive methodology enabled me to adopt a multimethod approach in which I collected and analyzed observational data from detention review hearings and interview data from interactions with participants.

My new research questions have a narrower focus on detention review hearings, but they still sought to investigate the lived experience of those subject to them, which again required interviewing former immigration detainees with first-hand knowledge of these proceedings. Interpretive research does not specify an ideal number of participants and in fact discourages "the language of sampling" due to its origins in the positivist paradigm (Schwartz-Shea \& Yanow, 2012: 87). Seeking a particular sample size implies that the researcher has complete control over the research setting, which is an incorrect assumption as various obstacles may affect the recruitment process. Schwartz-Shea and Yanow (2012) suggest using the term "exposure" as opposed to "sampling" to refer to interpretive researchers' preference for gathering thick descriptions and different meanings from situated participants (p. 88). On my end, although I did not specify a sample size, it was still important to continue negotiating access to at least a small group of respondents, who could share their detailed narratives. Previous attempts to seek help from Toronto activists taught me how difficult it was to bargain with gatekeepers and facilitate contact with former immigration detainees. Prior to investing more time in this research project, I tested its feasibility by conducting an informal recruitment of potential 
participants in July to August 2016. I did not have ethics approval at this time, but strictly made it a point not to interview interested candidates until after receiving clearance. For recruitment purposes, I used a multi-pronged approach to extend my reach as far as possible. I produced a call for participants, which I posted in publicly accessible university and community legal clinics in Ottawa and Toronto. I also distributed the poster to Toronto-based refugee houses and several non-governmental organizations offering services to migrants and refugees. I also began contacting legal counsel as potential participants and gatekeepers to immigration detainees, who may have been former clients. Again, I stress that I did not conduct interviews before obtaining ethics clearance. The objective of this informal recruitment was simply to investigate if I could even speak to a few former detainees. This plan was thankfully quite fruitful at the time as some organizations expressed interest in my research project, and suggested they would be able to connect me to potential participants.

Access challenges unfortunately prevented me from pursuing this research project further as it became even more evident that I would not be able to negotiate meaningful contact with former immigration detainees within my limited time frame. After obtaining ethics clearance in December 2016, I immediately began conducting formal recruitment of potential participants, who included former detainees and legal counsel. I reconnected with legal clinics in Ottawa and Toronto, and asked them to post an approved version of the call for participants. I also redistributed this poster to the refugee houses in Toronto and other NGOs located in both cities that previously welcomed my initial request. Although they were all willing to repost the call for participants and maintained interest in my project, they were less available to connect me to clients, who were former 
immigration detainees. I continued to follow up on leads from informal recruitment for several weeks and months, but my efforts were devastatingly unsuccessful in securing participants. Understandably, these organizations are likely under-resourced and had little time to play the gatekeeper role in my research project; however, my experience ultimately demonstrates the high level of difficulty in accessing former immigration detainees and researching the lived experience of vulnerable populations more generally. Despite conducting informal recruitment to test my project's feasibility and using multiple strategies thereafter, I was only able to interview two participants from this group. I sympathetically recognize that these individuals are likely reluctant to share their experiences, particularly while being in the precarious situation of awaiting deportation. They would be more concerned about obeying release conditions with research participation being a low priority. I am also very much an "outsider" in their immediate network without any previous connection to refugee and migrant organizations prior to graduate school. A stronger relationship with gatekeepers would have likely facilitated easier access.

In redesigning my project around detention review hearings, I identified refugee and immigration lawyers as potential participants because of their representation of detainees in these quasi-judicial proceedings. I intended to conduct interviews with them, believing they would be able to discuss their role as legal counsel and speak to their clients' experience of IRB hearings. I also perceived them as gatekeepers, who may be able to refer my research project to some clients. To this end, I asked them to pass my information to potential participants, who could then contact me if interested. Most of the lawyers accommodated this request, but were sceptical about clients' participation 
considering their preoccupation with legal proceedings, release conditions, and imminent removal. Similarly to previous attempts, it was still very difficult to enlist former detainees as participants even through legal counsel. I was only able to interview one client to whom my research project was referred and had the opportunity to contact another participant through my thesis supervisors. I was also hesitant to follow up with legal counsel and their clients because of the power relationship existing between them that might lead the latter to feel forced in partaking in my project. As a researcher, I needed to remain cognizant of these ethical issues and ensure that I was not causing harm to former detainees, who already belong to a vulnerable population. I will elaborate upon this decision and other ethical considerations in a following section.

As expected with interpretive research, new questions emerged once I began analyzing the first few interviews with legal counsel (Schwartz-Shea \& Yanow, 2012). My initial inquiry focused on the ways in which noncitizens with precarious statuses are (re)constructed into immigration detainees, and their lived experience of these processes. I mistakenly assumed, however, that lawyers would have the capacity to speak about these issues faced by their clients simply because they accompany each other through these quasi-judicial proceedings. I failed to consider that inasmuch as former immigration detainees have situated knowledge, so do legal counsel. As Schwartz-Shea and Yanow (2012) suggest, all participants 'possess valuable 'local knowledge,' concepts and their situated definitions that have grown out of their own daily practices and interactions, reflecting their own lived experiences..." (p. 50). This certainly manifested in interviews with legal counsel in which they emphasized their role and responsibilities as representatives of immigration detainees in detention review hearings. They used much 
more technical language and discussed legal procedures while sharing examples from past cases. Due to my limited access to former detainees, the greater part of my data is comprised of interviews with eleven refugee and immigration lawyers. This has resulted in my finalized research question on access to justice in immigration detention, particularly asking how this can be achieved through detention review hearings in the IRB quasi-judicial setting.

\subsection{Co-generated Data and Thematic Analysis}

Engaging with interpretive methodology, I conducted semi-structured interviews to understand the ways in which former immigration detainees experienced the quasijudicial proceedings of detention reviews. I also interviewed immigration and refugee lawyers, believing they could speak indirectly to their clients' experiences. This phenomenological approach was helpful as it allowed participants to elaborate upon their experiences using terminology that was "meaningful to them" (van den Hoonaard, 2012: 78). It gave them the opportunity to share their stories and feelings as situated experts. Although I prepared an interview guide, it served as a rough guide rather than a strict manual, keeping our conversation on track while giving the opportunity to explore ideas emerging from participants' responses. Also, interviews are much more than "neutral exchanges of questions and answers" as researchers are likewise involved in constructing narratives and meanings by engaging with their respondents (Tracy, 2013: 132). Throughout the interview process, it was important, therefore, to remain cognizant of my contributing to the "co-generation" of knowledge (Schwartz-Shea \& Yanow, 2012: 80). I was equally involved in generating data by bringing my own values and experiences into 
the interaction. Although this could have had the negative effect of "leading" participants in responding a certain way, I was careful not to interrupt while they were speaking and keep my opinions to myself as much as possible.

My thesis involves the participation of two different groups (see Appendix C). For the first sub-group of respondents, I sought the participation of adult former immigration detainees, who spent at least 48 hours under administrative confinement in either an IHC or provincial prison. This eligibility requirement ensured they participated in at least one detention review hearing. Recognizing there may be language barriers in research with noncitizens, I also only interviewed individuals, who were comfortable with speaking in English to minimize misinterpretation. I assigned a pseudonym to all respondents except for Deepan Budlakoti, who is currently involved in a high-profile case and wished to be named. As shared above, I used a multi-pronged approach to recruit former detainees. I started by seeking assistance from an activist group and posting a call for participants in university and community legal clinics, refugee houses and other NGOs in Ottawa and Toronto. Participating refugee and immigration lawyers were additionally asked to refer my study to past or current clients, who may be interested in sharing their experiences. Most of these efforts in recruiting former detainees were unfortunately unsuccessful as I was only able to interview two respondents. Felix is a refugee claimant whose application was denied. He was detained in a provincial prison after a delay in submitting his change of address to CBSA, who deemed him a flight risk. I was able to interview Felix through his lawyer's referral. Although he was a native French-speaker, we were able to comfortably communicate using both French and English. Deepan Budlakoti is the second former detainee, who 
participated in my study. He was put under an immigration hold after officials claimed he is not a Canadian citizen despite having an Ontario birth certificate and a Canadian passport (see Stasiulis, 2017). Today, he continues to fight against his stateless status to regain Canadian citizenship with his case now submitted to the UNHCR.

The second group of participants included refugee and immigration lawyers from Ottawa and Toronto, who represent clients in detention review hearings presided over by ID board members. I started by recruiting respondents in Ottawa as they are most accessible to me; however, with the general lack of interest among those contacted and due to the fact that there are more practising lawyers in Toronto, it was necessary to expand my scope. I identified potential respondents by first listing individuals, who I know are members of activist or advocacy groups, have spoken to the media, and/or participated in other research studies without using a pseudonym. I then conducted an Internet search of immigration lawyers practising in both cities, contacting them directly by phone or email. Snowball sampling was also used in which I asked participants to refer other colleagues, who might be interested in my study. In contrast to my recruitment of former detainees, these efforts were much more successful and resulted in eleven participants, including six lawyers from Ottawa and five from Toronto. Although I am not conducting a comparative study between the experiences of lawyers from these cities, the opportunity to interview participants from both provided a more enriched understanding of administrative confinement and its legal proceedings. For example, immigration detainees in Ottawa do not benefit from an IHC and are detained in OCDC where hearings are held by videoconference with the Montreal IRB. This is in comparison to detainees in Toronto, who may be confined in either the TIHC or a 
provincial prison. In interacting with Ottawa and Toronto lawyers, I was able to gather a more diverse set of experiences, particularly learning about the similarities and differences between the ways in which detention reviews proceed in different spaces.

In addition to employing the phenomenological approach of semi-structured interviews, I also conducted non-participant observation to further understand the process of detention review hearings. To use this ethnographic approach, researchers typically immerse themselves in the communities they seek to observe, deciding on the extent to which they want their research objectives to be known. For example, some may take on the role of "complete participant" and become full members without disclosing their research purpose, whereas others may choose to be a "complete observer" without any involvement in the group's activities (van den Hoonaard, 2012: 60). These levels of participation are not mutually exclusive, however, in that researchers may shift from one level to another throughout the research process, which may lead to a reconsideration of how much and at what point they are willing to disclose their objectives (van den Hoonaard, 2012: 61). This ethnographic approach was helpful in allowing me to further examine detention reviews, particularly learning about the actors involved in them, the spaces in which they occur, and the procedures followed in the process. Although most of my analysis relies on interviews, I was able to contextualize participants' stories and responses using observational data, and thereby provide a more well-rounded account of detention review hearings.

As previously mentioned, I collected observational data by watching public detention review hearings held in the Toronto IRB. Although I travelled to Toronto twice, bureaucratic issues forbade me from observing more than a couple of these proceedings. 
It was difficult to negotiate access to these tribunal spaces despite the fact that most hearings should be open to the public, often requiring some informal negotiation with institutional gatekeepers in charge of the schedule. Besides these challenges, I observed two detention review hearings and three admissibility hearings during two separate trips to Toronto in June and July 2016, but the latter were not included in my analysis. In addition, I had the opportunity to observe detention reviews by shadowing an Ottawabased immigration lawyer. She kindly and generously opened her practice to me, allowing me to accompany her to OCDC where she represented clients in IRB proceedings conducted by videoconference. This permitted me to observe five detention review hearings from September to October 2016. Again, although I am not conducting a comparative analysis, observing these hearings in two different settings led to a better understanding of how these procedures are carried out in Ottawa for immigration detainees held in the provincial jail of OCDC and in Toronto for those confined in the TIHC. It is also important to note that throughout this phase of data collection, I mostly adopted the role of complete observer and did not get involved in any of the processes. While some actors knew of my presence as an observer, I disclosed very little about my research objectives so as not to intervene with the setting. The only exception here is the lawyer I shadowed in OCDC, who was well informed about my research. I will discuss our researcher-participant connect in a following section.

With data analysis being the next step in my research design, I prepared my cogenerated data by transcribing all audio-recorded interviews. One participant refused to be recorded, but I compiled field notes right after his interview. Verbatim transcription was a long and tedious process as I listened to all interviews at least three times to ensure 
the highest level of accuracy as possible. I also compiled field notes on the process of detention review hearings based on short jottings from the field. I completed these within a day or two after my field visit to avoid forgetting important details. Prepared with my interview and observational data, I then consulted the guidelines for thematic analysis provided by Braun and Clarke (2006), who define it as "a method for identifying, analysing and reporting patterns (themes) within data." (p. 79). Although there is a lack of consensus regarding how this type of analysis should be conducted, these authors offered a step-by-step guide to help researchers in recognizing themes from their data. I adopted this process, and coded transcribed interviews and field notes using NVivo software. These first-level codes were organized and led to the identification of recurring patterns and overarching themes.

\subsection{Remaining Cautious for Ethical Research}

Studying the experience of former immigration detainees, it was imperative to be cautious with the ways in which I researched this extremely vulnerable population. I first sought ethics clearance from the Carleton University Research Ethics Board (CUREB) by demonstrating how my project would interview former detainees without causing harm. To this end, I started all interviews by obtaining participants' informed consent either orally or in writing (see Appendix D \& E). I explained all of the potential risks associated with participating in the study and importantly discussed how these would be minimized throughout the research process. For example, I reassured participants that if they felt uncomfortable at any stage, they could refuse to answer any specific question, stop the interview, or withdraw from the study altogether. I further assured them their information 
would remain confidential and anonymous. I was the only person, who had access to respondents' audio-recorded interviews. Pseudonyms were assigned and used throughout the transcribed data and study reports. Deepan Budlakoti, however, preferred to use his real name because of the high profile status of his case and its prominence in the media. I respected his request and did not assign him a pseudonym. Apart from him, I have and will continue to take the necessary precautions to protect my respondents' identities regardless of my study's end.

Although I incorporated several ways to mitigate potential risks to participants during the interview process, it did not occur to me that my recruitment strategies might cause harm to potential participants. Because of my limited access to former detainees, one of the methods I relied upon was referral from third parties. I sought help from lawyers, NGOs, and other service providers, who might be able to connect me to potential participants. In recognizing there may be power imbalances between third parties and referred individuals, particularly in cases where lawyers are recommending clients, I ensured that referring third parties would not be informed of referred persons' decision to participate or withdraw from the study. I also asked the former to share my contact information with interested candidates, who could then call me directly. There was an instance, however, in which I mistakenly called a referred participant rather than waiting for him to call me. The first interaction was somewhat distant as he was on his way to work. I suggested calling later to which he responded I could try, but to keep in mind he might still be busy. Our second phone call, however, ended very poorly. He asked me why I was calling and as I was explaining my research project, he said some inaudible statements then hung up the phone. As a novice researcher, it was a frightening 
experience as I realized my mistake and wanted to express my apology, but also hesitated calling back to avoid further harm. Noncitizens, who are criminalized and detained for immigration reasons, may understandably fear speaking about their experiences to avoid stigma and attention from law enforcement agencies. I should have been more careful with respecting boundaries to conduct research as ethically as possible. It is important for me to address this error in order to learn from my own experience and serve as a warning to other researchers studying vulnerable populations.

\subsection{Reflecting on Researcher Positionality}

Continuous engagement with reflexivity was an essential practice throughout my research process, starting from entering the field to writing my analysis. Situated within the framework of interpretive qualitative methodology, it was important to recognize and address the ways in which my identity and positionality, and how these are interpreted by situational participants might influence our meaning-making interactions. As SchwartzShea and Yanow (2012) suggest, "Participants of all status and power levels will size up a researcher quickly, making initial assessments interpreting bodily characteristics (e.g., sex, stature, age, etc.), dress, tone of voice, and manner: all those elements that comprise nonverbal communication." (p. 62). This heavily takes into account the impossibility of researchers existing outside of the setting being studied. In needing to understand how my identity influenced the research process, I used online and physical research diaries as reflexive tools to document reflections from the field, particularly after interviews and field visits (Browne, 2013). I always tried to write these journal entries as soon as possible to capture my immediate reactions then returned to them afterwards for further 
reflection. It is through reflexive practice as recorded in these diaries that I have been able to comprehend how my perceived identity affected interactions with former immigration detainees and legal counsel.

With interviews, one of my concerns was negotiating my researcher status as I feared participants would respond in ways they believe would appropriately align with my interests and project objectives. Although I expected this might be an issue for all respondents, I was particularly cautious with two individuals with whom I had some previous connection or relationship prior to the interview. They may already have general knowledge of my orientations and assumptions that could potentially lead them to emphasize points in support of these and/or omit parts that may not. The first participant, for example, was a former detainee referred by my co-supervisors, who had previously worked with him on advocacy campaigns. Due to his long-term relationship with other scholars, I found his answers were concise and straight to the point. It seemed interviews were quite routine to him as he fluently spoke the language of academics and lawyers. At one point, I asked him to slow down and retell his experience of immigration detention from the beginning, which he, albeit rightfully, assumed I knew either because of his case's media exposure or perhaps due to how we were connected through my cosupervisors. For the second participant, we shared an established relationship as I shadowed her cases for the purpose of collecting observational data on detention review hearings. As she generously opened her practice to me, I ensured I was equally transparent about my study's intentions and its critical regard of the detention system. I feared, however, that such previous knowledge might inadvertently influence her interview responses. To mediate these issues, I pointedly asked participants about their 
personal experiences, asking them to elaborate and give examples when possible. I also asked clarifying questions to give them the opportunity to reconsider their previous answer and add other details if needed. Although interpretive research disputes the possibility of ensuring truthfulness in participants' answers, I still hope these efforts were successful (Schwartz-Shea \& Yanow, 2012: 81).

As a graduate student without legal training, it was important for me to become familiar with legislation on immigration detention, and legal concepts and principles in general prior to interviewing lawyers, who have expertise on such subject matter. I prepared by reading the Immigration and Refugee Protection Act (IRPA) and its accompanying Regulations (IRPR), and CBSA and IRB policies and procedures. The purpose of this conscious effort was not necessarily to present myself as a complete insider, which typically refers to researchers belonging to the same group as their participants based on shared commonalities and experiences (Gair, 2012). I sought at least to speak a common language with these legal experts to ensure and demonstrate that I am prepared for our interaction; however, I also always made it a point to introduce myself as a graduate student to minimize their potentially omitting details they may assume I already know. Despite this and to my surprise, most respondents treated me as somewhat of an insider or perhaps a pseudo-member, who is knowledgeable of their practices. Lawyers cited case law or precedent-setting cases without much explanation. They used abbreviations and Latin terms in reference to legal principles. I would often have to ask clarifying questions to fully grasp their responses. Relatedly, it was much more difficult to negotiate an outsider status, which is typically assigned to researchers, who lack membership to the group under study (Gair, 2012). As Schwartz-Shea and 
Yanow (2012) warned, "experts and elites have considerable status and power themselves, and it is not clear that researchers will always have the upper hand..." (p. 61). I experienced this in a few interviews during which the respondents challenged my knowledge of immigration detention. One participant, for example, was quite dismissive and stopped our conversation to ask if I have ever even observed a detention review hearing. I also distinctly remember being told "what you should understand is" several times. In such cases, I found it difficult to manage the power imbalance because as much as I presented my knowledge and spoke a common language, I was still considered an outsider without legal expertise. These situations were out of my control and all I could do was to reflect upon them in my research diaries.

Interestingly, I also learned that the way in which my identity is perceived could shift depending on the space within which I am embedded and the people surrounding me. When I attended public hearings in the Toronto IRB, I was always asked about the purpose of my visit to which I responded with information on my Master's thesis. ID board members were notified of my presence as they are required to record observer attendance in case files. Recognizing my student status, there were several instances when members would allow me to ask questions after proceedings, sometimes explaining the Board's procedures and overarching legal principles. A notable example was during one of my visits when visitors were not allowed in the courtroom, but could observe by videoconference. The presiding member surprisingly made it a point to meet myself and another student after the hearing to answer our questions. Reflecting upon these experiences, it seemed that ID board members considered me as an outsider existing outside of their community. A few of them welcomed this however and allowed me to 
learn more about the detention review process. In contrast, I was treated as an immediate insider when I attended detention review hearings in OCDC. This is very likely attributable to my shadowing an immigration lawyer to her cases. That is, her insider status was automatically transferred to me. ID board members and prison guards acknowledged my presence, but did not wonder about my researcher identity. The former did not give me any opportunities to ask questions, perhaps assuming I was a law student familiar with IRB proceedings. Although I argue my identity plays an important role in the research process, I also recognize it becomes enmeshed with other factors (e.g., spaces within which I exist, people whom I am with), affecting how it is perceived.

\subsection{Lessons Learned as a Novice Researcher}

This chapter provides a detailed account of the way in which researching the vulnerable population of immigration detainees is extremely challenging. Without any previous relationship with migrant or refugee groups, it was very difficult to access potential participants. I had to persistently engage and negotiate with gatekeepers and organizations that were understandably protective of former detainees. This limited access ultimately forced me to reconsider my research questions and seek other types of evidence to be used for my study. It particularly changed the direction of my thesis from the lived experience of detainees in detention review hearings to access to justice in these quasi-judicial proceedings as recalled by former detainees and their lawyers. Although it has been a difficult journey, I speak of these experiences to explain and contextualize the methodological choices made throughout this thesis, as well as to share lessons learned as a novice researcher. More importantly, I discuss these stories, as they are reminders of 
noncitizens' experiences in the Canadian immigration detention system. They demonstrate that control by the sovereign state persists even when immigration detainees are in the community with most of them choosing to live in the shadows out of fear. Those released would rather remain silent about their experiences, abiding by imposed conditions until they are deported out of the nation state. This is unfortunately nothing new considering what they have already gone through. Taken away from our communities, noncitizens are confined in securitized immigration holding centres and provincial prisons. They are rendered invisible and hidden behind institutional walls (see Chak, 2014). Beyond their physical disappearance and as the next two chapters will demonstrate, they are further invisiblized by their limited access to justice in detention review hearings, which represent the principal legal avenue through which they can fight for release. These experiences on seeking immigration detainees encourage me to reiterate the importance of continuously questioning the very system leading to their erasure. 


\section{CHAPTER 4. ACCESS TO JUSTICE AND LEGAL REPRESENTATION}

Legal representation in detention review hearings is a significant means by which immigration detainees can access justice and seek release from their administrative confinement. Lawyers possess the legal expertise and speak the professional discourse required to navigate the immigration detention system. Their assistance can have a positive impact on detained noncitizens, who "are largely strangers to our language, our culture, and our laws - certainly the complicated maze of immigration laws" (Katzmann, 2008: 8). In Canadian legislation, the right to legal counsel is guaranteed under s. 167(1) of the IRPA which states: "Both a person who is the subject of Board proceedings and the Minister may, at their own expense, be represented by a barrister or solicitor or other counsel." As this chapter demonstrates however, immigration detainees face various intersecting and compounding barriers in securing legal representation, including the difficulty of seeking counsel while detained, the financial cost of representation, and language issues. It is also important to highlight that even when represented, they have limited access to procedural justice because of their transfer to remote provincial prisons burdened by lockdowns and the tight timelines of detention review hearings. Finally, this chapter concludes with a discussion on the similarities and differences between the immigration detention system and the criminal justice system, particularly referencing the precarious status of invisiblized populations and their place in a highly securitized political context wary of racialized others. 


\section{$\underline{4.1 \text { Vanishing in the Immigration Detention System }}$}

Noncitizens can be detained on entry and at any point while in the Canadian state according to s. 54 to 61 of the IRPA. When considering the heterogeneous group of immigration detainees, this can be extremely alarming to asylum seekers, who are seeking refuge from persecution in their home countries and now find themselves in administrative confinement. This may also come as a surprise to permanent residents, who can lose their status and be found inadmissible after being convicted of certain criminal wrongdoings. Deepan from Ottawa, for example, is currently stateless as the federal government refuses to acknowledge his citizenship despite being born on Canadian soil and possessing an Ontario birth certificate. His identity issues emerged when a prison guard from the Ottawa-Carleton Detention Centre (OCDC), where he was incarcerated, questioned his citizenship status and brought him to the attention of CBSA. He argues this was a case of racial profiling as "[o]ne can only speculate what combination of his brown skin, dark beard and 'foreign' name became significant actants in casting suspicion on Deepan Budlakoti's 'genuine' status as a Canadian citizen" (Stasiulis, 2017: 12). Deepan was found inadmissible as a permanent resident upon being criminally convicted and was placed on immigration hold in Toronto's West Detention Centre after serving his sentence. Remembering the beginning of his immigration case, he shared:

"While I was in Innes Road, they said to me that I'm not a citizen... They gave me a removal order, a piece of paper that said I'm facing removal... I was shocked. I was born and raised in Canada my entire life. I have an Ontario birth certificate, a Canadian passport but yet, they're trying to tell me that I'm not considered a citizen because this one guard went out of his way to contact CBSA [Canada Border Services Agency]. The CBSA - they verified if I'm not a citizen or not. And then they found a technicality 
where...I'm not a citizen. I was betrayed. They're screwing away my identity essentially." (Deepan, 2017, March 8)

Deepan's detention for immigration matters came as a complete surprise to him, believing he was a Canadian citizen throughout his life. He was rendered stateless by the Canadian state, which continues to pursue his removal. During his interview, Deepan also pointed to other vulnerable populations in immigration detention, recalling conversations with noncitizens, who did not even know why they were in detention:

"Sometimes they [detainees] don't understand whatsoever why they're there at all... They say: Oh I just came off a plane and they held me here. My wife and kids are somewhere else and I'm here. I don't know why I'm here. I did nothing wrong. I have no criminal record. Why am I in this facility? All kinds of different things. I don't know what's happening. I can't get a hold of Amnesty. I can't get a hold of my consulate." (Deepan, 2017, March 8)

As this demonstrates, some noncitizens are immediately apprehended at the border and placed in detention without being told of the reasons behind their deprivation of liberty. They seem to be provided with little information on where they have been brought, as well as where their separated family members might be. They very likely do not know who to call and how to reach them. One can only imagine how frightening it would be to be detained in a foreign land whose language you may not speak, and to be held in its carceral spaces without knowing why and lacking anybody to call for help.

Participating lawyers shared that even when clients know the grounds upon which their detention is justified, they do not understand why it is necessary. This is particularly prevalent among noncitizens, who are detained absent a criminal record. Dora is a practicing lawyer from Toronto and has written extensively about immigration issues. She describes her clients' understanding of detention, saying: 
"I think most of the time they do [understand]. I think with the ones, the refugees that are at the end of the line and get detained, they don't understand why they have to be detained. They know they're being detained 'cause the border guards wanna remove them... They understand that but they don't really understand why it's necessary because they've not breached any rules. They've always showed up so there's a difference between not understanding why and not understanding the reason, why it's considered to be necessary." (Dora, 2017, January 26)

Sid gave a similar response as Dora. Working as a legal counsel in Toronto, most of his clients are held in provincial prisons. When asked if they ever questioned being detained, he clarified: "There's a difference between understanding and accepting... Well they think the system [is] unfair. They understand that they're being held and they think it's unlawful. We've had a number of hunger strikes at Lindsay by people in immigration holds. Yeah, they know the reason why. They don't agree with the reason." (Sid, 2017, February 16). This exact sentiment was expressed by Felix, who is a former immigration detainee whose application for asylum was denied by the RPD. While awaiting judicial review from the Federal Court, he was detained in Maplehurst Correctional Complex in Milton for failing to notify CBSA of his change in address. He recalled being apprehended during a visit to an immigration office, sharing he was completely surprised by the sudden arrest because he reported his new address through his lawyer. Although Felix knew he was being detained for reporting issues, he argues the process was unfair:

"It was difficult for me. I came here to find the visa, to be free of people...to be free of people looking to put me in a bad situation. When I came here, it feels like I have a country where I can feel comfortable... [But] they don't give people... They don't understand people... They don't give people a chance to understand why this happened... Directly, they decide something then [say] no. For me, I made a mistake but it does not mean you have to deport me. You know exactly what my situation is back home. It's not fair. I have [a] problem in my country, [but] you decide to send me back because of [a] mistake with my address." (Felix, 2017, January 22) 
As Felix's story demonstrates, it is easy to get lost in the Canadian immigration detention system as it operates upon a complex set of laws and policies. Navigating through it and protecting one's rights can be very challenging. With noncitizens' liberty at stake, it is in these situations that legal representation can be of significant value.

Along with understanding the reasons for detention, there are several legal avenues through which immigration detainees can seek release from their administrative confinement; however, it largely requires knowledge of Canadian immigration laws and procedures to successfully go through them. Being subject to these proceedings can be particularly difficult for noncitizens, who may not speak either of the official languages (i.e., English or French), lack familiarity with legal discourse and procedures, and may not have family members or friends, who could provide emotional support and guidance. Detention review hearings, for example, represent the principal means by which detained noncitizens can convince ID board members that grounds for detention no longer exist; this would allow them to remain in the community pending removal. These proceedings are often confused with admissibility hearings in which presiding adjudicators decide on whether noncitizens are permitted to stay in Canada or should be deported out of the nation state. Faye, who primarily practices refugee law in Toronto, describes this common mistake among clients:

"[T]hey [clients] also often think that the detention review hearing will decide whether they're allowed to stay or not. So they'll want to present their case at the detention review hearings why [they] should be allowed to stay in Canada. I just have to keep insisting over and over again that the only purpose of the detention review hearing is to decide if they can remain in Canada while their immigration matters proceed... And then [I] also highlight the other proceedings that are going on. So if they do have simultaneous application to remain, that... will be decided elsewhere, that Immigration's already starting deportation. That sorta thing. Some clients will then understand. Some still sort of remain fixated on the fact that the 
judge they are appearing for sort of has the power to decide everything related to their immigration matters in Canada." (Faye, 2017, February 3)

Well-versed in the language used in this context, lawyers are able to guide immigration detainees through proceedings, as well as clear up misunderstandings by educating them about the system and their cases. The importance of legal representation is clearly summarized by Clive, who has over 30 years of experience as an Ottawa lawyer practicing immigration law. He specifically comments on legal jargon in connection to clients' broader understanding:

"Yes, there is considerable confusion. They usually - that is to say the detainee as well as their supports which include friends and relatives - they know what the allegation is because they're given that orally when they're arrested. So they know what the CBSA allegation is against them. They have a very confused understanding of the rest of it. That is to say, what their rights are, what it'll take to gain their freedom back... what other implications is it gonna have on their status in Canada, whether they're gonna be deported, whether they're gonna be taken right away to the airport in the handcuffs that were used to arrest them and take them to the jail, how long this will take, what will be terms and conditions. Yeah, all of that only comes clear to them in the hours and days and weeks following the first arrest. And it's very slow and very incremental. The terms used by the CBSA are not terms that detainees understand even though the CBSA uses interpreters, there is a jargon to this industry that is quite confused. I've been in it for 31 years and I myself have to sort of attenuate or use words that are lay words and constantly correct myself in the choice of words when we explain the procedure." (Clive, 2017, March 7-8)

These stories demonstrate the complicated nature of immigration laws and the detention system's various procedures, reiterating the need for legal representation. Although most of them are shared by legal counsel themselves, participating lawyers gain these experiences by working directly with detained noncitizens. On their part, Felix and Deepan's experiences as former immigration detainees further reaffirm the value of being represented by legal experts. Deepan spoke directly to this point, sharing: 
"I think it's very important to have a lawyer for immigration issues 'cause immigration issues are very technical... Over the years, I have become very familiar with the laws around immigration, particularly fighting on different grounds in my case. And looking back, I'm looking like: Wow... If people don't have legal aid lawyer or have a lawyer in general... [They] need to have a good, decent lawyer that actually knows what he's doing or she/he is doing, immigration will take advantage of you essentially, makes you sign papers, telling you lies just to fast track your deportation." (Deepan, 2017, March 8)

Although there is a lack of Canadian statistics on the extent to which legal representation is associated with release from administrative confinement, these qualitative interviews with former immigration detainees and lawyers demonstrate the many ways in which the latter can assist noncitizens in navigating the Canadian immigration detention system, which in many ways, is very foreign to them.

\subsection{The Role of Legal Representation}

Despite its importance, retaining a lawyer can be very challenging because of the lack of available information, the financial cost of this service, and language barriers. Prior to discussing these issues, it is important to note that immigration detainees are not always made aware of their right to legal counsel. At the point of arrest, the Canadian Charter of Rights and Freedoms obligates CBSA immigration officers to tell individuals the grounds upon which they are being arrested, their right to counsel, and their right to inform their home country's government of their arrest (CBSA, 2017). As examined in the previous section, they sometimes fail to provide detainees with the reasons for their arrest and detention, which seems to occur with their right to legal counsel as well. Although the reading of these rights is entrenched in the Charter, interviews with legal 
counsel suggest immigration officers' practices are inconsistent. Dora, for example, is unconvinced that detainees are given information on their rights, suggesting:

"They're supposed to be told that they have a right to a lawyer. I don't think that happens. CBSA's always saying, yes they comply with that but any of the transcripts that I've seen, it's never in the transcript of an interview or anything like that. And they always say: Oh we advise them of their right to a lawyer off the transcript. Well you know at some point, you just stop believing that because the client said they were never told they had a right to counsel." (Dora, 2017, January 26)

It is also equally important to ensure that noncitizens understand these rights, which means confronting potential language barriers; however, it is unclear if interpretation services are provided beyond the quasi-judicial proceedings of the IRB, which is clarified in the Guide to Proceedings Before the Immigration Division (IRB, 2005). Their capacity to exercise their right to legal representation highly depends upon being informed of this right in a language they understand, highlighting the need for interpretation services. This requires greater attention as failure to inform noncitizens can lead to severe negative consequences with the most notable example of indefinite detention. Relatedly, participating counsel also shared that immigration detainees' understanding of their right to counsel may depend on previous encounters with the legal system. Those convicted of criminal wrongdoings are more likely to be knowledgeable of their rights after being involved in the criminal justice system. They may have worked with a private criminal lawyer or received legal advice from duty counsel, who is also obligated to let noncitizens know that a guilty plea may affect their immigration status. This similarly applies to asylum seekers, who are seeking judicial review at the Federal Court after their applications were denied by the RPD. Felix, for example, already secured legal 
representation by the time he was detained by CBSA immigration officers and knew to reach out to his lawyer.

Seeking a lawyer while detained can be extremely difficult. Discussions with legal counsel suggest there is no standard practice across institutions to provide a list of immigration or refugee lawyers to detainees. Deepan, who was first held on criminal charges, claimed he was only given a list of lawyers after many days of asking prison guards. He said that the list did not specify if lawyers practiced "criminal or civil or anything like this... [Receiving the list] was after like multiple requests. I think it was like 7-8 day request just to get that list." (Deepan, 2017, March 8). At the time of their interview, some participants shared they have been working towards publishing a list of immigration lawyers to be circulated in one of the Ontario provincial jails, but it remains to be seen whether this will be regularly provided to new detainees.

Also, even when detained noncitizens obtain a lawyer's contact information, immediate access is unlikely because of various institutional barriers. They are oftentimes held in prisons fraught with security issues and lockdowns, limiting their access to telephones and communication with the outside world more generally (Pilieci, 2017, February 24; Robin, 2017, February 15; White, 2016, March 8; Robinson, 2016, January 9) Because of these issues, the majority of respondents explain it is typically detainees' families, friends or community support members who contact them. Carmyn, a practitioner previously based in Toronto and now in Ottawa, says she receives most calls from a family member, who is in contact with the detained individual:

"Usually it's not them [detainees]. Usually it's their family member who's contacting you because they're in jail. They're in touch with their family member... Very rarely is it them who's calling you. They're not shopping around for lawyers from jail. Their family member who's gonna be 
basically the surety is the one calling around and meeting with them." (Carmyn, 2017, February 22)

This demonstrates the importance of support networks in seeking counsel and by extension, in accessing justice; however, for those without family or friends in Canada, it can unfortunately be a long time before they can access a legal representative. Interestingly, participants share that immigration detainees also learn of their right to counsel by interacting with fellow detainees. They recall receiving cold calls from firsttime clients detained in provincial prisons, suggesting their contact information was likely shared by others clients. Faye, for example, explains that she prefers not to take on a detention case unless she is prepared to represent more than one client. She describes how detainees share information with each other, which often leads to referrals:

"And once I get one client in detention, then I'll start getting a whole bunch of people referred... I prefer not to take a client in detention unless I'm willing to take several because once you take one, they'll start telling everyone: I have this lawyer. Call this lawyer... Yeah, they're just sitting there all day long without much to do. Right? So it's very easy to spread information. Also, I speak Spanish and other staff at my office speaks Spanish so especially amongst Spanish speaking clients. 'Cause if there's a language barrier, it's really difficult to deal with when you're detained. So I find that very so much is once they take on one Spanish-speaking client, they'll spread the word that like: Oh you can call this lawyer and speak to her... You don't worry about dealing with interpretation. And then very much so I'll start to get a lot of calls." (Faye, 2017, February 3)

In communicating with other detainees, they learn about their right to counsel and how to reach out to lawyers with Faye's particular experience also highlighting the issue of language barriers. She received calls from Spanish-speaking clients with whom she would be able to speak comfortably and represent in detention reviews. Other participants similarly emphasized the challenge of working with clients, who do not speak English or French, which required the use of interpretation services in proceedings and during case 
preparation with clients. They also sought the assistance of family members for other translation, which could again be difficult when support networks are not available.

\section{$\underline{4.3}$ Detainees' Costly Right to Legal Counsel}

Although immigration detainees have the right to counsel, they are required to carry the financial burden of paying for legal services with s. 167(1) of the IRPA specifying that representation is "at their own expense." Exercising this right, therefore, largely depends on their capacity to afford legal representation, which can cost several hundred dollars per hour. If they meet the financial cut-off and seek counsel for detention review hearings, it is possible to request assistance from Legal Aid. In Ontario, where more than half of the 6,251-detainee population was held in 2016-2017, noncitizens can apply for a legal aid lawyer, which is largely provided by the Refugee Law Office (RLO), a specialized unit under Legal Aid Ontario (LAO). They can also apply for a legal aid certificate if retaining a private lawyer; however, it does not always guarantee legal representation as mentioned by Silverman and Molnar (2016). Interviews with counsel emphasize the difficulties of working under a certificate, which only pays for three hours of case preparation for the first hearing, one hour for a subsequent hearing, and appearance time in one detention review. Respondents argue this is not enough time to gather case information, meet clients in securitized spaces, and prepare a convincing release plan. This is one of the reasons that led Jamie, an Ottawa-based legal counsel, to decline new clients solely on a legal aid certificate.

"From my experience, no it's [three hours] not enough time. It's not even near enough time... When I was taking more detention reviews, I was a very new lawyer so everything takes more time and of course you become more efficient with more experience. Maybe it's partly my issue was just 
being new and figuring it out as I go, but I spent way more time than three hours preparing like probably I don't know ten hours as opposed to three. And I suspect that even with more experience, it would still go above the three to do a good job. And part of it is all this logistics. The amount of time you're spending just driving back and forth, waiting for access to your client. Those things take a lot of time and Legal Aid is definitely not going to compensate you for all of that. Yeah, I don't think any lawyer taking detention reviews on a legal aid certificate thinking that they're going to be... If I bill 15 hours, I'm going to get paid for 15 hours... You can't think of it that way. Even at the time, I would only take a detention review if it was a paying client or if it was an existing client on a legal aid certificate. I'm not just going to abandon them because they've been detained so those are the situations where they came up for me... I have gotten cold calls from the detention centre. Those aren't cases that I'm usually comfortable taking... As I get busier, it's a little bit unfortunate but I do have to make those kinds of decisions with my time. As you can see I work on my own here so I have to think about the administrative burden too and legal aid is far more administration than the average file so there's time spent doing that too. If I'm busy, then it's just not practical for me to take a detention review on a legal aid certificate." (Jamie, 2017, February 8)

Like Jamie, most participants expressed similar concerns about the feasibility of assisting clients on legal aid certificates. They posit that three hours is a very limited amount of time for case preparation, which does not only cover organizing submissions and arguments, but also traveling to meet clients in far-flung detention centres. Some respondents were particularly worried about representing long-term detainees, who may have multiple detention review hearings. They are undoubtedly forced to work beyond three hours and often have to take these cases pro bono. As for immigration detainees, the financial cost of legal representation and the limitations of legal aid certificates can make it difficult to find a lawyer, who is willing to assist them within these restrictions.

As argued in the first half of this chapter, legal representation can facilitate some access to justice in the immigration detention system. Detained noncitizens may not be informed of the reasons for their confinement, and often lack the necessary knowledge of complicated legal discourse and procedures to self-represent. Although they have the 
right to legal counsel, exercising it depends on being notified of this right in a language they understand. This thesis finds, however, that CBSA officers' practice of reading detainees' rights is inconsistent. Still, even when immigration detainees are notified of these rights, there continues to be challenges in seeking legal representation, particularly as they are detained in securitized spaces where there is a lack of information provided to them. They also have to overcome language barriers and financial burdens, which fail to be entirely mitigated by interpretation services that are restricted to detention review hearings and legal aid assistance that is limited to only a few hours of case preparation. The following half of this chapter demonstrates that despite securing legal counsel, the challenges to accessing justice in the immigration context persists. It shows how lawyers have limited access to clients in far-flung carceral spaces, which affects their capacity to prepare for the fast-approaching 48-hour detention review hearing. All of these issues compound and intersect to the detriment of immigration detainees.

\subsection{Carceral Spaces: From IHCs to Provincial Prisons}

Across Canada, there are three IHCs specifically designated for immigration detainees. These medium-security institutions are located in Toronto (195 beds), Laval (109 beds), and Vancouver (24 beds). In regions without these facilities or to address

overcrowding issues, the federal government rents out provincial prisons to sustain its administrative confinement of noncitizens. Immigration detainees, who are found inadmissible after being convicted of certain criminal wrongdoings, are also typically held in these contracted institutions, along with persons who display disruptive behaviour or have mental health issues. Gros and van Groll (2015) refer to this institutional transfer 
as a "legal black hole" because there is no indication as to which government agency is accountable to those who are relocated (p. 45). In 2016-2017, the border agency reported that 2,647 individuals or $38.5 \%$ of the total detainee population were held in non-CBSA facilities (CBSA, 2018a). Scholars have been highly critical of the use of these carceral spaces, which are associated with the deterioration of immigration detainees' physical and mental well-being (Gros \& van Groll, 2015). They also bring attention to the ways in which prison staff subject noncitizens to the same treatment and maximum-security conditions as the general population, which imposes dual punishment upon those who are transferred to immigration hold after serving their criminal sentence (Cleveland, 2015). Silverman and Molnar (2016) importantly highlight how imprisonment in holding centres and provincial prisons diminish access to justice as exemplified by detainees' difficulties with retaining legal counsel and obtaining relevant evidence on their cases. Consistent with these findings, this section will further elaborate upon how spaces of detention, particularly provincial prisons borrowed from the criminal justice system, consistently (re)produce barriers to legal representation by severely limiting lawyers' access to detained clients.

To adequately prepare for detention review hearings, it is imperative for lawyers to meet their clients and gather case information. The administrative confinement of detainees in provincial prisons, however, largely delays this process as it can take up to several weeks to schedule professional visits. Participants expressed frustration regarding the resulting limited access, more specifically lawyers from Ottawa where immigration detainees do not benefit from a separate holding centre and are automatically held in the provincial prison of OCDC. Clive insists that delays in meeting clients have been a 
persistent problem in the capital city. He argues that bureaucratic hurdles arising in dealing with the jail compound the pressure of tight timelines of detention reviews. He recounts the difficulties of limited access to clients held in OCDC, explaining:

"That has been a nagging challenge for us here in Ottawa because as I said, the hearing comes on in 48 hours. We're not often retained until the day before the hearing and getting to the jail - first of all, you've got to make an appointment. There's a whole bureaucracy and red tape and protocol to do so at the jail so that access to counsel and access to our client is extremely difficult..." (Clive, 2017, March 7-8)

Participants share their experiences of needing to navigate rules of the provincial prison in order to schedule appointments with clients. Without these meetings however, they may not be able to obtain key information that could convince board members to order release, compromising case preparation altogether. In her practice, Carmyn responds to these rules by using her negotiation skills, suggesting that friendlier interactions with prison staff often helps when trying to access clients. She states:

"Here, you've gotta call and you arrange the time. They only have so many rooms and you gotta like cajole and like try to find a way to go and meet the person. And I've been told - it depends - but I have been told in the past you gotta wait however many weeks. Weeks! Weeks is insane to me... The timelines are just nuts. And then you gotta call back. I don't have time to be cajoling." (Carmyn, 2017, February 2)

Considering the tight timelines of detention reviews, it is important for legal counsel to meet clients as soon as possible, but this process is severely impeded by OCDC's limited capacity and bureaucratic structure. Lawyers are required to be creative and negotiate access through interactions with gatekeepers of the securitised provincial prison in order to obtain case information and adequately represent clients in hearings.

Some participants from Ottawa further suggest their limited access to clients is likely caused by OCDC serving two different detainee populations. They recognize that 
the provincial jail is originally an institution for the criminal population, which means it primarily deals with professional visits from criminal defence lawyers. With immigration detainees simultaneously held in the jail, it is difficult for prison staff to accommodate all meeting requests without running into delays. When asked how long it takes to see clients after being retained, Eleanor responds, "That varies. It depends how busy they are, you know? 'Cause it's criminal counsel. It's like a general detention centre. Everyone's seeing their lawyers - criminal, immigration. It can take a while sometimes." (Eleanor, 2017, February 2). Faced with this institutional barrier, she also explains her strategy of attending OCDC during regular visiting hours, which grants her immediate access. She describes the jail has an area "where you can actually talk to your client through the glass and they'll [prison staff] let you - they'll come and pass documents back and forth. So if you really need to see your client, you get to see them behind the glass in the little room there." Eleanor opts for this alternative instead of remaining on the waiting list for professional visits. Much like Carmyn, she adapts to the current structure by using a different tactic to ensure meeting her clients in the overburdened and overcrowded provincial jail.

Perhaps more obviously, these access issues emerge due to the lack of an immigration holding centre in the capital city, which would likely give legal counsel greater access to detained clients. Petra, an immigration lawyer in Ottawa, deliberates the extent to which having a separate facility for noncitizens would lead to better accommodation of professional visits. Speculating if this could be the solution, she states, "I would expect that if there was, we would be able to see the clients more readily rather than in this manner where they're together." (Petra, 2017, February 14). The experience 
of Toronto lawyers, Faye and George, provide some support for Petra's theory. They claim that, although the TIHC is somewhat geographically inaccessible, provincial prisons are much farther away. Faye relays that traveling to the holding centre is very time-consuming due to its location on the outskirts of the Toronto Pearson International Airport, relatively far away from downtown Toronto; however, it still preferable over Ontario jails, such as the CECC in Lindsay or Maplehurst Correctional Complex in Milton, which are a few hours outside of Toronto. She relays her experience in dealing with both types of institutions:

"Inaccessible as it [TIHC] is, it's still more accessible than say Lindsay or Maplehurst, or even Toronto West... It's not necessarily farther, the Toronto West Detention Centre, the jail but it's more difficult to access if you're taking the TTC and so then you have to end up having to deal with a car and everything, and I don't have a car. I can access cars but it's just - it adds an extra layer of complication." (Faye, 2017, February 3)

Although the Toronto case gives evidence as to how a holding centre might provide greater access to clients, it is imperative to remain cautious about the suggestion of constructing such an institution in Ottawa because it does not necessarily mean all immigration detainees will be transferred to the new CBSA facility. This is exactly demonstrated by the Toronto example where provincial prisons continue to be contracted. As Pratt (2005) also observed, these holding centres ensure a "distinctly carceral experience" and often mirror institutions of the criminal justice system whose reach will only extend if more spaces of detention are created (p. 28).

As previously mentioned, despite the operation of a holding centre in the region, all Toronto participants largely represent detainees held in Ontario jails with the exception of Faye and George, who have also had clients in the TIHC. Even in the Toronto area, there is continuous reliance on provincial prisons for the confinement of 
noncitizens, which perpetuates similar access issues prevalent in Ottawa. These problems are even experienced on a grander scale in Toronto where there are numerous jails used for immigration detainees. For example, legal counsel have represented clients comingled with the criminal population in the Toronto South Detention Centre in Etobicoke, Toronto East Detention Centre in Scarborough, Niagara Detention Centre in Thorold, and Vanier Institute for Women and Maplehurst Correctional Complex in Milton. Detainees were also previously held in the former Old Don Jail and Toronto West Detention Centre. The CECC in Lindsay is an exception to these provincial prisons as it has a separate wing for noncitizens on immigration hold. This means that detainees, who were found criminally inadmissible, may remain in the same institution, but are transferred to a different area. Individuals, who fall in this category, have already served their sentence after being convicted of certain criminal wrongdoings, but their deprivation of liberty persists for immigration purposes (see Chan, 2005). Unlike participants from Ottawa, Toronto lawyers must negotiate access to clients in all of these institutions, which have their own operational policies, informal procedures, and staff members. It is, therefore, necessary for them to adapt their strategies to each provincial prison, as the tactic of using friendly interactions with prison staff might work for one but not the other. While this may be time-consuming, it might be the only way they can meet their clients without weeks of delay.

\subsubsection{Locating Detainees in Securitized Provincial Prisons}

Toronto lawyers are further challenged by the physical location of provincial jails, which adds another layer of barrier in the legal representation of immigration detainees. 
With these jails existing outside of the city centre, lawyers are required to travel for several hours and often need access to a vehicle due to limited public transportation. Sid elaborates on this issue in his discussion of detainees held in the far-flung detention centre of CECC. He describes the way in which the jail's location compromises noncitizens' ability to access justice, claiming: "The majority of immigration detainees are being held at Lindsay which is a two-and-a-half hour, two-hour drive... And due to the distance, we have an access to justice issue where it's very difficult for counsel to go up there and specifically meet the detainees." (Sid, 2017, February 16). He further notes how access issues are often exacerbated by frequent lockdowns in provincial prisons, which restrict prisoners to their cells for security and administrative reasons, such as protection against riot and management of staff shortage (Pilieci, 2017, February 24; Robin, 2017, February 15; White, 2016, March 8; Robinson, 2016, January 9). These have grave consequences for legal counsel and their clients alike as they result in the cancellation of visiting hours, access to telephones, and even scheduled detention reviews. Rohan, a practicing counsel based in Toronto, and other participants share instances when they would drive to a remote jail, like Lindsay's CECC, only to discover that a lockdown was in effect and they would not be able to see their client:

Rohan: "So particularly in terms of seeing clients in person in Lindsay, it's a bit of a challenge. Lindsay is about two-and-a-half - two, two-and-a-half hours drive from Toronto - maybe two. I'm trying to think right now but I think it's around maybe an-hour-and-a-half or two hours... There are certain set times in which counsel can visit detainees. What was frustrating was that even if you plan to arrive during the set times that you're allowed to visit the detainee, there could be lockdowns or other reasons why you can't access your detainee, your client. It would be really frustrating. I'd drive an-hour-and-a-half, two hours to get there only to learn once I got there that I wasn't able to see my client and so then you're kind of faced with the choice of waiting in Lindsay and hoping that there is some time that opens up during the day in which you can see the person or driving 
back and essentially wasting three and half, maybe four hours of your day just in travel time." (Rohan, 2017, March 16)

Sid: "There's an issue in terms of lockdowns. There's a lot of staff shortages at these facilities... There's some times I drive all the way to Lindsay and all of a sudden, there's a lockdown. It's been a waste of four hours and most of these people are funded on legal aid so there's not much opportunity to visit them if at all. Most lawyers aren't gonna spend a full day to travel to Lindsay. So the access to justice." (Sid, 2017, February 16)

George: "Yeah, I mean I can go all the way out there. I can get out to Peterborough on the bus around 8 in the morning and call the jail 'cause they don't know until 8:30 if there's gonna be a lockdown. Find out there's a lockdown, basically there's half the day gone. And for my client, it might be another I don't know two, three weeks before I can get there to see them and getting documents from them... That's terrible." (George, 2017, February 8)

The compounded issues of provincial prisons' inconvenient locations and institutional lockdowns have the deleterious effect of exhausting lawyers' resources and efforts. These challenges severely affect their ability to represent clients in detention reviews. If they cannot gather information in a timely manner or instruct clients on the next steps, it reduces their ability to abide by the procedural timelines of statutory hearings. For immigration detainees, the emergence of these barriers exemplifies the many ways in which they are excluded from justice as limited case preparation could easily prolong their deprivation of liberty.

Limited access to clients through visitation has alternatively led lawyers to use telephone communication, which is in itself already a limited resource in jails. That is, detained populations only have access to a limited number of telephones in each range. They are required to share these resources and may need to negotiate with others, or be unable to access phones if they are controlled by stronger prisoners. Phones on ranges are sometimes broken. Prisoners may be unable to call from inside the institution to cell 
phones. They are also only allowed to call collect to a landline for 20 minutes at a time, which may be insufficient if relaying case information. In addition to these institutional rules, detainees are denied access to the telephone system when a lockdown is in effect during which they are forced back into their cells and cut off from communication with the outside world. This includes contact with family and friends for support, and interactions with legal counsel, who are already challenged by provincial prisons' remote locations. Participants share that it would sometimes take several days before detainees are able to get in touch with them due to barred access to telephones. Eleanor recounts a typical conversation with clients held in OCDC, who would be denied all means of communication during lockdowns:

“"Cause you're kinda waiting for them to call you 'cause you can't call them to do things. Right? You say: Okay. Call me tomorrow. When can you call? [Immigration detainee]: Okay. Probably I can call around two. And then they won't call and then they'll call the next day saying: Oh yeah, we were on lockdown. I couldn't make a phone call. So that can be tricky." (Eleanor, 2017, February 2)

Forbidding access to the telephone system because of lockdowns demonstrates another example of how detainees "become 'lost' in the 'black box' of the system" (Silverman \& Molnar, 2016: 121; Markowitz, 2009). They are physically restricted to their cells and prohibited from contacting their support networks that are trying to arrange their release. It also becomes much more problematic in cases where detainees are transferred to another institution without being able to notify their representatives. Participants' experiences suggest that CBSA officers often fail to inform them of these transfers despite having jurisdiction over immigration detainees. This lack of communication, for example, has resulted in George missing a client's hearing. He shared, "I had a client in Maplehurst that I went for a hearing and they transferred [him] the night before. Nobody 
had told me so I wasn't there for his hearing." (George, 2017, February 8). Without access to telephones and with CBSA's deficient accountability, lawyers are then left to search for their clients, seeking them in other institutions while negotiating with policing agencies and prison staff (Silverman \& Molnar, 2016).

As a prominent advocate for prisoners' rights in the legal community, Dora suggests the issue of lockdowns and its other consequences are more particularly a testament to the unrelenting cruelty of the justice system. Lockdowns may be used to address understaffing, but their effect of limiting access to clients through the cancellation of visiting hours, and telephone communication is indicative of the latent function of immigration detention. It is here that Dora connects limited access to justice to the harms and punishment imposed by detention. She elaborates:

"Well if you're on a lockdown, you can't call people. They say lawyers can come in but they can't. I know they can't 'cause I didn't get in. There's all sorts of problems when they're on a lockdown. They're 24/7 in a cell with another person that they may not even get along with. It's very inhumane, but again, that's been going on for years - 20, 30, 40 - who knows how many years it's been going on. It's exacerbated by the fact that they've done these super jail centres now like Maplehurst. And so when they have the lockdowns, it's a way of managing staff. That's what it is. It's not an emergency. There's no reason for it. They're just understaffed and so they have lockdowns and they hurt the inmates. But again, that was going on for a long time. Nobody ever talked about it. It's like it was normal. And so when people go into those facilities, and it's the normal, they don't talk about it... The lockdowns - they're worried about staffing shortages. They're not worried about how the impact is... One guy told his sister, another guy told his daughter that they'd call and then they couldn't because of the lockdown then the little kid gets upset because there's no phone call. They're not thinking of the impact on the person or their family or their kids or anything like that. They're only thinking of the institutional concerns and that's the indifference that leads to cruelty." (Dora, 2017, January 26) 
Frequent lockdowns have resulted in exacerbating the pains of imprisonment suffered by immigration detainees and criminal populations alike. Ontario jails have been particularly notorious for subjecting all prisoners, including immigration detainees, to harsh living conditions and frequent lockdowns (Pilieci, 2017, February 24; Robin, 2017, February 15; White, 2016, March 8; Robinson, 2016, January 9). In addition to barred access to telephones and visitors during lockdowns, detained persons are restricted in overcrowded cells for extended periods of time without access to showers, yard time, and programs. Across the province, these inhumane conditions have prompted several lawsuits against the Ontario government. Prisoners from Ottawa's OCDC and London's Elgin Middlesex Detention Centre, for example, have launched separate class-action lawsuits in 2016 (Fedio, 2016, May 26; Syed, 2017, November 18).

\subsubsection{Negotiating Institutional Barriers}

In response to access issues caused by institutional conditions, legal counsel adopt different strategies to secure meetings with immigration detainees. As previously mentioned, some negotiate with gatekeepers of provincial prisons by establishing friendly rapports with prison staff, whereas others use regular visiting hours instead of remaining on the waiting list for professional visits. At times, participants also collaborate with detainees' family members and friends, who may have information about the case. Clive, for example, resorts to these alternatives in recognition of his limited access to clients held in OCDC. He explains that by involving support networks, it enhances his ability to represent clients in detention reviews:

"I mean look, my office is downtown. The jail is far away. You've got access issues. You've got interpretation and cultural issues going on there. 
Just getting to the jail, showing the detainee the document, the allegation is extremely challenging so we do what we can and that is share it with relatives and friends and colleagues and others who are inside the history of all this, who can help us sort through it." (Clive, 2017, March 7-8)

This highlights the importance of support networks in assisting immigration detainees throughout IRB quasi-judicial proceedings. Family members and friends typically seek out legal counsel for their loved one in detention as discussed earlier, but, as Clive points out, they also continue to be a significant resource for lawyers in case preparation by assuming a liaison role. He also asked family members or friends to relay case procedures to clients during their visits. He suggests this strategy further provides a level of comfort to clients as information is coming from a trusted family member or friend. Regarding this alternative strategy, Clive shares:

"You try in fact to get that trusted friend or relative to go to the jail the day before the hearing so that they get in and have a public meeting with their relative or friend to explain to them things that I don't have the time or cannot do. It's better they hear it from their friend or relative. [Family or friend]: Okay. There's a lawyer I've hired. [Immigration detainee]: Okay. What's his name? Why did you pick this lawyer? What's the lawyer gonna do? What does my case look like? And you let the relative in their language, using their cultural norms and trust go do that... The meaning is not as well conveyed or understood if it's left to me to try to explain that. I'd rather not be the one to do it. It's better off being handled by the relative that [has] come to my office." (Clive, 2017, March 7-8)

Clive favoured this method as opposed to simply accepting his limited access to clients due to institutional barriers. This more importantly exemplifies how legal counsel must continuously find ways to manage the challenges of representing immigration detainees in provincial prisons. Admittedly, incorporating family members and friends in case preparation is not always possible with some immigration detainees lacking support networks altogether. Their experience of administrative confinement would very likely differ from those who have connections to the outside world supporting them. 
In cases where it has so far been impossible to communicate with clients, legal representatives are sometimes able to spend a few minutes with them right before the first hearing; however, this entirely depends on the institution where detainees are held. Based on the interviews, it seems that OCDC has been most accommodating to these requests as five out six participants from Ottawa shared experiences of being granted time with clients prior to the hearing. As the following excerpts will suggest, although these meetings may only last for five to ten minutes, they nonetheless present a valuable opportunity for legal counsel to explain case details and hearing procedures:

Katherine: "If I'm meeting them for the first time, I always ask the board member: Well, could I have five minutes? Now usually when I come into the detention facility, they will put me in a room with my client before the hearing but they don't always. It just depends on if they're ready to proceed or not like if the jail is ready. They'll say: Oh we're early. You want five minutes with your client? I'll be like: Okay, great thanks. And in those five minutes, that's exactly what I'll do is...I'll introduce myself and be like: $I$ got this bondsperson. Everything's done..." (Katherine, 2017, January 24)

Petra: "Typically, if we manage to prepare, it would be if we can get cooperation from the detention centre to allow us to kind of see the detainee before the detention review. Sometimes, they're able to let us speak to them 15 minutes beforehand "cause normally, you have to make an appointment for an hour..." (Petra, 2017, February 14)

My ethnographic observations of detention review hearings in the Ottawa jail also served to provide evidence of this routine. After undergoing a security screening, the lawyer is given a visitor pass and escorted through double-gated doors into the hallways of the prison. They ask the prison guard if they can have time with their client prior to the hearing, which was granted in four out of five hearings observed in OCDC. These quick meetings were approximately five to eight minutes in length, and were typically held in a separate room away from videoconference cameras and the CBSA hearings officer. These interactions were extremely important as exemplified in one case in which the 
legal counsel was meeting their client for the first time. They also seemingly provide a sense of relief to immigration detainees, who are able to obtain information and instructions prior to the hearing, and more importantly, express their needs and feelings to their legal representative. Although lawyer-client meetings are typically needed for case preparation, this suggests legal counsel may also serve as a source of support to clients, which unfortunately gets denied when access to detainees are severely limited by institutional barriers.

\subsection{Tight Procedural Timelines: Immediacy of the 48-Hour Hearing}

Although the Canadian government has yet to implement a presumptive period for the confinement of noncitizens, it escapes criticism of practicing indefinite detention by referring to statutory detention review hearings where detainees may present their case for temporary release. Akin to bail hearings of the criminal justice system, these proceedings are held within the first 48 hours of detention, repeated within the next seven days, and continued every 30 days thereafter. They are presided over by ID board members from the independent quasi-judicial body of the IRB. Undoubtedly, these detention review hearings represent an important legal avenue for immigration detainees, who are deprived of their liberty and administratively confined in IHCs and provincial prisons. As this section discusses however, its tight procedural timelines, and the ways in which this interacts with other aspects of the detention system, have produced barriers to legal representation detrimental to immigration detainees. These issues particularly emerge because of the fast-approaching 48-hour detention review, which leaves very little time for lawyers to visit clients, process legal aid applications, and adequately 
prepare release plans. Although this limited time for case preparation is acknowledged by the IRB, there is little accommodation to mitigate its consequences (IRB, 2003: 2-4).

With their liberty at stake, it is imperative for immigration detainees to have access to a detention review process, particularly to the hearing within 48 hours, which can lead to their immediate release. This first proceeding is the most important as board members are examining the case for the first time and have no previous decisions to consider. As will be discussed in the next chapter, ID decision-making has become problematic because of the decision in Thanabalasingham where the Federal Court of Appeal ruled that board members must provide "clear and compelling reasons" when departing from previous decisions (Canada (Minister of Citizenship and Immigration) $v$ Thanabalasingham, [2004] 3 FCR 572, 2004 FCA 4, para. 10). Participants argue this has been misinterpreted in a way that has prevented board members from disagreeing with colleagues and ordering release. In the 48-hour hearing however, the decision-making of a presiding member would not be affected as there is an absence of previous decisions. It is unfortunately extremely difficult for legal counsel to take advantage of this situation as they are afforded very little time for case preparation. This is one of the reasons cited by Faye while explaining what led her to reduce her caseload of immigration detainees, who needed representation in detention review hearings. She describes how taking on these cases forced her to put a pause on other responsibilities as they required immediate attention. She relays that it was particularly challenging as her practice grew and became busier, sharing:

"I find it difficult to balance with other work... So I was a sole practitioner. Now I work with other lawyers but it takes a better part of the day and I don't often have last minute. I'm almost always busy tomorrow. It's very rare that I would have most of the day available tomorrow - maybe two 
weeks from now or three weeks from now but I would already have something that I need to finish or work on tomorrow... Even when I would get private files, they would call. I'm detained. My detention review is. Let's say it's Friday. Their thing is Monday. It's difficult for me to make that much space available in my schedule on such short notice 'cause I need to have time today to find out about the case, get on record, get the facts, speak with bondspersons, speak with the client, prepare and then the day of the hearing that's taking up most of my day. And I'm not gonna eat until later. I'm not even able to sort of be accessing emails, dealing with phone calls. So I found it very disruptive and difficult to balance once I was at a certain level of busyness because of the immediacy." (Faye, 2017, February 3)

Much like Faye, other participants also shared how they felt pressured by the tight timeline of the first hearing. Jamie, for example, suggests immigration detention cases oftentimes had to take precedence over other files. She recounts they "can kinda take over your life because it's such a limited amount of time to prepare whatever your argument [is] gonna be. You have to figure out what that argument can reasonably be and then you have to make it. So I mean you do the best you can..." (Jamie, 2017, February 8). These excerpts underline the value of the first hearing, which can temporarily free noncitizens from detention; however, they also demonstrate the challenge of preparing for this initial hearing due to how quickly it approaches. This tight timeline also intersects with other parts of the detention system, resulting in compounded barriers to legal representation.

Interestingly, a few participants also pointed out that the initial proceeding likely provides the greatest chances to release clients despite its immediacy as CBSA hearings officers are similarly pressed for time and less prepared. Katherine shares how she takes full advantage of these parallel time constraints by ensuring she is more organized than her CBSA counterpart, increasing her clients' chances for release:

"[G]oing back to why the 48-hour review is really important is because first of all, the client's not been in for very long. CBSA also has - I mean they'll get as much evidence as they can on the 48-hour review so 
strategically, less is more. So that is your best chance. And 48-hour review - technically both sides are not as prepared as they could be which cuts both ways. So my plan is always to be just more prepared than CBSA could be on this file, the hearings officer. So the hearings officer will normally get all their information from the enforcement officer but 48 hours is a quick turn around and they might not have a full idea. And that also means for me as a lawyer getting on a case in less than 48 hours, I'll also have a difficult time getting to know my client." (Katherine, 2017, January 24)

Although constrained by the tight timelines of detention review hearings, Katherine recognizes that hearings officers also face similar pressure. Keeping this in mind, she strategizes to at least be better organized that the Minister's counsel. This would, however, require greater effort at her end as there are many intersecting factors to be considered. For example, clients are not easily accessible in provincial prisons as previously discussed. They may also lack family members or friends to be used as bondspersons. This is to say that lawyers need to continuously adapt to the various challenges of representing immigration detainees.

\subsubsection{Preparation of the Release Plan}

The trouble involved in the organization of a convincing release plan is one of the reasons why 48 hours is inadequate time to prepare for a detention review hearing; it is very time-consuming and highly dependent on a client's available resources. Lawyers are responsible for putting this together and presenting it to the presiding board member as an alternative to detention. It typically involves cooperation from bondsperson(s), who must be able to supervise the detainee upon release, and have the financial means to pay a deposit (cash bond) or sign a promise-to-pay that seeks to prevent future breach of conditions (performance bond). Under strict time constraints, it is often challenging for 
legal counsel to find eligible individuals with the capacity to fulfil this demanding role. It would very much depend on the detainee's support network, such as family members and friends. Rohan shares that the availability of bondspersons can sometimes determine representation at the 48-hour hearing. When asked how often he does not appear at initial hearing, he claims it varies between clients and their support network:

"It depends on the case. For example, you know different clients and support networks for clients vary. If a client, who is facing a 48-hour review has a well-established support network who respond quickly, who understand sort of what is necessary to present, and who are able to take time off work for example to show up within a short period of time then chances are decent but as you can imagine, if you lead a busy life, if you have work obligations, family obligations, it's not easy to kind of rearrange all of that on a 48 hours notice. It did sometimes occur where you weren't able to put the plan together but I couldn't tell you sort of in generality percentages or times just because it varied based on the individual client and their support network.” (Rohan, 2017, March 16)

This demonstrates how the task of finding a bondsperson poses some difficulties, particularly if detainees do not have a responsive support network. Lawyers must not only ensure they are presenting candidates, who have the means to post bail and monitor the detainee, but they must also do this within the very limited time of 48 hours. If they cannot prepare this release plan, the board member can order continued detention, meaning their client will remain in the IHC or provincial prison until the following hearing that will occur within the next seven days.

Importantly, it is simply not enough to prepare a release plan in 48 hours; legal counsel must also complete this in a well-thought-out way because a negative decision on a proposed plan is harder to overcome in the following hearing. As briefly discussed above, with the way in which case law on immigration detention has developed, board members have to meet the "clear and compelling reasons" test in order to depart from 
previous decisions. This would, therefore, affect a board member's decision-making process in the following hearing as they would have to consider their colleague's prior negative ruling and rejection of the proposed release plan. Recognizing this challenge, Clive explains why taking on a detention review case necessitates putting a pause on everything else, and focusing on the preparation of a well-organized and convincing release plan within 48 hours. He stresses the importance of receiving a positive decision in the initial hearing, sharing:

"If they're not released, there's gonna be another detention review in seven days. So whatever is said or done on the first detention review is going to preoccupy the mind and the file of both the officer and the adjudicator even though it may be a new one at the detention review, which is seven days later. So you better get it right the first time because it's very tough to change if you don't prevail on the first go at this. So prevailing on the first go really means stop, drop and roll up to 48 hours before you get into the hearing because there's very little else you can manage during this time." (Clive, 2017, March 7-8)

The challenge, therefore, is two-fold. Lawyers need to prepare a release plan within 48 hours because an absence of one would likely result in lengthier detention for their client. However, if they are able to manage under the time constraint and put together a plan, it must be detailed and complete as a negative decision is more difficult to change later on, thus further prolonging their client's deprivation of liberty. Between these scenarios, the ultimate goal is then to prevail at the first hearing with a comprehensive release plan. This requires an immense amount of effort from legal counsel, who would have to search for other alternatives to detention if their client does not have a supportive network.

Additionally, a few participants also shared their difficult decision of appearing at the 7-day hearing instead of the initial review. Although this means their client will remain in detention for a longer period of time, they emphasize the challenges of 
preparing a release plan within 48 hours and demonstrate that the extra seven days provides them some time to secure a bondsperson or contact a supervisory organization. Rohan recalls instances in which he realized it would be impossible to represent his client at the 48-hour hearing, forcing him to opt for the 7-day review:

"It's very difficult. It's very difficult. I mean sometimes you realize that you actually can't represent the detainee at the 48-hour review and you would have to appear on the 7-day review because that just isn't enough time to talk to the client, talk to the family members, get a sense of their financial situation, get a sense of their living situation so that you can properly put together a plan that is going to be accepted by the Immigration Division. So often times you're having this conversation where you're trying to counsel your client to say: Well, I understand obviously being in detention is not ideal. It's a terrible place to be, but we wanna make sure that we can put together the strongest case to actually have you released." (Rohan, 2017, March 16)

Choosing to represent at the 7-day hearing as opposed to the 48 -hour review is a difficult decision as it prolongs clients' deprivation of liberty; however, it can be much more beneficial in the long-term as it gives legal counsel additional time to prepare a structured release plan, a key component in securing release. Without a convincing plan, it is possible for ID board members to order continued detention, which is harder to argue against in later hearings. Representation at the 7-day review also address legal aid issues as counsel, who does not appear in the first hearing, can save their compensation for the subsequent review. This strategy, therefore, allows lawyers to better prepare their case within the restrictions imposed by legal aid, but it also means their clients remain in detention for another week and are unrepresented at the 48-hour review, which can be intimidating given the power imbalance between them and the CBSA hearings officer. 


\subsection{Roots in Detainees' Non-Citizenship}

Each and every challenge to legal representation discussed above does not exist in isolation; they intersect and compound upon one another to create an unjust system for immigration detainees. Lawyers must adopt different strategies to mitigate their limited access to clients in provincial prisons, but they must also do this under strict time and financial constraints. Katherine summarizes this perfectly in articulating:

"[T] he problem with practising law is that I have certain rules to respect with the Law Society but when I'm functioning within a system where time is against me, and the institution itself is against me, it makes it really difficult. It's not just the institution, the people who pay me, Legal Aid, are constraining me. So I'm constrained in so many ways." (Katherine, 2017, January 24)

The effects of these constraints, however, ultimately trickle down to immigration detainees themselves whose deprivation of liberty continues. These findings from qualitative interviews expand Silverman and Molnar's (2016) research that demonstrates how the Canadian system is designed and operated so that it denies access to justice to immigration detainees, which they define as the "ability to participate competently and confidently in the legal system of Canada, with the power to find, communicate with, and retain counsel for representation in immigration matters, and to obtain, understand, and make use of relevant information about one's case to make informed choices." (p. 111). Without such ability to meaningfully participate in quasi-judicial proceedings with guidance from legal representatives, immigration detainees continue to suffer in IHCs that deliver a "distinctly carceral experience" (Pratt, 2005: 25) or actual provincial prisons of the criminal justice system fraught with their inhumane living conditions.

Admittedly, these challenges to legal representation are not new. They also exist in the criminal justice system, particularly in bail hearings, which are most similar to 
detention reviews of the immigration context. Bail hearings are legal proceedings in which the judge or justice of the peace measures an accused's level of risk and decides on temporary release to the community while awaiting trial. They are held within 24 hours of detention or as soon as possible to prevent arbitrary deprivations of liberty; however, they can also be adjourned unlike the statutory hearings for noncitizens that must be completed within 48 hours. As reported by Deshman and Myers (2014) of the Canadian Civil Liberties Association, $70.4 \%$ of requests for adjournment were forwarded by defence lawyers and their clients (p. 28). Case preparation was cited as one of the reasons for such requests with accused persons lacking time to seek counsel for representation and prepare a release plan that most often relies on sureties (Deshman \& Myers, 2014). Considering this study's findings, many of the barriers faced by immigration and refugee lawyers may serve as explanatory factors for the high percentage of adjournment requests. Although immigration detainees are mainly held in IHCs, the great majority of legal counsel interviewed for this study shared their experiences of representing clients in jails. The parallel, therefore, is attributable to the fact that both types of legal representatives are similarly dealing with clients held in overburdened provincial prisons. Much like immigration and refugee lawyers, defence counsel must also employ strategies to access their clients, who may be detained in remote institutions struggling with understaffing and lockdowns. They are also required to prepare a release plan that necessitates collaboration with bondspersons. While these issues highlight the failings of the criminal justice system, they also exemplify the ways in which "crimmigration law," or the increasing convergence between immigration and criminal law, manifests in relation to access to justice (Stumpf, 2006: 10). 
My analysis would be amiss without stressing the critical difference between immigration detention and criminal incarceration that lies in the citizenship status of detained populations. This distinction is key as Bosniak (2005) suggests citizenship is a multi-dimensional concept that is simultaneously a legal status guaranteeing certain rights and privileges, as well as an obligation to participate in civic society, and an affective bond. In stark contrast, non-citizenship "is associated with limits in terms of voice, membership, and rights in a political community, and with social exclusion and vulnerability." (Goldring \& Landolt, 2013: 3). It is neither a simple binary, however, as scholars also contend there are in fact varying degrees of citizenship and non-citizenship. This is notable in discussions of citizenship revocation, which has transformed citizenship into "a conditional privilege that is more difficult to acquire and easier to lose." (Stasiulis, 2017: 2; Macklin, 2014). Goldring and Landolt (2013) also add nuance to non-citizenship by introducing the concept of "precarious legal status" which can at times, be fraught with insecurity and vulnerability (p. 3). For their part, immigration detainees are located on this spectrum of non-citizenship as they include, but are not limited to the stateless, asylum seekers, failed refugee claimants, temporary migrant workers, and international students; they also encompass former permanent residents whose social benefits and freedoms to live in the nation state are extinguished along with their immigration status. These individuals embody precarious statuses that render them much more vulnerable to administrative confinement than their counterparts in the criminal justice system. They are trapped in an immigration detention system with severely limited access to justice as demonstrated by compounding and intersecting barriers. This difference between immigration detainees and criminal populations cannot 
be more extraordinarily stated than by Arendt (1958), who argues that prisoners have more rights than stateless individuals:

"The best criterion by which to decide whether someone has been forced outside the pale of the law is to ask if he would benefit by committing a crime. If a small burglary is likely to improve his legal position, at least temporarily, one may be sure he has been deprived of human rights. For then a criminal offense becomes the best opportunity to regain some kind of human equality, even if it be as a recognized exception to the norm. The one important fact is that this exception is provided for by law. As a criminal even a stateless person will not be treated worse than another criminal, that is, he will be treated like everybody else. ${ }^{5}$ Only as an offender against the law can he gain protection from it." (p. 286)

Arendt more pointedly suggests that the stateless embody an extreme rightlessness because there is no law for them; it is only in becoming a criminal that the law would materialize and they would be recognized by it. In the case of noncitizens held in the Canadian immigration detention system, they may not be completely invisible to the law; however, they are certainly becoming less visible with limited access to justice. Although they have rights to counsel, they are not always made aware of this and even when they are, there are many challenges in seeking legal representation, such as the poor response to their language needs and the lack of financial support from Legal Aid. Lawyers too discussed having little access to clients held in securitized carceral spaces. In my own research process, detainees' invisibility was a prominent issue as well; it was necessary for me adopt a multi-pronged approach to recruit participants and was still only able to interview two former immigration detainees.

It is in the treatment of noncitizens in the immigration detention system and its accompanying quasi-legal proceedings of detention reviews that the Canadian state and its overarching objective of protecting territorial boundaries reveal themselves once again. Sovereign power is masterfully exercised in the administrative confinement of 
immigration detainees, who are consistently denied access to justice and thereby fail to exercise the Arendtian notion of the right to have rights. Exercising this top-down authority is justified by Canada's character as a sovereign entity with the freedom to determine who belongs and who does not. As Pratt (2005) suggests, its "right to be selective with respect to whom it allows to enter and remain in Canada has always represented the bottom line in the justification of Canadian immigration law, policy, and practice..." (p. 75). My thesis argues that beyond controlling movement across borders, the Canadian state continues to reiterate the outsider status of noncitizens by creating a detention system in which "failure is hardwired" (Silverman \& Molnar, 2016: 110). These individuals are placed in securitized spaces oftentimes without being told of the reasons behind their deprivation of liberty. They are challenged in seeking legal representation because of the lack of information provided to them, the financial burdens of retaining a lawyer, and overall language barriers that are involved throughout their experience of detention. They are given less visibility and held within institutional walls where they are almost unreachable due to lockdowns and telephone systems functioning on collect calls. As the following chapter will demonstrate, even the quasi-legal means through which they can seek release is controlled in ways that reify borders of belonging.

I further suggest that immigration detainees' failure to access justice is deeply connected to the state's nation-building objectives and its persisting reproduction of white-settler colonial mentalities, imitating the British example (see also Coulthard, 2014; Abu-Laban, 2014). Canada has historically favoured immigrants from Britain, then expanded its preferred source countries to Europe and the US while still prioritizing white newcomers. As early as the 1890s, Brodie (2002) found that Speeches from the 
Throne referenced the need to attract the "suitable type" of immigrant, which does not encompass those from Asian countries (p. 47). Explicit racial discrimination was incorporated in consecutive versions of immigration legislation with the 1952 Immigration Act stating that Cabinet may exclude anyone based on "nationality, citizenship, ethnic group, occupation, class or geographic origin" (Pratt, 2005: 76). Several policies also targeted specific ethnic groups, including Chinese immigrants, who were charged a $\$ 500$ head tax for entry, and Japanese-Canadians, who were interned as "dangerous internal foreigners" (Dhamoon \& Abu-Laban, 2009: 169). In explaining this, I contend that the current practice of detaining noncitizens with minimal access to justice is a continuation of the Canadian state's colonial past and its treatment of racialized immigrants, who did not fit its white ideal.

Although there is a lack of statistical data examining the various ethnic groups making up this detained population, I rely on interviews with legal counsel, observations of detention reviews, activist groups (EIDN, 2017, May 15), and other academic research (Gros and van Groll, 2015; Pratt, 2005) indicating that most detainees are racialized people of colour. Canada's inaction towards facilitating their access to justice demonstrates its persistent consideration of this group as an Other, who needs to be hidden and deprived of liberty until they are permanently removed from the nation state. This is worrying particularly for stateless individuals, who do not have a home country to which they can be deported (see Stasiulis, 2017) and thus face a future of indefinite detention without a presumptive period in Canadian legislation.

I have so far argued that immigration detainees' severely limited access to justice and their inability to exercise the right to have rights are rooted in the detrimental 
exercise of sovereign power by the Canadian state. Adding nuance to this normative argument however, Wong (2017) suggests sovereignty alone is too simplistic as an explanation of administrative detention as "the restrictiveness of immigration control is also a function of how the politics of immigration unfold at the level of domestic institutions and political processes" (p. 4). He asserts that studying politics and its interactions with social conditions importantly provides another account of why governments implement their immigration practices and policies. To this end, Wong statistically analyzed the relationship between determining factors of immigration control (e.g., political orientation, legislative representation, etc.), and administrative confinement using data on 25 Western countries. Although right- and left-wing governments often differ in their immigration agenda such that the former is often associated with more conservative and sometimes racist notions, he intriguingly found that both political orientations of right and left were positively associated, albeit not statistically significant, with the increased prevalence of immigration detention.

Although I do not seek to replicate Wong's (2017) study, it is interesting to note that the population of noncitizens on Canadian immigration hold started to increase from 10,770 in 2004 until it reached its peak at 14,347 in 2008 under the Conservative government of Stephen Harper (Nakache, 2011: 41). In saying this, however, I am not suggesting that the Harper era is the sole explanatory cause for the rise in immigration detention although it is often assumed to be because of the rampant changes his administration conducted, which includes, but is not limited to the mandatory detention of DFNs, the revocation of Canadian citizenship, and the expansion of temporary migrant work programs with limited pathways to citizenship (Lenard, 2015, September 12). First, 
this observation is based on limited statistics from two different sources. Nakache's (2011) report provides statistics from 2004 to 2010, whereas the CBSA website shares statistics from 2012 to 2016 (see Appendix B). There is limited data on years prior to 2004, as well as the missing gap of 2011; therefore, it is difficult to conduct an accurate analysis of the trends in the population of immigration detention. Second, the increase in population began in 2005 under the Liberal government of Paul Martin and started to decrease in 2009 under the Harper administration. The IRPA and IRPR, which legislate the Canadian immigration detention system, were also ratified in 2001 under the Liberals.

Following Wong's (2017) analysis, the Canadian case exemplifies that the political context in which sovereign power plays out significantly matters when seeking an explanation for immigration control and access to justice more specifically. It also demonstrates that bipartisan politics is a weak indicator as both Liberal and Conservative governments were similarly involved in the rise of border enforcement and the detainee population. As previously discussed in the literature review, the Canadian government, irrespective of the political party in power, was very much involved in the securitization of migration whereby refugees and migrants in general were discursively constructed into illegal others. It capitalized upon the 1999 boat arrival of self-selected asylum seekers from Fujian, China and the terror attacks of September 11 to pass the foundation of IRPA and $I R P R$, which became known as "an almost clairvoyant, cutting-edge response to the new terrorist threat" (Pratt, 2005: 3). This process is repeated once more when MV Ocean Lady and MV Sun Sea reached the shores of British Columbia, resulting in the implementation of mandatory detention of "irregular arrivals" (Silverman, 2014: 28). It 
is in securitizing migration that the Canadian state is able to reassert sovereign power and achieve "exclusion when the border itself does not" (Dauvergne, 2008: 17).

In summary, this chapter focuses on noncitizens' severely limited access to justice in the immigration detention system. Legal representation is a means by which they can seek release from their deprivation of liberty; however, they are continuously challenged by the inconsistent communication on their right to counsel, the financial burden of legal services with limited assistance from Legal Aid, and language barriers that touch the entire process of detention. Even when detainees are able to retain counsel, lawyers face many barriers in case preparation due to their clients' confinement in securitized spaces, particularly provincial institutions burdened by lockdowns. It is difficult for them to meet clients and organize a comprehensive release plan while abiding by the tight timelines of detention review hearings. These issues compound and intersect with each other, exhibiting access to justice issues in this immigration context. Although these issues are similarly prevalent in the criminal justice system, immigration detainees are distinct as they embody precarious statuses that automatically give them fewer rights than their criminal counterparts as asserted by Arendt. Their limited access to justice is facilitated by the Canadian state's grand exercise of sovereign power, replicating its historical conduct towards racialized immigrants. A highly securitized political context under which this plays out also adds another layer to the analysis and will be discussed in greater detail to explain the inconsistent decision-making process of ID board members. The following chapter will also elaborate upon the discretionary basis of detention review hearings and its adverse effects on immigration detainees. 


\section{CHAPTER 5. DISCRETION IN DETENTION REVIEW HEARINGS}

Detention review hearings are quasi-judicial proceedings conducted within 48 hours of detention, repeated within the next seven days, and held every 30 days thereafter until the immigration detainee is deported or released. They are presided over by ID board members, who are public servants meant to serve as independent adjudicators in reviewing facts of the case and deciding if the detainee should be released into the community while awaiting removal. These hearings follow an adversarial process whereby the Canadian federal government is represented by a CBSA hearings officer, also referred to as the Minister's counsel, whereas immigration detainees may be accompanied by legal counsel or another representative (e.g., immigration consultant). In accordance with section 58 of the IRPA, an ID board member must order release unless the Minister's counsel can prove, on a balance of probabilities, that grounds for detention persist. If this leads to a positive determination, section 248 of the IRPR then requires the presiding member to consider more specific factors prior to rendering their decision, such as the reasons for and length of detention, and alternatives to confinement. Despite the fact that the burden of proof should be on the federal government, this chapter will demonstrate how the interpretation of jurisprudence in this arena has shifted the onus upon immigration detainees. Discretionary powers of the ID board members, however, largely remain unchecked as a result of limited access to and powers of judicial review at the Federal Court, forcing noncitizens and legal representatives to bring their case to the Ontario provincial courts and seek habeas corpus relief. Without a presumptive period in Canadian legislation, it is important to bring attention to these practices and processes that lead to the indefinite detention of invisiblized noncitizens. 


\subsection{Rubber Stamp of Continued Detention}

Participants urge that the review process in immigration detention is severely problematic because it shifts the burden of proof on to noncitizens in cases where previous decisions have been negative. This comes from the Thanabalasingham case where the Federal Court of Appeal ruled that ID board members must show deference to previous decisions made in each particular case and provide "clear and compelling reasons" if departing from them (Canada (Minister of Citizenship and Immigration) $v$ Thanabalasingham, [2004] 3 FCR 572, 2004 FCA 4, para. 10). As CBSA hearings officers are able to rely on reasons cited in earlier decisions on that file to argue for continued detention, the burden is effectively transferred on to immigration detainees, who must provide new arguments and evidence to demonstrate that such grounds for confinement no longer exist. Noncitizens are thus responsibilized into convincing board members to order release. Sid, a private practitioner from Toronto, refers to this shift in onus when explaining the unlawfulness of detention reviews:

"[T]he whole procedure of the detention review is problematic. It's unlawful... They take this position that - which is correct - that since detention is a violation of sec. 7 [of the Canadian Charter of Rights and Freedoms], that the government is taking away somebody's liberty, the government has the burden of proof, which is what it should be... The detainee makes his submissions and the government gets the last word because it has the burden of proof but what happens is two things. There's this Court of Appeal decision in Thanabalasingham that says that when the adjudicator makes a decision that departs from the decision of a previous decision-maker, he or she must give clear and compelling reasons to do so. So it's clear that since the first - since we're at a detention review, every other decision before that has been to detain. So if that's the case then, what the decision-maker needs to do is if he or she is gonna detain, they don't have to give clear and compelling reasons but if they're gonna release then they're forced to give clear and compelling reasons to release. In other words, the burden is shifted on to the detainee to give clear and compelling reasons to the adjudicator about why they should depart from previous members." (Sid, 2017, February 16) 
It is extremely difficult to carry this burden of proof with immigration detainees largely having to rely on legal counsel to gather new information on their behalf and represent them at detention review hearings. As this thesis finds however, there are various compounding challenges to the legal representation of noncitizens, namely limited access to clients in securitised institutions, tight procedural timelines, and the high cost of representation with very limited funding from Legal Aid. In even greater disadvantage are unrepresented noncitizens whose chances of accessing justice in this system are almost nonexistent (Gros \& van Groll, 2015).

In effect, the "clear and compelling reasons" test transforms detention reviews into quasi-de-novo hearings; this is to say hearings subsequent to the initial 48 -hour review are "not entirely new" (Gros \& van Groll, 2015: 55). They are merely follow-ups to previous proceedings where board members are required to consider earlier decisions. The legal justification is that because detention reviews are fact-based, adjudicators need to take into account previous rulings. Legal scholars Gros and van Groll (2015) critically argue, however, that this is an illogical rationale in this quasi-judicial tribunal context as all board members are triers of the fact, who are in themselves able to assess evidence presented at hearings. They contend that presiding members have access to case information and witnesses, and are able to evaluate them at every detention review. It should not be necessary, therefore, to defer to previous decisions from earlier hearings. This critique should be given greater attention because, as observed in practice, the "clear and compelling reasons" test creates undue hardship on immigration detainees to present new evidence and arguments that could be used by board members as justification for disagreeing with previous decisions and ordering release. Offering something new to the 
presiding member becomes key; as Jamie suggests, "If the information is the same, the decision's going to be the same." (Jamie, 2017, February 8). Faye also adds that the evidence may not necessarily be substantial, just different:

"Some members might really want something substantively different. Others might recognize that the previous decision is not something they would agree with but I find you usually have to at least give them a reason to distinguish it. Even if it's not a strong one, but just something so they're not like: I disagree with my colleague. I'm reaching a different decision. Rather than saying: Well, now there's this new factor or information or whatever it is. There's something else that's come to light and so therefore, I can reach a new conclusion." (Faye, 2017, February 3)

All respondents expressed concern regarding this jurisprudence. They share that it can be very difficult to present new information, specifically in cases where clients are held for reasons related to being unable to demonstrate their identities. This ground for detention imposes a different kind of burden compared to criminal inadmissibility or flight risk, involving noncitizens being able to prove who they actually are. It requires the submission of identity documents, which are almost impossible to acquire particularly for asylum seekers who may be fleeing war-torn countries. This is exemplified by the lengthiest cases of immigration detention in Canada, including Vincent Vinnetou, Michael Mvogo, Kashif Ali, and Ebrahim Toure, who were held indefinitely in the absence of identity documents.

Importantly, Dora shares an illuminating perspective regarding the reverse burden of proof in detention reviews, arguing it is the consequence of a gross misinterpretation of the "clear and compelling reasons" test by ID board members. She suggests the Federal Court of Appeal ruling is only supposed to mean that presiding members must consider previous decisions. They are not necessarily bound by them and in fact, have the power to decide differently as long as they provide reasons for doing so. This 
jurisprudence, however, has been mistranslated into practice where immigration detainees and their legal representatives have been required to take on the evidentiary burden and convince board members to order release. Dora elaborates:

"Thanabalasingham won... He'd gone to those monthly hearings. He was detained all the time. And finally, an Immigration Division member said: I'm gonna release you and these are the reasons why. And so the Court of Appeal said: That's fine as long as he gives reasons, compelling reasons to not follow the previous decision, he can order the release. And his compelling reasons was he disagreed with the previous board member. That case has been twisted... [W] hat's happened in practice is... [t] hey just always go to the previous orders and say: Well there's nothing different. There was nothing different for Thanabalasingham either. It's just that the Immigration Division member...disagreed with what the findings were of the previous member. You're entitled to do that but now the Immigration Division members think that they can't disagree... Totally twisted - what was a good decision. Thanabalasingham was a good decision, supporting an immigration official in saying: I think that you're wrong. I'm prepared to release him. And explaining why he thought that she was wrong... It was a good decision and now it's not. Now what it is is: You made a decision. I'm bound by that decision unless there's new evidence, you don't get out. They reversed the onus. The onus becomes that of the person, not the other way around.” (Dora, 2017, January 26)

A closer reading of the Federal Court of Appeal's decision in Thanabalasingham supports Dora's argument that a misinterpretation has occurred. The ruling clearly places a positive obligation on board members to consider previous decisions and expressly urges them to "explain what has given rise to the changed opinion, i.e., explaining what the former decision stated and why the current member disagrees." (Canada (Minister of Citizenship and Immigration) v Thanabalasingham, [2004] 3 FCR 572, 2004 FCA 4, para. 12). Although the Court cites the introduction of new arguments and evidence as valid justification for a different decision, it only refers to them as examples. It specifically asserts, "For example, the admission of relevant new evidence would be a valid basis for departing from a prior decision to detain. Alternatively, a reassessment of 
the prior evidence based on new arguments may also be sufficient reason to depart from a prior decision." (Canada (Minister of Citizenship and Immigration) v Thanabalasingham, [2004] 3 FCR 572, 2004 FCA 4, para. 11). Current practices that impose such requirements while citing this decision are problematic interpretations of the decision. Nothing in this statement indicates that new arguments and evidence from immigration detainees and their legal counsel are absolutely necessary for ID board members to end the pattern of continued detention; they are merely examples of what board members can use as "clear and compelling reasons". Further, although the Court emphasizes that these independent adjudicators are required to consider previous decisions, it also states they do not have to overtly discuss these reasons as "his or her reasons for doing so may be implicit in the subsequent decision. What would be unacceptable would be a cursory decision which does not advert to the prior reasons for detention in any meaningful way." (Canada (Minister of Citizenship and Immigration) v Thanabalasingham, [2004] 3 FCR 572, 2004 FCA 4, para. 13).

It is imperative to address this (mis)interpretation as it has been used to persistently deprive immigration detainees of their freedom. With the burden of proof shifted on to them, they must succeed against barriers to legal representation and scramble to produce new information as current IRB practices seem to insist, in order to convince the presiding member of their subsequent hearing to order release. Failure to do this leads to the deleterious consequence of continued detention and another negative decision to overcome in the following review. This is the greatest challenge in this quasijudicial context with legal counsel expressing immense frustration over the difficulty of dealing with consecutive negative decisions. Sid, who previously emphasized the 
unlawfulness of detention review hearings, continued to explain: " $[T]$ he reality is after the first two or three detention reviews, there's almost no point in trying to get somebody else [board member] unless you can get a very compelling release plan because there's gonna be a rubber stamp of detention, detention, detention." Dora echoes these sentiments and reiterates the problems caused by the (mis)interpretation of the Thanabalasingham ruling (Canada (Minister of Citizenship and Immigration) $v$ Thanabalasingham, [2004] 3 FCR 572, 2004 FCA 4):

"The one problem legally with these hearings is that once you're detained, the next hearing, you have to overcome the first order. So if you go through three, four, five of these hearings, you've got all these orders to overcome. Well you never overcome them. And so statistically, their records show that if you're detained longer than six months, your chances of getting out are pretty nil. They don't get out because they keep racking up the negative decisions then you never overcome them." (Dora, 2017, January 26)

This issue paves the way to long-term indefinite detention practiced by the Canadian immigration system. Summarily, immigration detainees have very limited access to procedural justice caused by the barriers to legal representation examined in the previous chapter. (Mis)interpretation of jurisprudence has additionally created a system in which the burden of proof is shifted on to them, particularly in cases where previous decisions have been negative. It created the requirement of new information to convince board members to order release.

\section{$\underline{5.2}$ Non-Custodial Measures for Immigration Detainees}

Constrained by current practices of ID board members, one way lawyers have addressed this "clear and compelling reasons" test is by presenting a release plan that attends to the concerns expressed by previous board members, thereby providing the 
presiding adjudicator with new information that would allow them to disagree with earlier decisions. As discussed in the earlier chapter, lawyers are already challenged with preparing a release plan under the strict time constraints of the 48 -hour hearing, but cases where decisions have been negative highlight how they face an even greater challenge. Although they may not be pressured by time, they need to organize a comprehensive plan that is different from previous proposals. For example, they may introduce a different bondsperson or seek an alternative community program. Eleanor shares her strategies in preparing a release plan for clients:

"Well, you wanna create some kind of release plan that's going to offset the member's concerns about this person. So if the concerns are that this person has a mental health problem and when they're not treated, that's when they tend to get themselves into trouble. I guess you wanna make sure that you've - maybe you've got workers from various mental health organizations involved. If it's somebody who has an addiction and that could be the underlying some of the reasons why they're in trouble with immigration, you wanna see if you can get them into some kind of program, even a residential treatment program. Right? So that can be good... If you think they're gonna need some money, some kind of a bond, you wanna find somebody who's gonna play a supervisory role like someone maybe that there's already a relationship with and that has a good profile you know no criminal record, like working and has a connection to them. And meet them and try to put together something about them beforehand." (Eleanor, 2017, February 2).

Legal counsel are required to prepare detailed release plans to convince board members to depart from previous decisions. This time-consuming case preparation needs to be completed as soon as possible because the longer the process continues and more negative decisions are accumulated, the harder they are to overcome. As Petra explains:

"Board members are hard to kind of persuade on these [release plans] points. Once the person has been detained let's say for two years or a year and a half, each time they're before the board member, they're going to look at all the other times where the other board members have said detention should be maintained. They need to have clear and convincing reasons to depart from those decisions. They tend to defer to the previous 
board member. It's not like a clean slate... It gets harder and harder to convince the board member to accept the release plan where they say: Well, all of these previous board members have found this person to be a danger and that's an issue." (Petra, 2017, February 14)

The organization of a release plan, however, largely depends on the availability of resources. For the demanding role of bondsperson, it is often family members or friends, who volunteer to supervise the detainee and offer monetary support; this often puts specific noncitizens like asylum seekers in a very difficult situation, as they may not have any personal connections in Canada. Anyone who seeks to be a bondsperson must also be an adult Canadian citizen or permanent resident with sufficient financial assets. In the immigration context, there are two types of bonds: performance bond and cash bond. The former includes monitoring the detainee to ensure they are abiding by release conditions, and paying a sum of money in case of a breach. It is similar to signing a recognizance bond in the criminal context, in which a surety or bondsperson promises to pay the court should a bail condition be broken. Alternatively, there are also cash bonds involving payments deposited up front. Both of these options impose financial burdens on detainees' support networks, who are required to offer their own money. Performance bonds also need to be put up against property, which means the family member or community support must own a home or land, whereas cash bonds can go up to several hundred dollars. Katherine explains the latter can even reach up to several thousands if criminality is involved. These financial requirements are very arduous as she points out,

"[I]t's only people of a certain income level that can basically get the client out because the alternative if you don't have a house.... is that you must put up a cash bond and the minimum cash bond in the simple straightforward case is five hundred [dollars]. But people with even a little bit of a history, it will be in the thousands. So think about our communities. Who can go ahead and put up thousands of dollars in cash, in a cash deposit... What if you are just a blue collar worker that doesn't have that cash flow, who's 
living pay check to pay check, and then one of your family members gets in trouble and you wanna really help them get out?" (Katherine, 2017, January 24)

These financial hardships for immigration detainees and their support networks are further compounded by the lack of community resources allocated to those without Canadian citizenship. That is, there are very few alternatives to detention apart from the payment of bond. One of the only available programs is the Toronto Bail Program (TBP), which can supervise detainees upon release. It can also provide support in terms of housing, mental health, and obedience to release conditions. Participants generally have a positive regard towards TBP whose involvement has previously resulted in their clients' release. They note, however, that there are long delays before an immigration detainee is accepted into the program. It is also funded by CBSA, which creates a conflict of interest when this federal organization is the opposing party in the detention review hearing. Sid highlights that although he has previously worked with TBP, it is important to note how it may very well be working with the Canadian government. He shares:

"They're good in what they do in terms of if a person has no one else then sometimes the Toronto Bail can step in and be a bondsperson, but again, they're an arm of the CBSA. Right? They're funded by the CBSA... So it's not the case that they're an independent organization that makes an independent evaluation of whether they're gonna take on a case or not. If the CBSA says: No. Do not be - You cannot take on this - We disagree that you should take on this case. It's not within your mandate. Serious criminals, they won't take then they're not gonna do it. Then the problem occurs when the CBSA, well the Minister's counsel says: Well, even the Toronto Bail Program said no so that means this person should not be released. Meanwhile they're the ones who told the Toronto Bail Program to say no and then they're using that no as a further reason why a person shouldn't be released." (Sid, 2017, February 16)

Sid suspects that with the federal government funding TBP, the two organizations may collaborate with each other to decide which noncitizens should be accepted into the 
program. He suggests this close relationship could lead to bias, resulting in the targeted exclusion of specific people, who must then remain in detention if lacking bondspersons and access to other alternative programs. As evident in its name, the TBP also only exists in Toronto, which means it is exclusively accessible to immigration detainees within that region. As the Canadian Council for Refugees (CCR) points out, this causes inconsistency and unfairness as individuals "are treated differently depending on where they are detained." (CCR, 2015, January). In areas where it does not operate, the challenge persists for legal counsel, who must then seek other alternatives to ensure their client's release. In the future, it would be a fruitful endeavour to research the TBP.

If anything, the "clear and compelling reasons" test exposes the federal government's practice of indefinite detention. Routine detention review hearings are often used to deny the charge of indeterminately depriving noncitizens of their liberty, but a critical analysis of these proceedings demonstrates the way in which reversing the burden of proof produces insurmountable barriers for immigration detainees, who have little access to alternatives to detention, and could remain in IHCs and provincial prisons for an unknown number of years until finally released or deported. There are also no time limits in immigration detention, which interacts with the "clear and compelling reasons" test to produce the outcome of indefinite detention. The CBSA most recently reported that in 2016-2017, the average number of days spent in detention was 19.5 days. It also shared that the number of long-term detainees, who are defined as having spent 90 days or more in detention, reduced from 623 in fiscal year 2015-2016 to 439 in the following year (CBSA, 2018a). Although this suggests that the federal government is confining noncitizens for shorter periods of time, it does not negate the fact that it has yet to 
implement a time limit on this detention practice or change the process of detention review hearings leading to lengthy confinement. Indefinite detention is still a reality.

\subsection{Making Sense of the IRB Decision-Making Process}

Board members routinely exercise discretionary powers in detention review hearings. This is in relation to section 248 of the $I R P R$, which puts a positive obligation on these independent adjudicators to consider the following factors prior to rendering their final decision: (a) reason for detention; (b) the length of time in detention; (c) whether there are elements that can assist in determining the length of time that detention is likely to continue and, if so, that length of time; (d) any unexplained delays or unexplained lack of diligence caused by the Department or the person concerned; and (e) the existence of alternatives to detention. This list is not exhaustive, suggesting board members must absolutely deliberate these issues, but also have space to consider other factors beyond them. The prevalent problem with granting discretionary power, however, is that it allows for potentially arbitrary and inconsistent decision-making, which produces deleterious consequences in a setting where noncitizens' liberty is at stake. Respondents share that even when they were able to overcome access issues and time constraints, and prepare a comprehensive release plan that addressed previous concerns, there was a tendency for board members to reject them using reasoning that legal counsel could not understand. Some participants posit that rulings are much more based on affective responses with little incorporation of logical arguments. This is further fostered by the lack of extensive case law and legal structure in immigration detention, except for the dominant Thanabalasingham decision, to check these discretionary powers (Canada 
(Minister of Citizenship and Immigration) v Thanabalasingham, [2004] 3 FCR 572, 2004

FCA 4). Examining the decision-making process of ID board members will, therefore, necessarily bring about a discussion on the law/discretion dichotomy, which will be discussed in a following section (Pratt, 2005).

Reiterating arguments made above, the preparation of a release plan is one of the ways in which legal counsel are able to meet the "clear and compelling reasons" test. This process is oftentimes hindered by the absence of a support network, especially among migrants, who have no family or friends in Canada, as well as the financial burdens associated with fulfilling the supervisory role. As such, it is quite significant when lawyers are able to secure a bondsperson, who is willing to monitor the detainee post release and shoulder the bond payment. From interviews with participants, this thesis finds, however, that accepting release plans involving bond very much depends on ID board members, as there are few specific guidelines defining who is an acceptable bondsperson. Including the eligibility requirements of immigration status, age, and residence in Canada, the bondsperson must also know the detainee and use their own money in fulfilling their supervisory role. Despite these, the single presiding member continues to possess some discretion in deciding the suitability of a bondsperson, which according to participants, can and has resulted in incomprehensible and unfair decisions. Rohan, for example, shares his experience where an ID board member did not accept a detainee's mother as a bondsperson, reasoning that their connection is too close and would prevent her from reporting any breach of conditions. On the other end, he also reveals another member has also refused a client's release, perceiving that the proposed 
bondsperson does not have a close enough relationship with the detainee. This clearly demonstrates an inconsistency in board members' judgement as Rohan relays:

"I've had it go both ways in front of an Immigration Division member where you put up someone who's very close to your client. You know you put up their mom. The mom says: Yes, I'm willing to put up a certain amount of money. I'm going to supervise my son. And their response is: Well, you're a little too close to your son. We don't believe that you're going to be able to turn your son in or call the authorities if you believe your son's gonna breach. And then on the flip side, if you put someone who's a little bit more distant, you hear from the Immigration Division member: Well, the relationship isn't quite strong enough for this person to want to comply under your supervision. So it can be difficult." (Rohan, 2017, March 16)

Here, board members placed emphasis on the relationship between the immigration detainee and the proposed bondsperson in their decision to continue detention. While it may be necessary to consider the connection between these two parties in light of the supervision required, presiding adjudicators can still exercise their discretion even if the eligibility requirements only specify that a bondsperson should know the detainee without pinpointing a certain degree of separation needed in the relationship between them. As such, these decisions can seem very arbitrary and be perceived as a source of injustice in the immigration detention system.

Arbitrary decision-making is also in evidence where ID board members are perceived to use emotions as opposed to legal and logical reasoning when maintaining detention. Katherine describes cases where presiding members would reject release plans because they did not trust the immigration detainee. Rather than reviewing the plan's substance, the adjudicators ordered detention as they perceived breach of conditions would be the outcome. She argues this type of emotion-based reasoning would be difficult to overcome and could lead to prolonged deprivations of liberty. She explains 
that, "the way they [ID board members] deal with decision-making just drives me crazy 'cause some of them just seem very emotional-based. They'll for example say: The plan is good like there's nothing wrong with the plan. We just don't trust you. Okay but by that logic, there's no plan ever that could have this man or woman released. How does that work?" (Katherine, 2017, January 24). As she expressed, this reasoning would be very difficult to address in a subsequent release plan, which might have to establish the trustworthiness of the detainee. One could only speculate how more difficult this would be if conditions of release were previously broken. Rohan expressed that emotions can certainly play into board members' decision-making process, but pointed to the more general lack of consistent and transparent reasoning as the dominant problem. He refers to his example above on the bondsperson-detainee relationship and responds:

"I don't quite know if the decisions are emotional in nature. I would say that...they take into account factors and reasons, and reasoning that sometimes are difficult for me as counsel to understand and to appreciate. So certainly for example, what I just described where certain family members are considered too close, whereas other family members are considered too distant to adequately supervise. Well I'm not really too sure sort of how you respond to that like I'm not really too sure how you penetrate that kind of thinking or understand. So in that sense it's really difficult to advocate for your clients sometimes." (Rohan, 2017, March 16)

It is difficult for legal counsel to counter such negative decisions because of their lack of legal or logical reasoning. Taking Rohan's example, it would be very challenging to demonstrate how relationships with bondspersons and their varying degrees of distance would not interfere with reporting breaches to CBSA. One board member may not accept the mother-child relationship considering the risk of non-reporting, whereas another might perceive it to be beneficial as the parent would ensure obedience of release conditions to prevent their loved one's return to detention. 
A few participants also wondered if the arbitrariness in board members' decisionmaking might actually be a targeted response to the racialized population with whom they are dealing. Faye was specifically distraught by the treatment of Mexican asylum seekers in detention review hearings. She recalls that some board members sometimes capitalize on individuals' refugee applications when ordering detention, stating that they are a flight risk and unlikely to show up for an examination due to fears of being sent back to their country of origin. Faye shared her concern that refugee applications were being used to detain particular groups of people, stating:

"[W]hen I started practicing, there were a lot of [refugee] claimants from Mexico... They were sort of disliked in the system... Detention was continued. They were refused by the Refugee Protection Division. They really had sort of a tough going. And I recall I had a member... We were able to explain what had happened or the concern. We addressed it sufficiently. The member was satisfied but said: I'm gonna continue their detention because you're a refugee claimant. Your [being] afraid of returning back poses a flight risk. I had not long later a detention review with the same member. It was a client from another country... I think it might've been an identity issue. He was able to resolve it. He provided documents. And she said: Okay. You satisfied the means of your identity. The fact that you're a refugee claimant is not sufficient to continue detention. I'm releasing you. So for a Mexican claimant, she continued detention and for the other country - it was very much a refugee producing country, that's considered by Canada as a refugee producing country - she allowed release. So it was very obvious there that there was a country bias." (Faye, 2017, February 3)

While Faye refers to this as a "country bias" by one board member, it brings attention to the potential discrimination in ID members' decision-making process. One could speculate that their tolerance of the shift in evidentiary burden and their orders for continued detention are connected to the racialization of noncitizens subject to these proceedings. This point will be further analyzed in another section on discretion as a powerful means of governing populations. 


\subsection{To Bear the Evidentiary Burden}

For immigration detainees, the detention review process is supposed to be an avenue through which they can seek release; however, it can also be a source of hopelessness and disappointment as the evidentiary burden is shifted upon them and board members use their discretionary power to prevent their release. Lacking new arguments or evidence to put forward, their deprivation of liberty persists without a presumptive period in Canadian legislation. Some participating lawyers explain that clients do not typically follow the proceedings in the beginning, but gain a better understanding as they continue going through them. These long-term detainees, however, tend to develop a negative perception of the review process. Sid shares how some clients describe these hearings as unfair and pointless processes:

"They understand that in principle, these hearings are supposed to be their opportunity to speak and be able to present their case to be released but in reality, they know that...it's gonna be unfair... What's gonna happen is they're gonna go there and CBSA's gonna say a lot of lies or a lot of things...that they'll feel that are an exaggeration and then they're gonna get frustrated or angry and they're just gonna be in detention again. It's almost like giving them false hope that they actually have a legitimate way of being able to be released." (Sid, 2017, February 16)

This frustration is evident in the narratives of Felix and Deepan, who were both subject to several detention review hearings. Felix, whose asylum application was denied, had three reviews while detained for around one month at Maplehurst Correctional Complex. He allegedly failed to disclose his change in address and recalled trying to explain this miscommunication to the presiding board members, who consistently referred to him as a flight risk. He describes interactions with adjudicators, saying:

"The main problem to them... They don't believe me that if they release me, I will come. Maybe I will run away. They don't know if I will come back or not. This was the main problem to release me... They say they 
don't believe me because I changed my address so for them it's we don't trust you anymore. I tried to explain to them. They say: No, it's too late for that." (Felix, 2017, January 22).

Felix also mentioned that each of his detention reviews only lasted around 30 to 40 minutes, which he claimed was an insufficient amount of time to argue his case. For his part, Deepan was much more explicit about his criticism of the detention review process, identifying it as "bureaucratic limbo jumbo just to have the say that the people are seeing an adjudicator essentially, to say they have rights to bail, but in actual reality, it's not really helping at all." He recalls participating in a total of eight proceedings lasting around five to six minutes each during his more than one-year in immigration detention. He goes on to question ID board members' decisions on keeping him detained as a flight risk despite being born in Canada and rendered stateless:

"It's [detention review process] so arbitrarily messed up. You go in first 48 hours then after that, you have a 7-day hearing and then after that, you have a 28-day hearing... During these hearings, it's the same thing. The Immigration representative will say something else. The Minister representative will say something else then the board member. And you just stand there, listen to what they're saying... Try to set up a plan to get out. It's not really a hearing. First of all, you're not in front of a judge. You're in front of a board member who has no legal training whatsoever. Just a person that's been hired to look at this detention case... Based on detention reviews, I provided a surety...but they denied me on danger to the public or flight risk. I ask myself: How do they deny me...? Well first, I'm born and raised in Canada. That's not a flight risk issue. I'm a danger to the public but you have the federal system classify me as low risk. So each division is separated and they don't take that into consideration whatsoever." (Deepan, 2017, March 8)

Much like legal counsel in the previous section, both Felix and Deepan are frustrated with and confused by ID members' decision-making process, failing to understand their decisions and perceiving them as arbitrary. These quasi-judicial proceedings should be a 
means through which they can seek release, but they were instead cycled through them with more negative decisions to overcome leading to prolonged deprivations of liberty.

\subsection{Checks and Balances on Discretionary Powers}

Beyond the problematic (mis)interpretation of the "clear and compelling reasons" test, as discussed above, there is considerable variation in board members' decisions to release immigration detainees; this is illustrated by the experiences of both legal counsel and former immigration detainees. Some respondents from the former group accept this lack of consistency, citing differential individual experiences, political orientations, and biases among board members. They suggest it is to be expected when dealing with different people, ID board members in this case, who have different life experiences and values that influence their decisions. For instance, Eleanor recalls that some adjudicators were more open to releasing noncitizens than others, which she suggests is simply part of the decision-making process: “They're different too. Some of them are more liberal about releasing and maybe think more like that. Some just don't kind of release someone. They're very negative about criminality and things like that... I think it varies, yeah. That's what you get with when you get case-by-case individual decision-making. You're gonna get variance." (Eleanor, 2017, February 2). Rohan similarly shares that although he hopes like cases are treated equally, he also recognizes it is not realizable in practice:

"I can tell you in Toronto, certainly there are some members who are more likely to release and other members are less likely to release based on sort of the exact same set of facts, the exact same release plan. And so that can be difficult to deal with. You know you would hope that like cases get treated alike and you know who the decision maker is shouldn't matter but it does. It's a human process. People have different views, different experiences... It's not an easy thing to deal with but it is a reality of, I guess, a human process." (Rohan, 2017, March 16). 
Legal counsel may understandably need to adopt this viewpoint to avoid being counterproductive in their work. They must remain realistic to the challenges in the field and use different strategies to ensure their clients' release. Carmyn cites these reasons when asked if she has ever questioned a board member's decision to order continued detention. She suggests there is little point to arguing against the adjudicator:

"But I mean look, there's no point in arguing. Once the decision is yes or no, I mean like what are you gonna do? Stomp your feet? There's no point... The point at which to be kind of convicted in what you're trying to get through your client is when your making your submissions and you're doing your preparing and all of that but you do the best you can and sometimes, it is as simple as the decision-maker you get and it can be oftentimes a 50/50 crap shoot. And so sometimes it's yes, sometimes it's no. Yeah, you can get very frustrated but I mean you certainly don't want it to become something... You have to kinda keep it at bay. You don't want to internalize it and have it become something that's counterproductive." (Carmyn, 2017, February 2)

This acceptance of board members' decisions as final and the normalization of inconsistency can be worrying. As mentioned, perhaps it is a tactic used by legal counsel to remain productive when faced with negative decisions; however, it can also suggest a lack of willingness to advocate for clients whose deprivation of liberty persists. Failing or refusing to question such perceived arbitrariness and variance protects the status quo in detention review hearings, allowing adjudicators to continue rendering decisions with little logical reasoning. Although very few participants shared these sentiments, it is concerning particularly when considering the previous chapter's argument that legal representation can provide essential assistance to clients in navigating the Canadian immigration detention system and the quasi-legal proceedings of detention reviews.

Admittedly, inconsistencies in decision-making are not restricted to ID board members presiding over detention review hearings. They are also present in the context 
of refugee determination, where cases are heard by the RPD. Rehaag (2017, March 8) has consistently found variance in the recognition rates among board members, which the IRB suggests is to be expected due to specialization that involves members being assigned cases from specific geographic locations associated with high or low rates. He argues, however, that specialization alone is an inadequate explanation with subjectivity of the decision maker still playing an important factor (Bellemare, 2017, August 22). Elsewhere, he also states, "It goes without saying that outcomes of refugee determinations - in which the human rights and the very lives of refugees may be at stake - should hinge on the merits of refugee claims presented, not on the identity of the Board Member who happens to be assigned to a particular claim." (Rehaag, 2008: 340) (see also Colaiacovo, 2013; Schoenholtz, Ramji-Nogales \& Schrag, 2007).

This issue is all too familiar in the criminal justice system where the characteristics of adjudicators (Rachlinski \& Wistrich, 2017), and the groups to which an accused belongs have resulted in inconsistent decision-making with the notable example of the overrepresentation of Aboriginals and African Canadians in the correctional system (Roberts \& Reid, 2017; Owusu-Bempah \& Wortley, 2014). Returning to the Canadian immigration detention system, this thesis' qualitative findings on the inconsistencies in ID members' decision-making is also supported by a recent report by the National Post, which states that the geographical location of a board member is another factor that can explain the variation in release orders. Analyzing data from 2013 to 2016, Humphreys (2017, March 7) found that Central Region (Toronto) had the lowest release rate at $11 \%$ in comparison to the Eastern Region (Montreal) at 28\% and Western Region (Vancouver) at 30\%. Although it may be impossible to achieve absolute 
consistency, it is important to address the perceived arbitrariness and resulting variation in ID members' decision-making process because of the shift in onus in detention review hearings, which places the burden on immigration detainees to prove they should not be in detention. These individuals also have limited access to legal remedies to be used in reviewing ID members' decisions as will be discussed in the next section.

Some participants were less understanding about the decision-making process of ID board members. They emphasize the unfairness of decisions to uphold detention without logical reasoning, and on the basis of allegations with thin evidence. They argue the process is arbitrary as adjudicators are able to use their discretionary powers to impose deprivations of liberty. When she was still representing clients at detention review hearings, Faye recalls she had routinely found members' decisions to be unfair. She suggests that the immigration court has developed a negative reputation in that "there's very much the perception that the Immigration Division in particular is sort of the wild west of legal decision-making. It's very arbitrary. It's very unfair. It depends on the decision-maker and it's rarely challenged in court." (Faye, 2017, February 3).

Constrained by the need to remain professional and protect their clients, legal representatives sometimes rely on judicial review at the Federal Court to counter this perceived arbitrariness; however, as will be discussed here, their access to this legal tool is quite limited. Interestingly, only one participant shared his experience of scrutinizing a board member's decision at the hearing itself. Believing the adjudicator's consecutive rulings for continued detention were unreasonable, George remembers telling the member "that she needed to excuse herself from the case... She should not be the one who should be presiding over his [client's] detention review. She was very unhappy... 
She was very angry." (George, 2017, February 8). Although he lost this case as the member claimed "she had every right to hear the case," it prompted him to use other means, namely filing for habeas corpus relief, to secure his client's release. This will be contextualized in the recent court case of (Chaudhary v Canada (Public Safety and Emergency Preparedness), 2015 ONCA 700).

One of the ways in which immigration detainees and their lawyers counter consecutive negative decisions and the perceived arbitrariness of decision-making are by applying for judicial review. This process begins with seeking leave from the Federal Court, which conducts an initial review of the case prior to proceeding with an oral hearing. Despite its availability, respondents suggest it is an ineffective legal tool with Sid going as far as to say, "[A] judicial review is not a good method of trying to overcome these barriers to a lawful detention review." (Sid, 2017, February 16). They are largely deterred from using it because for one, there is often significant delay in obtaining leave, taking around one year or several months if expedited. Clients also remain in detention during this processing time and will still be subject to their monthly detention review, whose decision will supersede the previous negative decision being questioned. Participants also refer to the substantive purpose of a judicial review, which they deem problematic as the Federal Court can only check the reasonableness of a board member's decision without the capacity to "substitute its opinion for that of the ID Member" (Gros \& van Groll, 2015: 72). In other words, it can order a new detention review, but not the release of a detainee. Dora cites these reasons in expressing her disappointment with the judicial review. She claims that as legal counsel, she looks to the courts in seeking remedy; however, the ineffective nature of this process is discouraging. She explains: 
"What I found really frustrating was if a person's decision is continued and you think it's wrong in law, we go over to Federal Court. Two or three months later, we'd still be waiting for the Court to decide whether it's gonna expedite it or not, meanwhile the person [is having] other hearings. You have to file an application in court each time. Judges aren't looking to see if the detention's lawful. They're looking to see if the immigration official was reasonable. That's a big difference. So that was for me the most depressing part as a lawyer because my remedy - if I see something wrong in law - is to try and take it to court and have a court look at it, and say this is right or wrong. And you can go up through the courts - with difficulty, but you can do it... It wasn't effective for detention cases because they stayed in jail while that whole process is going on. And really the issue is: should the person be detained, not whether or not it was reasonable." (Dora, 2017, January 26)

The process of judicial review is also costly, adding to the financial burden imposed on immigration detainees. According to Sid, it can reach up to five to six thousand dollars, which is usually paid out of pocket by clients because of minimal legal aid. He claims that beyond the substantive and procedural issues of judicial review, its cost is another reason why legal representatives typically refuse to apply for leave and instead use this money to offer a larger cash bond in the next detention review hearing, sharing:

"If it's a private client, then they have a choice... They [Legal Aid clients] don't usually have money. It's the bondsperson funding their immigration lawyer. The JR [judicial review] is gonna cost five or six grand so wouldn't it be better to put six more thousand dollars in terms of a stronger cash bond? So because of that and JRs can take a while unless you have a lawyer who knows how to do an expedited motion and all this stuff... So most people don't do JRs and most people don't want to pay money for a JR when the only thing that a judge is gonna say is: Well, you have to come back for another decision. It's not like the JR is gonna get them released. They're still gonna have to have another detention review anyways." (Sid, 2017, February 16)

Due to its high cost, Petra agrees that representation in this process is difficult to do on a Legal Aid certificate, which can only be acknowledged by lawyers on LAO's Refugee and Immigration Appellate Panel. She more specifically states that, "it's the kind of work that has to be done pro bono because you're not gonna get funding for it in time from 
Legal Aid. And most of the time, clients don't have resources. That's another issue as well. The cost of litigation is expensive." (Petra, 2017, February 14). Because of these substantive, procedural, and financial issues associated with judicial review at the Federal Court, legal counsel prefer not to file for leave and alternatively wait for the next hearing with a stronger release plan. This highlights another access to justice problem in the Canadian immigration detention system.

With severely limited access to justice in detention review hearings and judicial reviews at the Federal Court, immigration detainees continue to be held indefinitely in IHCs and provincial prisons across the country, signalling the desperate need for new legal remedies. For 2016-2017, the CBSA reports that noncitizens spent an average of 19.5 days in detention (CBSA, 2018a); however, absent a presumptive period in Canadian legislation, noncitizens can still spend years in administrative confinement. Seeking to fight against indefinite detention, immigration detainees and their legal representatives argued for the right to habeas corpus relief at the Ontario provincial courts, which they successfully won in Chaudhary $v$ Canada (Public Safety and Emergency Preparedness), 2015 ONCA 700. More specifically, the Ontario Superior Court of Appeal affirmed that immigration detainees have the right to challenge their unlawful detention at the provincial courts, which is incredibly important as it can lead to release from detention rather than a mere review of ID board members' decisions. It also recognized the shift in evidentiary burden resulting from the (mis)interpretation of the "clear and compelling reasons" test. Although this decision is limited to detainees in Ontario and still imposes the financial burden of legal proceedings, it nonetheless provides more access to justice than was previously available. 
Beyond this victory however, it does not seem legislative changes will be implemented any time soon with regards to setting a time limit to immigration detention. The Federal Court of Canada recently ruled that the government's practice is constitutional and does not violate the Canadian Charter of Rights and Freedoms. Justice Simon Fothergill maintained that the onus is always on the Minister, reversing the evidentiary burden "is a problem of maladministration, not an indication that the statutory scheme is itself unconstitutional" (Brown v Canada (Attorney General), 2017 ONSC 251, para. 120). Although this decision brings into question ID board members' decisionmaking practices, it nonetheless maintains the status quo of indefinite detention without the incorporation of a presumptive period in Canadian legislation. For its part, the IRB has announced it will be reviewing its detention review practices (IRB 2018c; Loriggio, 2017 August 17).

\subsection{Discretion as a "Powerful Form of Government"}

In seeking to explain the perceived arbitrariness of ID members' decision-making process, Dora points to the lack of legal structure in detention reviews and in the immigration detention system more generally:

"The other thing that you should just keep in mind too that's part of this is the fact that there isn't any legal structure for it. The Immigration Act says detain - that they have the power to detain but there's no corrections act in terms of what the standards are for detaining people so when they're in the provincial facilities, they're subject to the provincial rules which is criminal, not immigration, not administrative. And when they're held at Rexdale or at the federal immigration holding centres, there's no rules at all. There's no statutory structure. There's nothing. It's completely lawless. And that's one of the big problems..." (Dora, 2017, January 26) 
Although the IRB provides guidelines to board members, there continues to be a lot of space for discretion that leads to inconsistencies and seemingly arbitrary decisions. Importantly, Dora's argument introduces the greater debate between the rule of law and discretion, which Pratt (2005) refers to as a "zero-sum game" (p. 54). Legal theory has historically perceived the two as "discrete and distinct entities that are negatively correlated in much the same way as liberty/authority and freedom/security: more of one means less of the other" (p. 54). When discretion is seen to lead to unfair decisions, the rigid law is oftentimes perceived as the only solution. Pratt (2005) argues, however, that such a response does not guarantee access to justice and only ignores how discretion is in fact a "powerful form of governance" (p. 53). Its incorporation in the decision-making process deceives immigration detainees into believing that their individual circumstances are given consideration when in reality, their identities and actions are being governed. The National Post reported that ID board members' caseload has declined in recent years; they conducted 12154 hearings in 2013, which went down to 9023 in 2016 (Humphreys, 2017, March 7). Although the release rates have increased from 15 percent in 2013 to 20 percent in 2016, the likelihood of release still very much depends on the location of individual adjudicators as previously argued in reference to regional IRB release rates (Humphreys, 2017, March 7). To some extent, discretion imagines greater access to justice where adjudicators can exercise reasonable compassion; however, it continues to be about controlling immigration detainees.

In analyzing these inconsistencies founded on discretionary powers, I return to the highly securitized political context within which this immigration control plays out. This was interestingly alluded to by Dora, who associated the problematic decision-making 
process of board members with the Conservative government of Stephen Harper. She argues that as public servants, it is possible these adjudicators were negatively influenced by the anti-immigrant sentiment of the federal government:

"And then we had a government that was very anti-immigrant for the last ten years. What was interesting is it shows that you don't have to change the law to effect a change in policy. You probably have access to the statistics 'cause I don't have them here but the detention rate went way up... under the Harper government without changing the legislation at all. It was just the tone and the message the government was sending to the civil service. And what I found appalling through that whole ten years experience was how the civil service caved. They just caved in and became horrible when they didn't used to be." (Dora, 2017, January 26)

Remaining cautious, I reiterate that although the population of immigration detainees reached its peak in 2008 under the Conservatives, it has been on a decline since then; the increase also began in 2004 under the Liberals (Nakache, 2011: 41). Again, there are gaps in statistical data that prevent a more in-depth analysis of this relationship and as I have argued in the previous chapter, bipartisan politics provide an inadequate explanation to detainees' limited access to justice and immigration control more generally. This is to say that the Canadian government, under both the Liberals and Conservatives, has been involved in securitizing migration and detaining racialized detainees throughout history. I am reminded that the IRPA and IRPR received Royal Assent under the Liberals' leadership in 2001 with Former Immigration Minister Elinor Caplan constructing two types of refugees: the deserving asylum seeker waiting for her turn to enter the nation state, and the undeserving refugee claimant, who spontaneously arrives on Canadian territory. It is also important to note here that these laws were in the works well before 9/11, which suggests the Liberal government already had plans for more restrictive border controls prior to the commencement of the global war on terror (Pratt, 2005). 
Certainly Harper's Conservative government also made rampant changes to border enforcement and immigration control. Specifically in regards to immigration detention, the Conservatives implemented mandatory administrative confinement by passing Bill C-31, Protecting Canada's Immigration System Act, in 2012. This was in response to the boat arrivals of MV Ocean Lady carrying 492 Tamils and MV Sun Sea with 76 Sri Lankans on board; they arrived on the coast of Vancouver Island in October 2009 and August 2010, respectively. Bill C-31 introduced new provisions allowing the Minister of Public Safety to name any group of noncitizens aged 16 or older as "designated foreign nationals" (DFN) and order their mandatory detention if there is insufficient time to examine their identities or if there are grounds to believe they were assisted by human smugglers. With this designation, Cleveland (2015) argues "Continued detention is the rule, and release the exception" as DFNs only have two weeks to prove their identity and if unsuccessful, they do not have access to a review for another six months during which they remain in detention (p. 82). If their asylum application is refused, there is no appeal process and they will be removed immediately. When working within a political context that institutes the mandatory detention of noncitizens, it is possible for ID board members to be less inclined to release racialized detainees, whose existence has been re-imagined as a threat to national security.

As this chapter demonstrates, immigration detainees are made to fail in detention review hearings where the evidentiary burden is shifted upon them, forcing them to prove grounds for detention no longer exist. My respondents argued that this is the result of a (mis)interpretation in jurisprudence where ID board members are required to provide "clear and compelling reasons" when departing from previous decisions. The result is 
that immigration detainees are indefinitely detained in holding centres and provincial prisons. Apart from detention reviews, they have few legal remedies such that judicial review at the Federal Court is substantively and procedurally inefficient, whereas habeas corpus is limited to those in Ontario. Finally, this chapter also analyzed adjudicators' discretionary powers and their inconsistent decision-making within the context of the increasing securitization of migration, which can influence their rulings on racialized noncitizens. 


\section{CHAPTER 6. CONCLUSION}

One of the motivations for this thesis is my personal interest in exploring the intersections between critical criminology, and citizenship and immigration studies. I wanted to understand the daily experiences of individuals with precarious statuses, seeking to listen to their voices and hoping others might hear them too. With the increasing invisibility of detainees however, it was also extremely helpful to speak to immigration and refugee lawyers to explore the immigration detention system from their perspective. My thesis was further inspired by the resistance of approximately 50 immigration detainees, who initiated a hunger strike in July 2016 to protest their indefinite detention in Ontario maximum security prisons. Their actions resulted in the investment of \$138-million, which will be allocated to alternatives to detention and the expansion of IHCs. Yet the federal government steadfastly continues to ignore their plea for a presumptive period without the implementation of a time limit in administrative confinement. It is within this context that I follow other scholars in opening the "black box" of immigration detention and exploring the Canadian system's treatment of noncitizens (Markowitz, 2009: 558; Silverman \& Molnar, 2016).

My thesis has importantly found that immigration detainees have extremely limited access to justice due to barriers in seeking legal representation with inadequate legal aid funding while being detained in far-flung institutions, and trying to meet the tight timelines of detention review hearings. These challenges are further exacerbated by ID board members' (mis)interpretation of jurisprudence, which shifts the onus on detainees to prove that grounds for continued detention no longer exist. My analysis documents how the limited access to justice occurs for racialized migrants from the 
global South, consistent with the racial hierarchies that have characterized nationbuilding within Canada's colonial past and its incessant reproduction of white settler mentalities. These individuals have also been re-imagined as threats consistent with the rise of Islamophobia and with the increasing political securitization of migration, enabling the nation state to reaffirm sovereign power and adopt restrictive border controls. This closing chapter will continue to summarize key findings of this thesis, demonstrating its sociological contributions to academic literature. It will also elaborate upon study limitations, provide suggestions for future research, and challenge the continued use of immigration detention.

\subsection{Summary of Sociological Contributions}

Success in detention review hearings is partially determined by legal representation; however, immigration detainees are not consistently informed of their right to counsel, as well as the reasons for their confinement. Even when they are, it is difficult to access lawyers while detained in securitized settings where telephone communication is limited; this issue also intersects with inadequate legal aid funding and language barriers as most detainees, particularly those from the Global South, do not speak either of the official languages. The current system is built upon and continues to operate on ensuring the failure of noncitizens whose access to justice is severely limited (Silverman \& Molnar, 2016). As Pratt (2005) finds, IHCs inflict a "distinctly carceral experience," mimicking punitive spaces of the criminal justice system (p. 28). With only three of these institutions across the nation, the federal government facilitated an even greater overlap by contracting provincial prisons to hold immigration detainees, which 
reduced legal counsel's access to their clients. This is exemplified in the Ottawa case where noncitizens do not benefit from a separate holding centre and are confined in the province-run OCDC. Some lawyers share their often frustratingly long delays to meet their clients as it can take up to several weeks to schedule professional visits. They hypothesize this is likely the consequence of OCDC serving both immigration and criminal populations. Although such statements might suggest the need for an IHC in Ottawa, this thesis should not be read as an encouragement for expanding detention spaces which in themselves cause pain and suffering (see Gros \& Song, 2016; Kronick, Rousseau \& Cleveland, 2015; Gros \& van Groll, 2015; Cleveland \& Rousseau, 2013; Cleveland, Rousseau, \& Kronick, 2012; Pratt, 2005). Experiences of Toronto lawyers also serve as evidence of the Canadian state's persistent use of provincial prisons despite the TIHC's existence, nullifying the idea that constructing new spaces might be the correct response.

Beyond delays in professional visits, legal counsel must also overcome other institutional barriers caused by the federal government's use of provincial institutions. Toronto lawyers often need to travel several hours outside of the city centre, which does not necessarily guarantee a face-to-face meeting with their clients. Ontario jails have been notorious for its practice of institutional lockdowns to manage staff shortage (Robin, 2017 February 15; White, 2016 March 8; Robinson, 2016 January 9). Respondents recalled instances during which they would arrive at the prison only to discover that a lockdown was in effect, leading to the cancellation of visitation hours and detention reviews. These lockdowns have also resulted in inhumane conditions for immigration detainees, who are restricted to their cells without access to yard time and telephones. It 
is in reflecting upon these conditions that Dora criticizes the detention system for its intense cruelty towards imprisoned populations. These issues of access nonetheless force legal counsel to adopt diverse strategies to ensure they can meet their client. A few participants formed friendly relationships with prison staff members, who play the gatekeeper role in jails. Some also visited during regular visiting hours, requested time with clients prior to the detention review, and/or collaborated with family members to obtain case information.

Legal counsel necessarily need to adopt these strategies to ensure access to clients as the first hearing is conducted within 48 hours of detention. Although this short time period ensures noncitizens have an immediately-available legal avenue through which they can challenge their detention, it presents difficulties for case preparation, particularly if Legal Aid is involved. Participants expressed they are often required to put a pause on all of their other tasks once they are retained for a detention review because of how quickly it approaches. They need to prepare a release plan that generally includes securing a bondsperson, who have the financial capacity to pay a cash or performance bond. Seeking this person can be very time-consuming and highly depends on their clients' support networks. It is insufficient, however, to simply prepare a release plan within 48 hours. Lawyers must organize them in a way that convinces the presiding board member to order release. Because of the way in which jurisprudence has been (mis)interpreted in this quasi-judicial context, it is extremely difficult to overcome a negative decision in a subsequent hearing. Succeeding in the 48-hour detention review, therefore, becomes key to ending an immigration detainee's deprivation of liberty at the earliest possibility. The exploration of these barriers provide further evidence supporting 
the conclusions of Silverman and Molnar (2016) "that factors that impede access to justice for immigration detainees in Canada are interdependent, self-reinforcing, and prone to snowballing to a level that disrupts a detainee's access to justice" (p. 125).

Another set of barriers in the Canadian immigration detention system presents itself in the quasi-judicial proceedings of detention review hearings. Respondents expressed concern over the problematic shift of evidentiary burden on to immigration detainees in cases where previous decisions have been negative. They suggest it comes from a misinterpretation of the Thanabalasingham case where the Federal Court of Appeal ruled that ID board members must show deference to earlier decisions and provide "clear and compelling reasons" if departing from them (Canada (Minister of Citizenship and Immigration) v Thanabalasingham, [2004] 3 FCR 572, 2004 FCA 4, para. 10). With the Minister's counsel being able to reference previous grounds for continued detention, the onus is transferred on to immigration detainees and their legal counsel to prove such grounds no longer exist, requiring them to present new evidence and arguments. Their inability to carry this burden, however, has the deleterious consequence of prolonged deprivation of liberty without the guarantee of a presumptive period in Canadian legislation. Much like their negotiation of access to clients, lawyers must employ different strategies to challenge the rubber stamp of continued detention, particularly by organizing and presenting a release plan that addresses board members' concerns; however, they also share the frustrations of inconsistent decision-making among adjudicators whose verdicts seem to be based on emotions and lack logical reasoning. This is consistent with Rehaag's (2008) study on the variance in IRB refugee 
grant rates, and Humphreys' (2017, March 7) report on the inconsistencies of ID board members' release rates based on their geographical location.

This thesis' greatest sociological contribution lies in its analysis of the limited access to justice in detention review hearings as it relates to the precarious status of noncitizens and the multiple powers involved in their governance. To some degree, the findings on barriers to legal representation are not new in that they are also faced by criminal lawyers retained for bail hearings (Deshman \& Myers: 2014); however, the most significant difference lies in the citizenship status of the detained individuals with immigration detainees existing at different points on the spectrum of non-citizenship. Some are permanent residents, who have lived in Canada for a long time, lose their residency status, and are deemed criminally inadmissible after being convicted of certain wrongdoings. Others include foreign temporary workers or international students, who have violated their visa terms. Approximately half are asylum seekers awaiting first examination or whose applications have been denied by the RPD. Disturbingly, some of those who are incarcerated, with family members or on their own, are children. My thesis does not negate the challenges faced by criminal populations, but it contributes to the 'crimmigration' literature, which reveals how noncitizens whose only 'crime' is to lack official status in Canada are criminalized and treated in similar punitive ways. Importantly, my research demonstrates that the inequalities embedded in the detention system are necessarily about drawing boundaries between deserving members and underserving outsiders for the protection of the sovereign state. This is a continuation of the nation state's historical past as a white settler colony throughout which the state's gatekeepers have sought to reject racialized noncitizens. Various governments, 
irrespective of the political party in power, achieve this by reconstructing this population into threats to national security - presumably as threats to 'legitimate,' 'law-abiding' citizens and immigrants, who had sought entry into Canada through the 'front door', thus justifying greater restrictive immigration and border controls.

\subsection{Limitations and Future Research}

My methodological orientation of interpretive research does not require a specific number of participants and in fact opposes "the language of sampling," but interviewing more immigration and refugee lawyers could have strengthened this thesis, allowing for different kinds of analyses to be conducted (Schwartz-Shea \& Yanow, 2012: 87). First, most of my study's lawyer respondents represented clients held in provincial prisons with only about two having had experience in dealing with the TIHC. This still allowed me to explore and discover barriers to legal representation, but with a narrower focus on immigration detainees in Ontario jails. This is perhaps to be expected because of my own geographical location and resource limitations. As an Ottawa resident, it was much easier to access lawyers working with clients held in OCDC, which is the only institution in the capital city where noncitizens are confined. Similarly, participants from Toronto also represented clients in provincial prisons. Although I did not explicitly intend to examine access to justice of detainees in the TIHC and Ontario jails, having a more diverse group of participants with varying experiences with both types of institutions would have facilitated and allowed for a comparative analysis. For example, it seems lawyers have greater access to clients in the holding centre as suggested by Faye. She would sometimes leave messages for her clients, who were often given more flexibility with their use of 
telephones. This would have likely affected her capacity to prepare for the case and perhaps increase her client's chance for release. With my limited scope, I was only able to interview legal counsel from Ottawa and Toronto; however, immigration detention is a nation-wide practice, which means lawyers from other parts of Canada may have a different perspective on accessing clients in IHCs or provincial prisons, and overall legal representation in detention review hearings.

Relatedly, although my thesis argues that legal representation can mitigate access to justice issues, it assumes that all immigration and refugee lawyers always provide high quality services to their clients. This point importantly acknowledges there are inconsistencies in representatives' practices as well. I briefly mentioned that some participants were less inclined to question board members' decisions and while this may be due to other factors like the limitations of legal aid and the hopelessness of judicial review, it brings attention to the possibility of poor representation in the immigration context (see Keung, 2015 April 20). In saying this, I do not refer to specific respondents whatsoever, but rather, address the potential reality of poor or even malicious activities by members of the legal community that were not taken into consideration in this thesis. This was additionally alluded to by one participant who said, "[T]here are lawyers and consultants out there that literally scam the system so people are wary about that as well." We did not discuss his point in greater depth, but this highlights that while legal representation can have a positive incredible impact, it also depends on the specific lawyer retained along with all of the barriers in accessing justice in the immigration detention system. 
In highlighting the decision-making process of ID board members, I recognize that all findings reported in this thesis were based on interviews with lawyers and former immigration detainees, and observations of detention review hearings. These data sources were extremely important in allowing me to understand the IRB's quasi-judicial proceedings, providing answers to my overarching research question. It would have been interesting nonetheless to speak to the Board's independent adjudicators in order to understand their thought processes and use of discretionary powers. This may importantly illuminate the perceived (mis)interpretation of the "clear and compelling reasons" test, which shifted the evidentiary burden on to immigration detainees and often resulted in the rubber stamp of continued detention. In addition, I also recognize that ID board members are but one of the groups involved in governing noncitizens. There are other actors whose roles and actions within this immigration context warrant greater attention than was possible in this thesis, including CBSA hearings officers, who act on behalf of the federal government in detention review hearings. Participating lawyers also shared experiences in which they were able to negotiate and co-operate with the Minister's counsel to arrange their client's release. Examining this dynamic could be a great contribution to academic literature.

Most importantly, I continue to insist on the need to understand the lived experience of immigration detainees whether this be about their deprivation of liberty in IHCs and provincial prisons, or their struggle in detention review hearings. Interdisciplinary scholars have also called attention to this issue, citing limited research on the lived experience of detainees (Bhui, 2013; Bosworth, 2014). This is exemplified in the Canadian context where previous scholarship has mostly focused on asylum seekers 
(Goettl \& Jeanes, 2015; Pratt, 2005), their mental health (Cleveland, Rousseau, \& Kronick, 2012; Cleveland \& Rousseau, 2013; Gros \& van Groll, 2015), and the consequences of detaining asylum-seeking children (Gros \& Song, 2016; Kronick, Rousseau, \& Cleveland, 2015). The category of immigration detainees, however, is much more heterogeneous with multiple and varying identities, pointing to the potential gaps in our knowledge. For this thesis, despite all of my efforts in seeking out participants, I was only able to speak to two former detainees, which shifted my research question towards access to justice in the review process. I sincerely hope, however, that my experiences as a novice researcher in ultimately failing to access this vulnerable population can be used as learning lessons for future research. Undertaking such a research project may take more time as it requires building relationships, but it is only in listening to the voices of noncitizens with precarious statuses that we can understand the lived experience and human impact of the Canadian state's immigration detention practices.

\subsection{Potential for Undoing Injustice}

I urge the Canadian government to implement a presumptive period in immigration law and end its practice of indefinitely detaining immigration detainees. Although statutory detention review hearings are supposed to act as a means through which release can be secured, this thesis demonstrates there are various intersecting and compounding barriers that limit noncitizens' access to justice through these quasi-judicial proceedings, leading to prolonged deprivations of liberty. The CBSA reported that the average number of detention days in 2016-2017 is 19.5 days; however, it also held 439 noncitizens for more than 90 days in the same time frame (CBSA, 2018a). Although 
these long-term detainees account for $7 \%$ of the total 6,251 people in immigration detention, it is nonetheless important for the federal government to adopt a time limit considering the documented physical and mental health impact of administrative confinement (Gros \& van Groll, 2015). I more specifically call to them to heed the warning forwarded by activists, advocates and scholars, and enact a 90-day presumptive period in the Canadian immigration detention system (Hussan, 2014).

In August 2016, Minister of Public Safety Ralph Goodale announced the NIDF with plans "to create a better, fairer immigration detention system that supports the humane and dignified treatment of individuals while protecting public safety" (CBSA, 2018c). Although the federal government intends to invest some of its \$138-million budget in alternatives to detention, it also seeks to expand the carceral spaces of IHCs. I argue this is extremely counterproductive as the former proposes release to non-carceral environments while the latter constructs more securitized institutions for immigration hold. Couched in the language of ensuring the "well-being of detainees" and reduced reliance on provincial prisons, there is little consideration that IHCs in themselves produce a "distinctly carceral experience" with evidence of severe effects on the physical and mental health of detained noncitizens (Pratt, 2005: 28; Cleveland \& Rousseau, 2013; Cleveland, Rousseau, \& Kronick, 2012). In the absence of more transparent updates from the CBSA, it is unclear how much will be invested in both infrastructure and alternatives; however, I strongly contend that public money be spent on the latter in favour of releasing noncitizens into the community.

I further encourage the Canadian government to review its use of the TBP, which is one of the few alternatives currently available to immigration detainees. Although 
participating lawyers acknowledged how it can be helpful in securing release, they also pointed to the issues of long delays prior to program acceptance, conflict of interest with CBSA as the funding agency, and lack of availability in other parts of the country. Elsewhere, the CCR also raised its concern about the TBP's design based on the criminal justice system model, which can potentially perpetuate the discursive construction of racialized noncitizens into criminal foreigners and justify the expanding securitization of migration (2015, January). It unfortunately seems, however, that the national framework on Alternatives to Detention (ATD) being developed by the CBSA relies on similar processes as the TBP. The federal department reported it plans to implement a Community Case Management and Supervision (CCMS) program, a voice reporting system, and the use of electronic supervision technologies - all of which are used in the criminal justice system (CBSA, 2018c). To prevent the greater criminalization of noncitizens, organizations and scholars have called for alternatives "premised on the inherent difference" between immigration detainees and criminal populations with suggestions like minimizing enforcement, and providing access to transportation, translation and interpretation services and healthcare (Gros \& van Groll, 2015: 9; CCR, 2015 January).

Importantly, other activists and advocates argue that alternatives to detention have little value, pushing instead for the abolition of the Canadian immigration detention system. The End Immigration Detention Network (EIDN), a Toronto-based coalition of immigration detainees and community allies, particularly takes this position despite forwarding several short-term demands, such as the implementation of a 90-day presumptive period and changes to the adjudication process. As the group clearly 
articulates in their 2014 report, "There is no reform or rehabilitation in immigration detention. It must end." (Hussan, 2014: 4). Reflecting upon this, it is perhaps in abolishing the Canadian state's practice of administrative confinement that we can truly begin to recognize immigration detainees, who have been rendered invisible for so long. It is here that I end my thesis with a challenging thought from Chak (2014: 31), who reminds us about the great possibility of undoing the wrongs, harms, and injustices of immigration detention:

So how do remove the elements of distinction, challenge the integrity of the wall, how do we make the borders disappear?

Mass incarceration is a modern idea. We can unlearn and re-imagine, and design a world without prisons. 


\section{Footnotes}

1. Habeas corpus, the Latin translation for "that you have the body," is a fundamental right enshrined in section 10(c) of the Canadian Charter of Rights and Freedoms, which states: "Everyone has the right on arrest or detention to have the validity of the detention determined by way of habeas corpus and to be released if the detention is not lawful." It allows individuals to challenge their unlawful detention imposed by the government and to be released following a positive determination.

2. In November 2017, the Australian government stopped funding the detention centre on Manus Island, Papua New Guinea in an effort to shut down the facility. When asylum seekers protested against this closure, Papua New Guinea police forcibly removed and transferred them to other local facilities (Amnesty International, 2017, February 1).

3. In August 2016, Public Safety Canada launched the National Immigration Detention Framework (NIDF) to increase alternatives to detention and expand detention infrastructure. This involves an estimated $\$ 138$ million investment, which will be partially allocated to renovating the Toronto Immigration Holding Centre, repurposing a former RCMP property to replace the Vancouver facility, and constructing a new institution to replace the current Laval holding centre (CBSA, 2018c).

4. Former prisoners, Mark Zuccala and Jude Joseph, who were incarcerated in the Ottawa-Carleton Detention (OCDC), launched one of the class-action lawsuits currently faced by the Ontario government. They are suing the province for inhumane treatment suffered during their incarceration, which includes overcrowding and frequent institutional lockdowns. The have also invited other prisoners to join their case, which will be represented by the law firm of Paul Champ (Seymour, 2016, May 25).

5. In reiterating this point, I do not mean to discount the differential treatment of certain categories of the criminal population based on the intersections of race, gender, and class. My only intention here is to comment on the difference in rightlessness between prisoners and immigration detainees. Comparing how these intersections figure on these two groups would require greater analysis beyond the scope of my thesis. 


\section{References}

Abu-Laban, Y. (2014). Citizenship and Foreignness in Canada. In E.F. Isin \& P. Nyers (Eds.), Routledge Handbook of Global Citizenship Studies (pp. 274-283). New York: Routledge.

Ali v Canada (Attorney General), 2017 ONSC 2660

Aliverti, A. (2012). Making People Criminal: The Role of the Criminal Law in Immigration Enforcement. Theoretical Criminology, 16(4), 417-434.

Amnesty International. (2018, February 1). Manus Island: Australia Abandons Refugees to a Life of Uncertainty and Peril. Retrieved from https://www.amnesty.org/en/latest/news/2018/02/manus-island-australiaabandons-refugees-to-a-life-of-uncertainty-and-peril/

Arendt, H. (1958). The Origins of Totalitarianism. Cleveland: Meridian Books.

Ball, D.P. (2012, June 27). Immigration Minister Jason Kenney Besieged by Critics During BC Visit [Web log post]. Retrieved from https://thetyee.ca/Blogs/ TheHook/Federal-Politics/2012/06/27/jason-kenney-critics-visit/

Bashford, A. \& Strange, C. (2002). Asylum-Seekers and National Histories of Detention. Australian Journal of Politics and History, 48(2), 509-527.

Bellemare, A. (2017, August, 22). Refugee Approval Rates Reflect Subjectivity of Decision-Makers, Prof Says. CBC News. Retrieved from http://www.cbc.ca/

Bhui, H.S. (2013). Introduction: Humanizing Migration Control and Detention. In K.F. Aas \& M. Bosworth (Eds.), The Borders of Punishment: Migration, Citizenship, and Social Exclusion (pp. 1-17). Oxford: Oxford University Press.

Black, D. (2015, August 22). Canada Border Services Agency Confirms Identity for 'Man with No Name'. The Toronto Star. Retrieved from https://www.thestar.com/

Bosniak, L. (2005). Citizenship. In P. Cane \& M. Tushnet (Eds.), The Oxford Handbook of Legal Studies (pp. 183-201). Oxford: Oxford University Press.

Bosworth, M. (2014). Inside Immigration Detention. Oxford: Oxford University Press.

Bosworth, M. \& Turnbull, S. (2014). Immigration Detention, Punishment, and the Criminalization of Migration. In S. Pickering \& J. Hamm (Eds.), The Routledge Handbook on Crime and International Migration (pp. 91-106). New York: Routledge. 
Braun, V. \& Clarke, V. (2006). Using Thematic Analysis in Psychology. Qualitative Research in Psychology, 3(2), 77-101.

Brodie, J. (2002). Three Stories of Canadian Citizenship. In R. Adamoski, D.E. Chunn, \& R. Menzies (Eds.), Contesting Canadian Citizenship: Historical Readings (pp. 43-66). Peterborough: Broadview Press.

Brown v Canada (Citizenship and Immigration), 2017 FC 710.

Browne, B.C. (2013). Recording the Personal: The Benefits in Maintaining Research Diaries for Documenting the Emotional and Practical Challenges of Fieldwork in Unfamiliar Settings. International Journal of Qualitative Methods, 12(1), 420435.

Canada Border Services Agency. (2017). Arrests, Detentions and Removals. Retrieved from https://www.cbsa-asfc.gc.ca/security-securite/arr-det-eng.html

Canada Border Services Agency. (2018a). Annual Detention Statistics - 2012-2017. Retrieved from https://www.cbsa-asfc.gc.ca/security-securite/detent/stat-20122017-eng.html

Canada Border Services Agency. (2018b). Detentions. Retrieved from https://www.cbsaasfc.gc.ca/security-securite/detent/menu-eng.html

Canada Border Services Agency. (2018c). National Immigration Detention Framework. Retrieved from https://www.cbsa-asfc.gc.ca/security-securite/detent/nidf-cndieng.html

Canadian Broadcasting Corporation. (2015, August 31). Ottawa Courthouse Using Metal Detectors, Screening as of Monday. $C B C$ News. Retrieved from http://www.cbc.ca/

Canadian Council for Refugees. (2015). Alternatives to Detention: CCR Comments Regarding the Toronto Bail Program. Retrieved from http://ccrweb.ca/en/alternatives-detention-comments-toronto-bail-program

Canada (Minister of Citizenship and Immigration) v Thanabalasingham, [2004] 3 FCR 572, 2004 FCA 4

Chacón, J. (2012). Overcriminalizing Immigration. The Journal of Criminal Law \& Criminology, 102(3), 613-652.

Chak, T. (2014). Undocumented: The Architecture of Migrant Detention. Montreal: The Architecture Observer. 
Chan, W. (2005). Crime, Deportation, and the Regulation of Immigrants in Canada. Crime, Law \& Social Change, 44(2), 153-180.

Chaudhary v Canada (Public Safety and Emergency Preparedness), 2015 ONCA 700.

Choudry, A. \& Smith, A.A. (2016). Unfree Labour? Struggles of Migrants and Immigrant Workers in Canada. Oakland: PM Press.

Cleveland, J. \& Rousseau, C. (2013). Psychiatric Symptoms Associated with Brief Detention of Adult Asylum Seekers in Canada. Canadian Journal of Psychiatry, $58(7), 409-416$.

Cleveland, J., Rousseau, C., \& Kronick, K. (2012). The Harmful Effects of Detention and Family Separation on Asylum Seekers' Mental Health in the Context of Bill C-31. Retrieved from the Centre de santé et de services sociaux de la Montagne website: https://www.csssdelamontagne.qc.ca/fileadmin/csss_dlm/Publications/Publication s_CRF/brief_c31_final.pdf

Cleveland, J. (2015). Not So Short and Sweet: Immigration Detention in Canada. In A. Nethery \& S.J. Silverman (Eds.), Immigration Detention: The Migration of a Policy and Its Human Impact (pp. 79-87). New York: Routledge.

Colaiacovo, I. (2013). Not Just the Facts: Adjudicator Bias and Decisions of the Immigration and Refugee Board of Canada (2006-2011). Journal on Migration and Human Security, 1(4), 122-147.

Coulthard, G.S. (2014). Red Skins, White Masks: Rejecting the Colonial Politics of Recognition. Minneapolis: University of Minnesota Press.

Dauvergne, C. (2007). Security and Migration Law in the Less Brave New World. Social \& Legal Studies, 16(4), 533-549.

Dauvergne, C. (2008). Making People Illegal: What Globalization Means for Migration and Law. New York: Cambridge University Press.

Dawson, C. (2014). Refugee Hotels: The Discourses of Hospitality and The Rise of Immigration Detention in Canada. University of Toronto Quarterly, 83(4), 826-846.

Dawson, C. (2016). In Plain Sight: Documenting Immigration Detention in Canada. Migration, Mobility, \& Displacement, 2(2), 126-140.

Deshman, A. \& Myers, N. (2014). Set Up To Fail: Bail and the Revolving Door of PreTrail Detention. Retrieved from the Canadian Civil Liberties Association website: https://ccla.org/cclanewsite/wp-content/uploads/2015/02/Set-up-to-failFINAL.pdf 
Dhamoon, R. \& Abu-Laban, Y. (2009). Dangerous (Internal) Foreigners and NationBuilding: The Case of Canada. International Political Science Review, 30(2), 163-183.

Diop, P.M. (2014). The "Bogus" Refugee: Roma Asylum Claimants and Discourses of Fraud in Canada's Bill C-31. Refuge, 30(1), 67-80.

End Immigration Detention Network. (2016, July 12). \#MigrantStrike Day 2 - More Detainees Join Strike, Goodale Brushes Them Off, then Lies [Web log post]. Retrieved from https://endimmigrationdetention.com/2016/07/12/migrantstrikeday-2-more-detainees-join-strike-goodale-brushes-them-off-then-lies/

End Immigration Detention Network. (2016, July 18). \#MigrantStrike - Week 1 Reportback [Web log post]. Retrieved from https://endimmigrationdetention.com/ 2016/07/18/migrantstrike-week-1-reportback/

End Immigration Detention Network. (2016, July 25). \#MigrantStrike Week \#2 Detainees Running Out of Time, CBSA Trying to Break the Strike [Web log post]. Retrieved from https://endimmigrationdetention.com/2016/07/25/ hungerstrikeweek2/

End Immigration Detention Network. (2017, May 15). Media Release: Federal Court Questions Border Enforcement on Constitutionality of Indefinite Detention [Web log post]. Retrieved from https:/endimmigrationdetention.com/2017/05/15/ media-release-federal-court-questions-border-enforcement-on-constitutionalityof-indefinite-detention/

Fedio, C. (2016, May 26). Former OCDC Inmates Launching Lawsuit Over 'Degrading Treatment,' Lawyer Says. CBC News. Retrieved from http://www.cbc.ca/

Fleay, C. \& Briskman, L. (2013). Hidden Men: Bearing Witness to Mandatory Detention in Australia. Refugee Survey Quarterly, 32(3), 112-129.

Foucault, M. (1977). Discipline and Punish: The Birth of the Prison. New York: Vintage Books.

Gair, S. (2012). Feeling Their Stories: Contemplating Empathy, Insider/Outsider Positionings, and Enriching Qualitative Research. Qualitative Health Research, 22(1), 134-143.

Gerard, A. \& Pickering, S. (2014). Crimmigration, Criminal Justice, Refugee Protection and the Securitisation of Migration. In B. Arrigo \& H. Bersot (Eds.), The Routledge Handbook of International Crime and Justice Studies (pp. 587-611). New York: Routledge. 
Gibney, M.J. (2008). Asylum and the Expansion of Deportation in the United Kingdom. Government and Opposition, 43(2), 146-167.

Global Detention Project. (2012, March). Canada Immigration Detention Profile [Web log post]. Retrieved from https://www.globaldetentionproject.org/ countries/americas/canada

Gobo, G. (2008). Doing Ethnography. London: Sage Publications Ltd.

Goettl, T. \& Jeanes, J. (2015). Detained in the New Refugee Determination System: Highlighting the Experiences of Detained Refugee Claimants. Retrieved from the Action Réfugiés Montréal website: http://www.actionr.org/documents/DetainedRefugee-System0315.pdf

Goldring, L, Berinstein, C., \& Bernhard, J.K. (2009). Institutionalizing Precarious Migratory Status in Canada. Citizenship Studies, 13(3), 239-265.

Goldring, L. \& Landolt, P. (2013). The Conditionality of Legal Status and Rights: Conceptualizing Precarious Non-Citizenship in Canada. In L. Goldring \& P. Landolt (Eds.), Producing and Negotiating Non-Citizenship: Precarious Legal Status in Canada (pp. 3-27). Toronto: University of Toronto Press.

Griffiths, M. (2012). Anonymous Aliens? Questions of Identification in the Detention and Deportation of Failed Asylum Seekers. Population, Space and Place, 18, 715-727.

Griffiths, M. (2013). Living with Uncertainty: Indefinite Immigration Detention. Journal of Legal Anthropology, 1(3). 263-286.

Griffiths, M. (2014). Out of Time: The Temporal Uncertainties of Refused Asylum Seekers and Immigration Detainees. Journal of Ethnic and Migration Studies, 40(12), 1991-2009.

Griffiths, M. (2015). ‘A Proud Tradition'? Immigration Detention in the United Kingdom. In A. Nethery \& S.J. Silverman (Eds.), Immigration Detention: The Migration of a Policy and Its Human Impact (pp. 13-21). New York: Routledge.

Gros, H. \& Song, Y. (2016). "No Life for a Child": A Roadmap to End Immigration Detention of Children and Family Separation. Retrieved from the University of Toronto, International Human Rights Program website: https://ihrp.law.utoronto.ca/utfl_file/count/PUBLICATIONS/ReportNoLifeForAChild.pdf

Gros, H. \& van Groll, P. (2015). “We Have No Rights”: Arbitrary Imprisonment and Cruel Treatment of Migrants with Mental Health Issues in Canada. Retrieved from the University of Toronto, International Human Rights Program website: 
https://tspace.library.utoronto.ca/bitstream/1807/80128/1/Gros\%20and\%20Groll_ 2015_\%20We\%20Have $\% 20$ No\%20Rights.pdf

Haas, B.M. (2017). Citizens-in-Waiting, Deportees-in-Waiting: Power, Temporality, and Suffering in the U.S. Asylum System. ETHOS, 45(1), 75-97.

Hernández, C.C.G. (2014). Invisible Spaces and Invisible Lives in Immigration Detention. Howard Law Journal, 57(3), 869-898.

Hernández, D.M. (2013). Pursuant to Deportation: Latinos and Immigrant Detention. In J.A. Dowling \& J.X. Inda (Eds.), Governing Immigration Through Crime: A Reader (pp. 199-215). Stanford: Stanford University Press.

House of Commons. (2001, February 26). 37th Parliament, 1st Session. Retrieved from http://www.ourcommons.ca/DocumentViewer/en/37-1/house/sitting-21/hansard

Humphreys, A. (2017, March 7). Immigration and Refugee Board in Ontario Less Likely to Release Detainees than in Rest of Canada: Analysis. The National Post. Retrieved from http://nationalpost.com/

Hussan, K. (2014). Indefinite, Arbitrary and Unfair: The Truth About Immigration Detention in Canada. Retrieved from http://www.truthaboutdetention.com

Immigration and Refugee Board of Canada. (2003). Guide to Proceedings Before the Immigration Division. Retrieved from http://www.irb-cisr.gc.ca/Eng/BoaCom/ references/LegJur/Documents/GuideIdSi_e.pdf

Immigration and Refugee Board of Canada. (2018a). Grounds for Detention Reviews. Retrieved from http://www.irb-cisr.gc.ca/Eng/detention/stats/Pages/detenGr.aspx

Immigration and Refugee Board of Canada. (2018b). Refugee Protection Claims (New System) by Country of Alleged Persecution - 2017. Retrieved from http://www.irb-cisr.gc.ca/Eng/RefClaDem/stats/Pages/RPDStat2017.aspx

Immigration and Refugee Board of Canada. (2018c). Immigration and Refugee Board of Canada to Carry Out Audit of Long-Term Detention Reviews. Retrieved from http://www.irb-cisr.gc.ca/Eng/NewsNouv/NewNou/2017/Pages/aud-ver-det.aspx

Immigration, Refugees, and Citizenship Canada. (2015). Enforcement Manual (ENF-20) Detention. Retrieved from http://www.cic.gc.ca/english/resources/ manuals/enf/enf20-eng.pdf

Inda, J.X. \& Dowling, J.A. (2013). Introduction: Governing Migrant Illegality. In J.A. Dowling \& J.X. Inda (Eds.), Governing Immigration Through Crime: A Reader (pp. 1-39). Stanford: Stanford University Press. 
Jakubowski, L.M. (1999). Immigration and the Legalization of Racism. Halifax: Fernwood Publishing.

Katzmann, R.A. (2008). The Legal Profession and the Unmet Needs of the Immigrant Poor. Georgetown Journal of Legal Ethics, 21(1), 3-30.

Kaufman, E. (2015). Hubs and Spokes: The Transformation of the British Prison. In K.F. Aas \& M. Bosworth (Eds.), The Borders of Punishment: Migration, Citizenship, and Social Exclusion (pp. 166-182). Oxford: Oxford University Press.

Kelley, N. \& Trebilcock, M. (2010). The Making of the Mosaic: A History of Canadian Immigration Policy (Second Edition). Toronto: University of Toronto Press.

Kennedy, B. (2017, March 17). Caged by Canada. The Toronto Star. Retrieved from http://www.thestar.com/

Kennedy, B. (2017, October 5). Maximum-Security Jail Ruled Unconstitutional in Immigration Detention Case. The Toronto Star. Retrieved from http://www.thestar.com/

Keung, N. (2015, April 20). Legal Aid Vows to 'Weed Out' Bad Refugee Lawyers. The Toronto Star. Retrieved from https://www.thestar.com/

Kronick, R., Rousseau, C., \& Cleveland, J. (2015). Asylum-Seeking Children's Experiences of Detention in Canada: A Qualitative Study. American Journal of Orthopsychiatry, 85(3), 287-294.

Larsen, M., Harkat, S., \& Harkat, M. (2008). Justice in tiers: security certificate detention in Canada. Journal of Prisoners on Prison, 17(2), 1-14.

Larsen, M. \& Piché, J. (2009). Exceptional state, pragmatic bureaucracy, and indefinite detention: the case of the Kingston Immigration Holding Centre. Canadian Journal of Law and Society, 24(2), 203-229.

Leerkes, A. \& Broeders, D. (2010). Deportable and Not So Deportable: Formal and Informal Functions of Administrative Immigration Detention. In B. Anderson, M.J. Gibney, \& E. Paoletti (Eds.), The Social, Political and Historical Contours of Deportation (pp. 79-104). New York: Springer.

Lenard, P.T. \& Straehle, C. (2012). Legislated Inequality: Temporary Labour Migration in Canada. Montreal: McGill-Queen's University Press.

Lenard, P.T. (2015, September 12). Stephen Harper's Abhorrent Record on Refugees and Immigration [Web log post]. Retrieved from http://www.broadbentinstitute.ca/ pattitamaralenard/harper_dimal_record_refugees_immigration 
Logan, N. (2015, August 25). 'Man with No Name' Detainee Deported from Canada: Source. Global News. Retrieved from https://globalnews.ca/

Loriggio, P. (2017, August 17). Immigration Board to Audit Long-Term Detention Process after 'Endless Circle of Mistakes'. $C B C$ News. Retrieved from http://www.cbc.ca/

Macklin, A. (2005). Disappearing Refugees: Reflections on the Canada-U.S. Safe Third Country Agreement. Columbia Human Rights Law Review, 36(365), 365-426.

Macklin, A. (2014). Citizenship Revocation, the Privilege to Have Rights and the Production of the Alien. Queen's Law Journal, 40(1), 1-54.

Majcher, I. \& de Senarcles, C. (2015). Discipline and Punish? Analysis of the Purposes of Immigration Detention in Europe. AmeriQuests, 11(2).

Mallick, H. (2012, December 14). Canada Puts Asylum Toddlers Behind Razor Wire. The Toronto Star. Retrieved from http://www.thestar.com/

Mann, A. (2009). Refugees who Arrive by Boat and Canada's Commitment to the Refugee Convention: A Discursive Analysis. Refuge, 26(2), 191-206.

Markowitz, P.L. (2009). Barriers to Representation for Detained Immigrants Facing Deportation: Varick Street Detention Facility, A Case Study. Fordham Law Review, 28, 541-575.

Martin, L.L. (2012). 'Catch and Remove': Detention, Deterrence, and Discipline in US Noncitizen Family Detention Practice. Geopolitics, 17(2), 312-334.

Martin, L.L. \& Mitchelson, M.L. (2009). Geographies of Detention and Imprisonment: Interrogating Spatial Practices of Confinement, Discipline, Law, and State Power. Geography Compass, 3(1), 459-477.

Mickleburgh, R. (2000, May 11). Canada Deports Chinese Migrants En Masse. The Globe and Mail. Retrieved from https://www.theglobeandmail.com/

Miller, T.A. (2003). Citizenship \& Severity: Recent Immigration Reforms and the New Penology. Georgetown Immigration Law Journal, 17(611), 611-666.

Molnar, P. \& Silverman, S.J. (2017, November 14). Migrants are Dying in Detention Centres: When will Canada act? [Web log post]. Retrieved from https://theconversation.com/migrants-are-dying-in-detention-centres-when-willcanada-act-87237

Mountz, A. (2011). Seeking Asylum: Human Smuggling and Bureaucracy at the Border. Minneapolis: University of Minnesota Press. 
Mountz, A., Coddington, K., Catania, R.T., \& Loyd, J.M. (2012). Conceptualizing Detention: Mobility, Containment, Bordering, and Exclusion. Progress in Human Geography, 37(4), 522-541.

Nakache, D. (2011). The Human and Financial Cost of Detention of Asylum-Seekers in Canada. Retrieved from the United Nations High Commissioner for Refugees (UNHCR) website: http://www.unhcr.ca/wp-content/uploads/2014/10/RPT-201112-detention_assylum_seekers-e.pdf

Owusu-Bempah, A. \& Wortley, S. (2014). Race, Crime, and Criminal Justice in Canada. In S. Bucerius \& M. Tonry (Eds.), The Oxford Handbook of Ethnicity, Crime, and Immigration (ch. 10). Oxford: Oxford University Press.

Pilieci, V. (2017, February 24). Lockdown at Ottawa Jail for 'Security Reasons' Causes Court Delays. The Ottawa Citizen. Retrieved from http://ottawacitizen.com/

Pratt, A. (2005). Securing Borders: Detention and Deportation in Canada. Vancouver: UBC Press.

Rachlinski, J.J. \& Wistrich, A.J. (2017). Judging the Judiciary by the Numbers: Empirical Research on Judges. Annual Review of Law and Social Science, 13, 1-44.

Ramji-Nogales, J., Schoenholtz, A., \& Schrag, P.G. (2007). Refugee Roulette: Disparities in Asylum Adjudication. Stanford Law Review, 60(2), 295-412.

Rehaag, S. (2008). Troubling Patterns in Canadian Refugee Adjudication. Ottawa Law Review, 39(2), 335-365.

Rehaag, S. (2017, March 8). 2016 Refugee Claim Data and IRB Member Recognition Rates. Retrieved from the Canadian Council for Refugees website: http://ccrweb.ca/en/2016-refugee-claim-data

Richardson, R. (2010). Sending a Message? Refugees and Australia's Deterrence Campaign. Media International Australia, Incorporating Culture \& Policy, 135, 7-18.

Roberts, J.V. \& Reid, A.A. (2017). Aboriginal Incarceration in Canada Since 1978: Every Picture Tells the Same Story. Canadian Journal of Criminology and Criminal Justice, 59(3), 313-345.

Robin, R. (2017, February 15). The \$1-Billion Hellhole. The Toronto Life. Retrieved from https://torontolife.com/

Robinson, M. (2016, January 9). 'Astounding' Number of Lockdowns at Maplehurst Correctional Complex. The Toronto Star. Retrieved from https://www.thestar.com/ 
Rushowy, K. (2017, October 3). Ontario's Correctional System Needs Overhaul, Report Says. The Toronto Star. Retrieved from https://www.thestar.com/

Rygiel, K. (2008). The Securitized Citizen. In E. F. Isin (Ed.), Recasting the Social in Citizenship (pp. 210-238). Toronto: University of Toronto Press.

Rygiel, K. (2012). Governing Mobility and Rights to Movement Post 9/11: Managing Irregular and Refugee Migration Through Detention. Review of Constitutional Studies, 16(2), 211-241.

Sampson, R. (2015). Mandatory, Non-reviewable, Indefinite: Immigration Detention in Australia. In A. Nethery \& S.J. Silverman (Eds.), Immigration Detention: The Migration of a Policy and Its Human Impact (pp. 104-113). New York: Routledge.

Schwartz-Shea, P. \& Yanow, D. (2012). Interpretive Research Design: Concepts and Processes. New York: Routledge.

Seymour, A. (2016, May 25). Inmates File Class-Action Lawsuit over 'Deplorable' Conditions at Ottawa Jail. The Ottawa Sun. Retrieved from http://ottawasun.com/

Sharma, N. (2006). Home Economics: Nationalism and The Making of 'Migrant Workers' in Canada. Toronto: University Of Toronto Press.

Silverman, S.J. (2011). How Long is Too Long? A Preliminary Examination of the Practice of Protracted Immigration Detention in Canada (January 1, 2011). Presented at the 4th Annual Ethnic and Pluralism Studies Graduate Research Conference. Retrieved from http://papers.ssrn.com/sol3/papers.cfm? abstract id $=1881790$

Silverman, S.J. (2014). In the Wake of Irregular Arrivals: Changes to the Canadian Immigration Detention System. Refuge, 30(2), 27-34.

Silverman, S.J. \& Massa, E. (2012). Why Immigration Detention is Unique. Population, Space and Place, 18, 677-686.

Silverman, S.J. \& Molnar, P. (2016). Everyday Injustices: Barriers to Access to Justice for Immigration Detainees in Canada. Refugee Survey Quarterly, 35(1), 109-127.

Silverman, S.J. \& Nethery, A. (2015). Understanding Immigration Detention and its Human Impact. In A. Nethery \& S.J. Silverman (Eds.), Immigration Detention: The Migration of a Policy and Its Human Impact, (pp. 1-12). New York: Routledge.

Stasiulis, D. \& Jhappan, R. (1995). The Fractious Politics of a Settler Society: Canada. In D. Stasiulis \& N. Yuval-Davis (Eds.), Unsettling Settler Societies: Articulations 
of Gender, Race, Ethnicity and Class, (pp. 95-131). London: SAGE Publications Ltd.

Stasiulis, D. (2017). The Extraordinary Statelessness of Deepan Budlakoti: The Erosion of Canadian Citizenship through Citizenship Deprivation. Studies in Social Justice, 11(1), 1-26.

Stumpf, J. (2006). The Crimmigration Crisis: Immigrants, Crime, and Sovereign Power. American University Law Review, 56(2), 367-420.

Syed, F. (2017, November 18). Inmates Allege Systematic Negligence at Southern Ontario Prison. The Toronto Star. Retrieved from https://www.thestar.com/

Tracy, S.J. (2013). Qualitative Research Methods: Collective Evidence, Crafting Analysis, Communicating Impact. Malden: Wiley-Blackwell.

Turnbull, S. (2016). 'Stuck in the Middle': Waiting and Uncertainty in Immigration Detention. Time \& Society, 25(1), 61-79.

Turnbull, S. (2017, March 29). Immigration Detention and Punishment. Retrieved from the Oxford Research Encyclopaedia of Criminology website: http://criminology.oxfordre.com/view/10.1093/acrefore/9780190264079.001.0001/ac refore-9780190264079-e-231

Turnbull, S. \& Hasselberg, I. (2017). From Prison to Detention: The Carceral Trajectories of Foreign-National Prisoners in the United Kingdom. Punishment \& Society, 19(2), 135-154.

van den Hoonaard, D.K. (2012). Qualitative Research in Action: A Canadian primer. Don Mills: Oxford University Press.

White, P. (2016, March 8). Jail Sentences Reduced for Ontario Offenders who Endured Lockdowns. The Globe and Mail. Retrieved from https://www.theglobeandmail.com/

Wilsher, D. (2011). Immigration Detention: Law, History, Politics. Cambridge: Cambridge University Press.

Wong, T.K. (2015). Rights, Deportation, and Detention in the Age of Immigration Control. Stanford: Stanford University Press.

York, G. (2016, June 14). Freed from Canadian Detention, South African Man Left in Limbo. The Globe and Mail. Retrieved from https://www.theglobeandmail.com/ 


\section{Appendix A: Categories of Immigration Detainees}

\section{Detainees by Immigration Status}

- Asylum seekers awaiting examination

- Refugee claimants with denied applications

- Designated Foreign Nationals (DFN)

- Noncitizens on expired visitor, work, or student visa

- Noncitizens who violated the terms of their visa

- Permanent residents with certain criminal convictions

- Permanent residents or noncitizens on security certificate

- Accompanied or unaccompanied minors

- Stateless persons

Please note this was compiled after a review of various Canadian studies (see Cleveland, 2015; Hussan, 2014; Global Detention Project, 2012, March; Silverman, 2011). It is not an exhaustive list of the different categories of immigration detainees; however, it demonstrates the heterogeneity of this population. It is also possible that these categories overlap for a single individual (Silverman, 2011). 


\section{Appendix B: Statistics on Canadian Immigration Detention}

Part 1: Detention Statistics - 2004-2011

\begin{tabular}{||c|c|c|c|c|c|c|c|}
\hline Year & $\begin{array}{c}\text { Total } \\
\text { immigration } \\
\text { holds }\end{array}$ & $\begin{array}{c}\text { Detained } \\
\text { "Refugees" }\end{array}$ & $\begin{array}{c}\text { "Refugees" } \\
\text { as a of all } \\
\text { immigration } \\
\text { holds }\end{array}$ & $\begin{array}{c}\text { Average } \\
\text { "Refugee" } \\
\text { detention } \\
\text { (days) }\end{array}$ & $\begin{array}{c}\text { "Refugees" } \\
\text { detained in } \\
\text { a CBSA } \\
\text { facility } \\
\text { (IHC) }\end{array}$ & $\begin{array}{c}\text { "Refugees" } \\
\text { detained in } \\
\text { a non- } \\
\text { CBSA } \\
\text { facility }\end{array}$ & $\begin{array}{c}\text { Refugee } \\
\text { claims } \\
\text { referred } \\
\text { to IRB }\end{array}$ \\
\hline $\begin{array}{l}2004- \\
2005\end{array}$ & 10770 & 4475 & $42 \%$ & 18 days & $72 \%$ & $28 \%$ & 24412 \\
\hline $\begin{array}{l}2005- \\
2006\end{array}$ & 11660 & 5107 & $44 \%$ & 18 days & $73 \%$ & $27 \%$ & 20843 \\
\hline $\begin{array}{l}2006- \\
2007\end{array}$ & 12837 & 5198 & $40 \%$ & 17 days & $73 \%$ & $27 \%$ & 23452 \\
\hline $\begin{array}{l}2007- \\
2008\end{array}$ & 13977 & 5803 & $42 \%$ & 17 days & $74 \%$ & $26 \%$ & 30518 \\
\hline $\begin{array}{l}2008- \\
2009\end{array}$ & 14347 & 5961 & $42 \%$ & 17 days & $72 \%$ & $28 \%$ & 36242 \\
\hline $\begin{array}{l}2009- \\
2010\end{array}$ & 9423 & 4125 & $44 \%$ & 24 days & $66 \%$ & $34 \%$ & 29913 \\
\hline $\begin{array}{l}2010- \\
2011\end{array}$ & 8838 & 4151 & $47 \%$ & n/a & n/a & n/a & 22500 \\
\hline
\end{tabular}

This table is reproduced from Delphine Nakache's (2011) report, The Human and Financial Cost of Detention of Asylum Seekers in Canada.

Part 2: Detention Statistics - 2012-2017

\begin{tabular}{|c|c|c|c|c|c|}
\hline Fiscal Year & $\begin{array}{c}\text { \# of } \\
\text { persons } \\
\text { detained }\end{array}$ & $\begin{array}{c}\text { Average } \\
\text { length of } \\
\text { detention } \\
\text { (days) }\end{array}$ & $\begin{array}{c}\text { \# of detentions } \\
\text { in a CBSA } \\
\text { facility (IHC) }\end{array}$ & $\begin{array}{c}\text { \# of detentions } \\
\text { in a non-CBSA } \\
\text { facility }\end{array}$ & $\begin{array}{c}\text { \# of long-term } \\
\text { detainees } \\
\text { (90+) days }\end{array}$ \\
\hline $2012-2013$ & 8,739 & 20 & $\begin{array}{c}6,127 \\
(63.7 \%)\end{array}$ & $\begin{array}{c}3,487 \\
(36.3 \%)\end{array}$ & 678 \\
\hline $2013-2014$ & 7,722 & 23 & $\begin{array}{c}5,366 \\
(63.3 \%)\end{array}$ & $\begin{array}{c}3,115 \\
(36.7 \%)\end{array}$ & 706 \\
\hline $2014-2015$ & 6,768 & 24.5 & $\begin{array}{c}4,469 \\
(60.7 \%)\end{array}$ & $\begin{array}{c}2,889 \\
(39.3 \%)\end{array}$ & 694 \\
\hline $2015-2016$ & 6,596 & 23.1 & $\begin{array}{c}4,379 \\
(60.1 \%)\end{array}$ & $\begin{array}{c}2,909 \\
(39.9 \%)\end{array}$ & 623 \\
\hline $2016-2017$ & 6,251 & 19.5 & $\begin{array}{c}4,232 \\
(61.5 \%)\end{array}$ & $\begin{array}{c}2,647 \\
(38.5 \%)\end{array}$ \\
\hline
\end{tabular}

This table is a partial reproduction of statistics from CBSA (2018a). 
Appendix C: Participant List

\begin{tabular}{|c|c|c|c|}
\hline $\begin{array}{l}\text { Pseudonym or } \\
\text { Participant Name }\end{array}$ & Participant Group & Participant Location & $\begin{array}{l}\text { Date of } \\
\text { Interview }\end{array}$ \\
\hline Carmyn & Legal Counsel & Ottawa & 2017, February 2 \\
\hline Clive & Legal Counsel & Ottawa & 2017, March 7-8 \\
\hline Deepan Budlakoti & $\begin{array}{l}\text { Former Immigration } \\
\text { Detainee (Stateless) }\end{array}$ & Ottawa & 2017, March 8 \\
\hline Dora & Legal Counsel & Toronto & 2017, January 26 \\
\hline Eleanor & Legal Counsel & Ottawa & 2017, February 2 \\
\hline Faye & Legal Counsel & Toronto & 2017, February 3 \\
\hline Felix & $\begin{array}{c}\text { Former Immigration } \\
\text { Detainee (Asylum } \\
\text { Seeker) }\end{array}$ & Toronto & 2017, January 22 \\
\hline George & Legal Counsel & Toronto & 2017, February 8 \\
\hline Jamie & Legal Counsel & Ottawa & 2017, February 8 \\
\hline Katherine & Legal Counsel & Ottawa & 2017, January 24 \\
\hline Petra & Legal Counsel & Ottawa & 2017, February 14 \\
\hline Rohan & Legal Counsel & Toronto & 2017, March 16 \\
\hline Sid & Legal Counsel & Toronto & 2017, February 16 \\
\hline
\end{tabular}




\section{Appendix D: Consent Form (Former Immigration Detainees)}

\section{Carleton}

U N I V E R S T Y

\section{Written Consent Form}

Project Title: Examining Noncitizens as Immigration Detainees and their Experience of Detention Review Hearings

Researcher: Marie Coligado, Master's student

Department of Sociology and Anthropology, Carleton University Email:

Tel:

Funding Source: Social Sciences and Humanities Research Council, Canada Graduate Scholarships (Master's Program)

Date of Ethics Clearance: December 8, 2016

Ethics Clearance for the Collection of Data Expires: December 30, 2017

I, , volunteer to participate in this study on Canadian immigration detention, which seeks to examine how noncitizens (i.e., individuals who are not Canadian citizens) are detained under an immigration hold and their experience of detention review hearings. The researcher for this study is Marie Coligado in the Department of Sociology and Anthropology, Carleton University. She is working under the co-supervision of Dr. Aaron Doyle and Dr. Daiva Stasiulis in the Department of Sociology and Anthropology, Carleton University.

\section{Eligibility:}

To participate in the study, you must meet the following criteria:

- Have spent at least 48 hours (2 days) in a Canadian immigration holding centre and/or provincial prisons under an immigration hold

- Have participated in at least one detention review hearing

- Be comfortable with speaking in English

- Be at least 18 years old

\section{Procedure:}

- Participants will engage in a 1-hour interview with the researcher. With your informed consent, the interview will be audio-recorded and transcribed (i.e., written out word-for-word). Should you refuse to be audio-recorded, the researcher will only take notes during the interview. 


\section{Risks and benefits:}

- There are mild psychological risks associated with this project, but the likelihood of them occurring is low. Participants will be asked about their experience of potentially traumatic events, which may cause emotional discomfort. To minimize these risks, you may refuse to answer specific questions, stop the interview at any point, or withdraw from the study. Should you experience any discomfort during or after the interview, you will be referred to the appropriate health services.

- There are also high social/economic risks, but the likelihood of them occurring is low. Participants could lose some privacy and face stigma (i.e., negative reaction to your situation). Legal issues could also arise should collected data and records be subject to subpoena or court order. To minimize these risks, the researcher will be very careful in protecting your identity. This will be done by using pseudonyms (fake names), by making sure your name cannot be connected to your answers, and by destroying identifying information as soon as possible.

\section{Confidentiality}

- Participants are free to withdraw from the study, for any reason and without penalty, up to four weeks after the interview. If applicable, referring third parties will not be informed of your decision to withdraw. You can withdraw by contacting the researcher or researcher supervisors (by phone or email). If you withdraw from the study before the deadline, all information you have provided will be destroyed.

- Research data will be saved on an encrypted USB and external hard drive. These devices and any hard copies will be stored in a secure location. Research data will only be accessible to the researcher and researcher supervisors.

- When the project is completed, all research data will be stored for three years and potentially used for future projects. They will be securely destroyed after this time limit. Electronic data will be deleted, USB and external hard drives will be reformatted, and hard copies will be shred.

- The researcher has a professional duty to report to the appropriate authorities in cases of immediate harm to self and/or others.

You will receive a $\$ 20$ honorarium as a token of appreciation and to cover costs associated with participation (e.g., transportation). If you withdraw from the study during or following the interview, you will still receive this honorarium.

Ethics review information: The ethics protocol for this project was reviewed by the Carleton University Research Ethics Board-A, which provided clearance to carry out this research. Should you have any questions or concerns related to your involvement in this research, please contact:

\section{REB contact information: \\ Dr. Andy Adler, Chair \\ Carleton University \\ Research Ethics Board-A \\ Email: ethics@carleton.ca \\ Tel: 613-520-2600 (ext. 4085)}


Contact information: If you have any questions or concerns about the study, you are free to contact the researcher or researcher supervisors.

Researcher: Marie Coligado, Master's student

Department of Sociology and Anthropology, Carleton University

Email:

Tel:

Researcher Supervisors:

Dr. Aaron Doyle, Associate Professor Dr. Daiva Stasiulis, Professor

Department of Sociology and

Department of Sociology and

Anthropology, Carleton University

Email:

Tel: Anthropology, Carleton University

Email:

Tel:

Authorization: I have read this consent form and understand its content. I know my participation is voluntary and I have the right to withdraw at any time. I give my informed consent to participate in this study.

Do you agree to be audio-recorded? (Yes) (No)

Name and Signature of Participant

Date

Name and Signature of Researcher

Date

Note: The researcher will provide participants with a copy of the signed consent form. Participants should retain a copy for their records. This form has been printed on one side of three sheets. 


\section{Appendix E: Consent Form (Legal Counsel)}

\section{Carleton}

U N I V E R S I T Y

\section{Written Consent Form}

Project Title: Examining Noncitizens as Immigration Detainees and their Experience of Detention Review Hearings

Researcher: Marie Coligado, Master's student

Department of Sociology and Anthropology, Carleton University Email:

Tel:

Funding Source: Social Sciences and Humanities Research Council, Canada Graduate Scholarships (Master's Program)

Date of Ethics Clearance: December 8, 2016

Ethics Clearance for the Collection of Data Expires: December 30, 2017

I, , volunteer to participate in this study on Canadian immigration detention, which seeks to examine how noncitizens are detained under an immigration hold and their experience of detention review hearings. The researcher for this study is Marie Coligado in the Department of Sociology and Anthropology, Carleton University. She is working under the co-supervision of Dr. Aaron Doyle and Dr. Daiva Stasiulis in the Department of Sociology and Anthropology, Carleton University.

\section{Eligibility:}

To participate in the study, you must meet the following criteria:

- Have clients previously or currently held in Canadian immigration detention

- Have represented clients in detention review hearings presided over by the Immigration and Refugee Board's Immigration Division

\section{Procedure:}

- Participants will engage in a 1-hour interview with the researcher. With your informed consent, the interview will be audio-recorded and transcribed. Should you refuse to be audio-recorded, the researcher will only take notes during the interview.

\section{Risks and benefits:}

- There are high risks associated with participating in this study, but the likelihood of them occurring is low. You will be asked about your role and responsibilities as legal counsel to immigration detainees. You will also be asked to speak indirectly 
to clients' experience of detention review hearings. Although it is highly unlikely that you would share information that could endanger or threaten the privacy of clients, unintentional disclosure might occur which could subsequently affect your professional reputation and relationship with clients. Legal issues could also arise should collected data and records be subject to subpoena or court order. To minimize these risks, the researcher will not ask questions regarding specific cases or clients. The researcher will also be very careful in protecting your and your clients' identities. This will be done by using pseudonyms and ensuring responses are non-attributable. The list of identifying information will also be destroyed as soon as possible.

- You might benefit from the study's findings by gaining a better understanding of how immigration detainees experience the quasi-judicial proceedings of detention review hearings and subsequently find ways to improve interactions with future clients. If you would like a copy of the finished research project, you are invited to request an electronic copy, which will be provided to you.

\section{Confidentiality}

- Participants may refuse to answer specific questions or stop the interview at any point. You are also free to withdraw from the study, for any reason and without penalty, up to four weeks after the interview. You can withdraw by contacting the researcher or researcher supervisors (by phone or email). If you withdraw from the study before the deadline, all information you have provided will be destroyed.

- Research data will be saved on an encrypted USB and external hard drive. These devices and any hard copies will be stored in a secure location. Research data will only be accessible to the researcher and researcher supervisors.

- When the project is completed, all research data will be stored for three years and potentially used for future projects. They will be securely destroyed after this time limit. Electronic data will be deleted, USB and external hard drives will be reformatted, and hard copies will be shred.

You will not be compensated for participating in this study.

Ethics review information: The ethics protocol for this project was reviewed by the Carleton University Research Ethics Board-A, which provided clearance to carry out this research. Should you have any questions or concerns related to your involvement in this research, please contact:

\section{REB contact information:}

Dr. Andy Adler, Chair

Carleton University

Research Ethics Board-A

Email: ethics@carleton.ca

Tel: 613-520-2600 (ext. 4085)

Contact information: If you have any questions or concerns about the study, you are free to contact the researcher or researcher supervisors. 
Researcher: Marie Coligado, Master's student

Department of Sociology and Anthropology, Carleton University

Email:

Tel:

Researcher Supervisors:

Dr. Aaron Doyle, Associate Professor

Department of Sociology and

Anthropology, Carleton University

Email:

Tel:

Dr. Daiva Stasiulis, Professor

Department of Sociology and

Anthropology, Carleton University

Email:

Tel:

Authorization: I have read this consent form and understand its content. I know my participation is voluntary and I have the right to withdraw at any time. I give my informed consent to participate in this study.

Do you agree to be audio-recorded? (Yes)

Name and Signature of Participant

Date

Name and Signature of Researcher

Date

Note: The researcher will provide participants with a copy of the signed consent form. Participants should retain a copy for their records. This form has been printed on one side of three sheets. 